\title{
ASCE 7-05 DESIGN RULE FOR RELATIVE STRENGTH IN A TALL BUCKLING- RESTRAINED BRACED FRAME DUAL SYSTEM
}

\author{
A Thesis \\ Presented to \\ The Faculty of California Polytechnic State University \\ San Luis Obispo, California
}

In Partial Fulfillment

of the Requirements for the Degree

Master of Science in Architecture with a Specialization in Architectural Engineering

by

Lisa Jaylene Aukeman

March 2011 
(C) 2011

Lisa J. Aukeman

ALL RIGHTS RESERVED 
COMITTEE MEMBERSHIP

TITLE:

ASCE 7-05 Design Rule for Relative

Strength in a Tall Buckling-Restrained Braced Frame

Dual System

AUTHOR: $\quad$ Lisa Jaylene Aukeman

DATE SUMBMITTED: $\quad$ March 2011

COMMITTEE CHAIR: $\quad$ Professor Peter Laursen, Ph.D., P.E.

COMMITTEE MEMBER: $\quad$ Professor Abraham Lynn, Ph.D.

COMMITTEE MEMBER: $\quad$ Lucie Fougner, S.E.

COMMITTEE MEMBER: Professor Deborah Wilhelm 


\section{ABSTRACT \\ ASCE 7-05 Design Rule for Relative Strength \\ in a Tall Buckling-Restrained Braced Frame Dual System \\ Lisa Jaylene Aukeman}

In mid- to high-rise structures, dual systems (DS) enable a structural designer to satisfy the stringent drift limitations of current codes without compromising ductility. Currently, ASCE 7-05 permits a variety of structural systems to be used in combination as a dual system yet the design requirements are limited to the following statement: Moment frames must be capable of resisting $25 \%$ of the seismic forces while the moment frames and braced frames or shear walls must be capable of resisting the entire seismic forces in proportion to their relative rigidities.

This thesis assesses the significance of the $25 \%$ design requirement for the secondary moment frames (SMF) in dual systems with consideration of current structural engineering practice. Three 20-story buckling-restrained braced frame (BRBF) dual system structures were designed with varying relative strengths between the braced and special moment frame systems. The SMF system wa designed for $15 \%, 25 \%$, and $40 \%$ of seismic demands and the BRBF system design has been adjusted accordingly based on its relative stiffness with respect to the moment frame. These structures were examined with nonlinear static and nonlinear dynamic procedures with guidance from ASCE 41-06.

The drift, displacement and ductility demands, and the base shear distribution results of this study show similar responses of the three prototype structures. These results indicate a secondary moment frame designed to less than $25 \%$ of seismic demands may be adequate for consideration as a dual system regardless of the $25 \%$ rule.

Keywords: Buckling-Restrained Braced Frames, Dual Systems, Mixed Systems, Tall Buildings, 25\% Rule 


\section{TABLE OF CONTENTS}

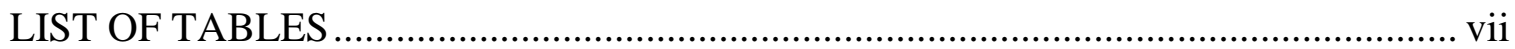

LIST OF FIGURES …....................................................................................... vii

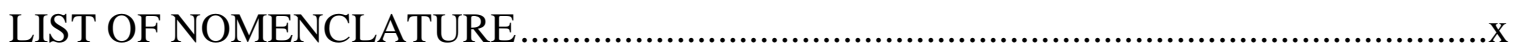

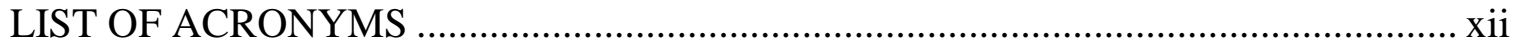

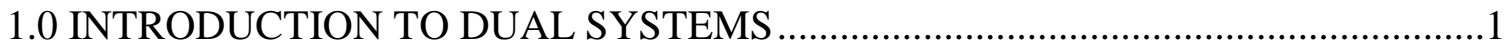

1.1 History of Code Requirements ........................................................................ 3

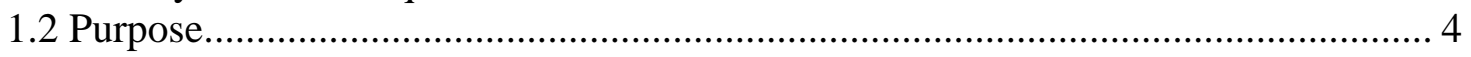

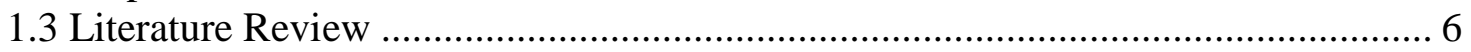

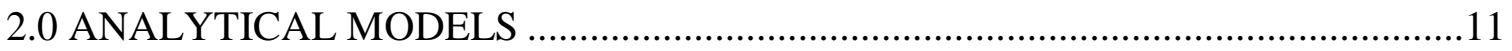

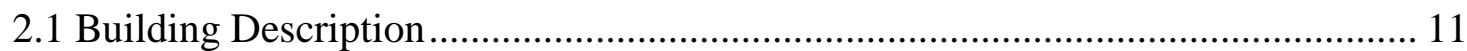

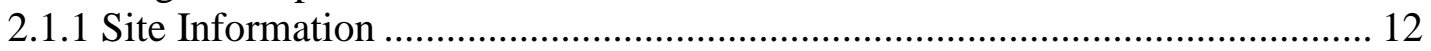

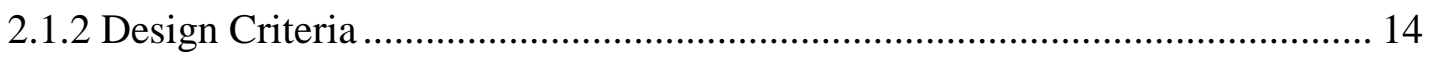

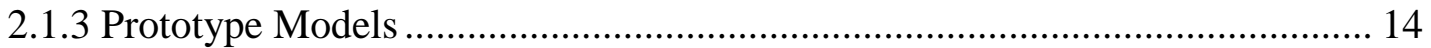

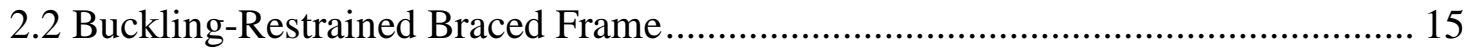

2.3 Design Procedure ............................................................................................. 16

2.3.1 Magnusson Procedure Step 1: Design of BRBF.......................................... 19

2.3.2 Magnusson Procedure Step 2: Design of SMRF ....................................... 22

2.3.3 Magnusson Procedure Step 3: Adjustments for Dual System Interaction ....... 23

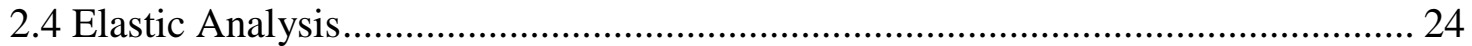

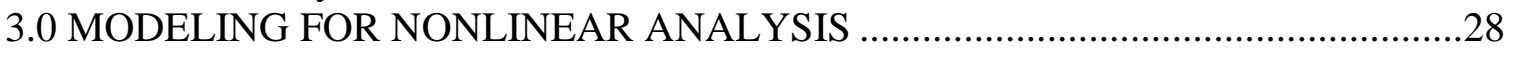

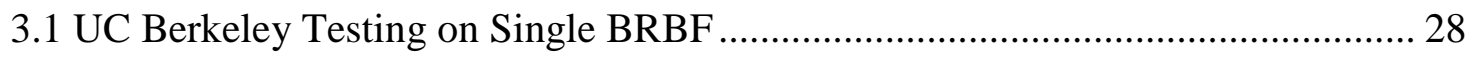

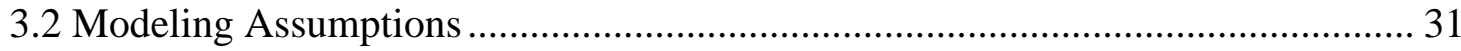

3.2.1 BRB Perform 3D Element Compounds ........................................................ 34

3.2.2 Moment Rotation Hinge.......................................................................... 38

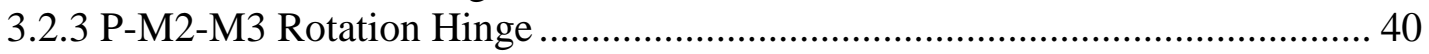

3.3 Perform Modal Analysis ............................................................................ 41

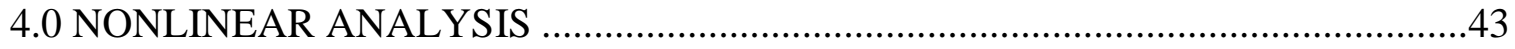

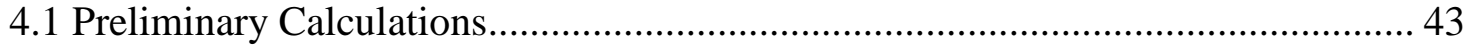

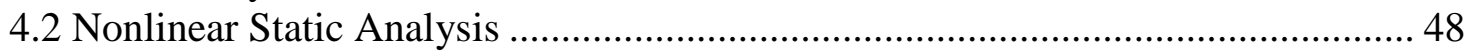

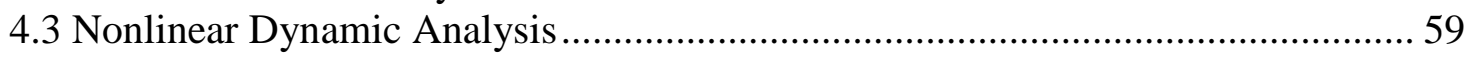

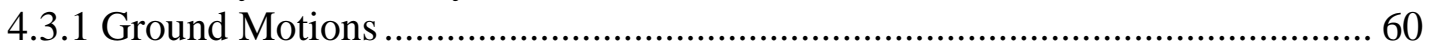

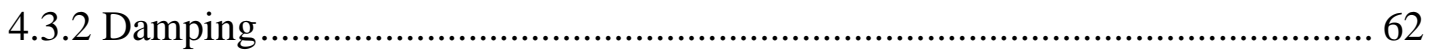

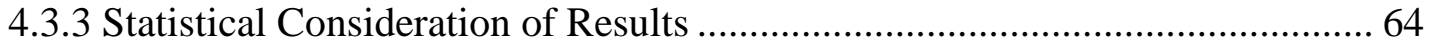

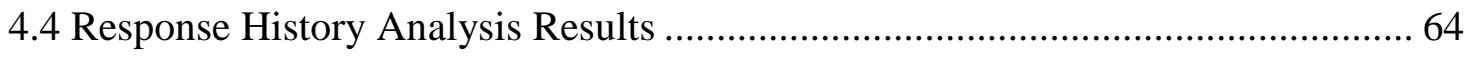

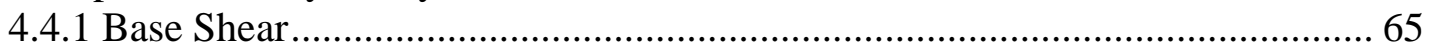

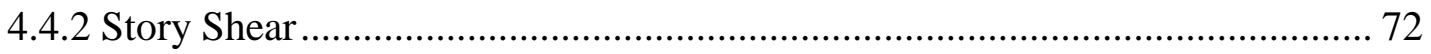

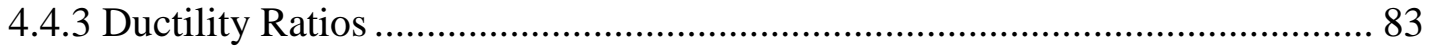

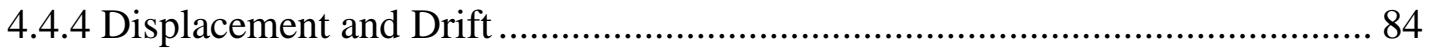

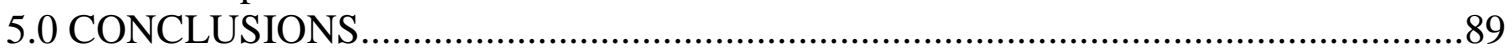

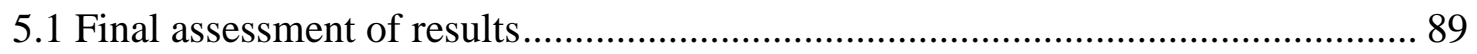

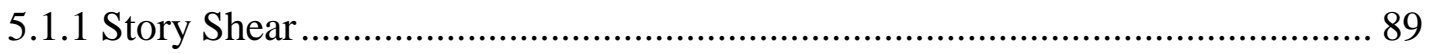

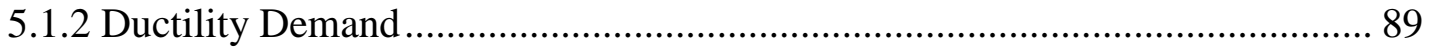

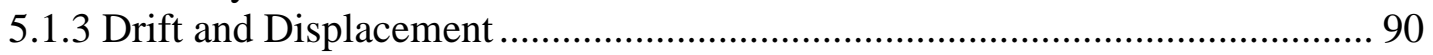




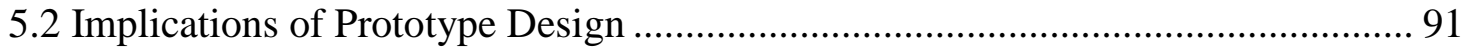

5.2.1 Buckling-Restrained Braced Frame Design................................................... 91

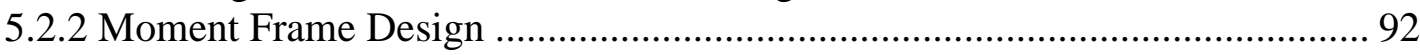

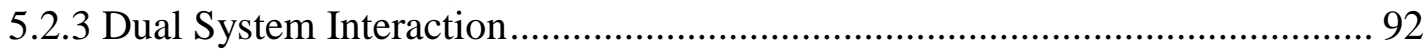

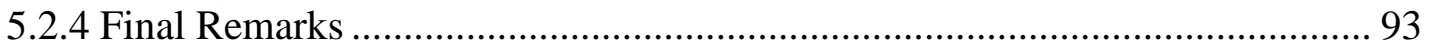

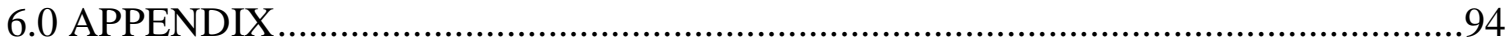

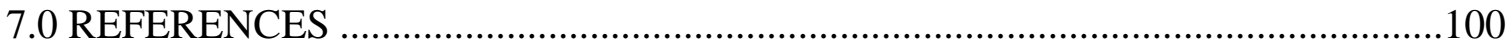




\section{LIST OF TABLES}

Table 1: Seismic design values for BRBF dual systems with non-moment-resisting connections per ASCE 7-05 Table 12.2-1 ....................................................... 14

Table 2: Seismic calculations for Model 25 ............................................................ 18

Table 3: ETABS periods and mass participation for dual system models........................ 24

Table 4: Raleigh Ritz Approximation................................................................. 25

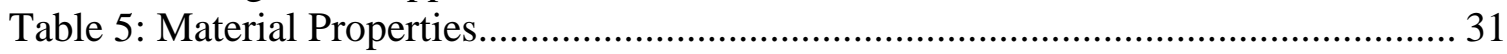

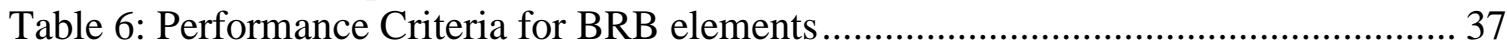

Table 7: Perform 3D periods and mass participation for dual system models ................. 42

Table 8: BRB and RBS Limit states defined by ductility ................................................ 45

Table 9: Hand calculations for ductility factors and story drift angle .............................. 47

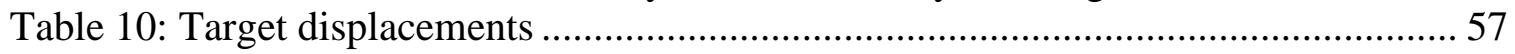

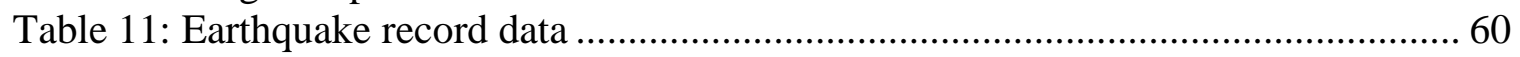

Table 12: Comparison of Median Nonlinear Dynamic MF base shear demands to ASCE 7-05 design base shear. ...........................................................................70

Table 13: Comparison of Median Nonlinear Dynamic MF base shear demands to

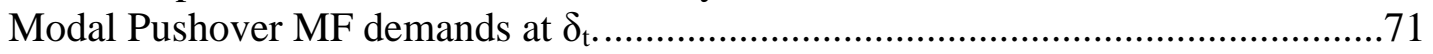

Table 14: Comparison of Median Nonlinear Dynamic MF base shear demands to

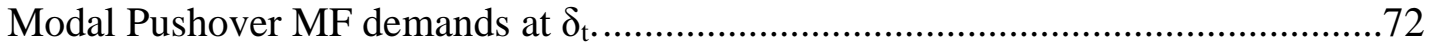

Table 15: Ground motion records contributing the nonlinear dynamic median results for total story shear from Figure LL. .....................................................................77

Table 16: Ground motion records contributing the nonlinear dynamic median results for maximum MF story shear from Figure PP.....................................................8

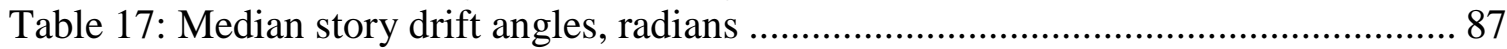

Table 18: Load takeoff and calculations for analytical modeling................................... 95

Table 19: Member sizes for Model 15 ………………........................................... 97

Table 20: Member sizes for Model 25 .................................................................... 98

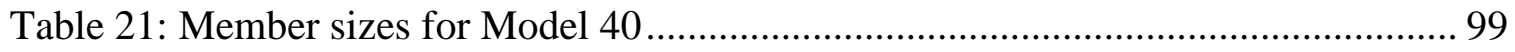




\section{LIST OF FIGURES}

Figure A: Simplified displaced shape of respective systems in tall buildings.................. 2

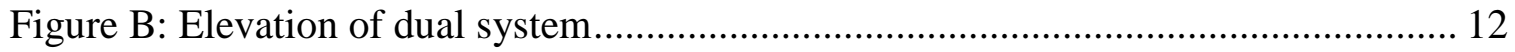

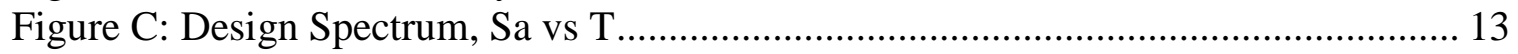

Figure D: Conceptual diagrams of Buckling-Restrained Brace elements ........................ 16

Figure E: Free body diagram for typical braced frame loading due to seismic loads ...... 20

Figure F: Free body diagram for typical braced frame loading due to gravity loads ....... 21

Figure G: Elastic Shear calculated by ESFP showing relative stiffness of MF to BF for

Model 15, Model 25 and Model 40 ............................................................. 26

Figure H: Elastic base shear distribution as absolute and relative base shear quantities

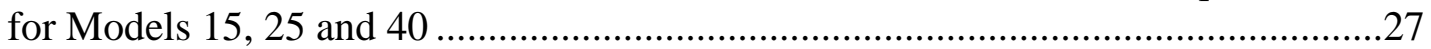

Figure I: Test setup for UC Berkeley Unbonded Braced Frame .................................... 29

Figure J: Testing data compared to analytical modeling in Perform 3D .......................... 30

Figure K: Analytical interpretation of typical braced frame...................................... 32

Figure L: Analytical Interpretation of RBS Moment Connection ................................. 34

Figure M: Diagram of Buckling-Restrained Brace.................................................... 35

Figure N: Hysteresis response of Buckling-Restrained Brace....................................... 36

Figure O: Backbone Curve for nonlinear elements as defined in ASCE 41-06 .............. 38

Figure P: Perform 3D inputs for moment rotation hinge .......................................... 39

Figure Q: Axial interaction on moment rotation column hinges ................................ 41

Figure R: Schematic relationship between BRBF and MRF in series........................... 43

Figure S: Force distribution along building height for uniform and modal pushover ...... 48

Figure T: Model 15 pushover with uniform load pattern ........................................... 51

Figure U: Model 15 pushover with mode 1 load pattern .............................................. 52

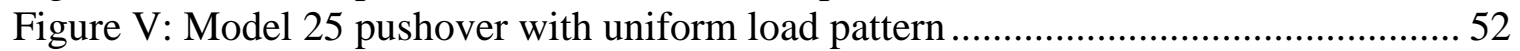

Figure W: Model 25 pushover with mode 1 load pattern ............................................. 53

Figure X: Model 40 pushover with uniform load pattern ........................................... 53

Figure Y: Model 40 pushover with mode 1 load pattern ............................................. 54

Figure Z: Pushover results for models 15, 25 and 40 with uniform and Mode 1 load

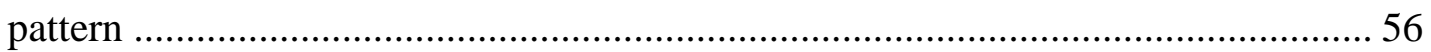

Figure AA: Shear distribution at $\delta_{\mathrm{t}}$ based on mode 1 nonlinear pushover analyses ......... 58

Figure BB: Nonlinear base shear distribution at $\delta_{\mathrm{t}}$ as absolute and relative base shear

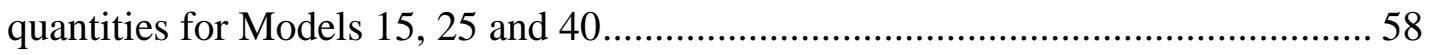

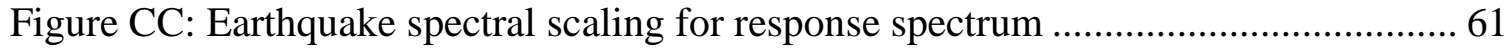

Figure DD: Raleigh damping ratio variation with period .......................................... 63

Figure EE: Model 25 normalized base shear demands from nonlinear dynamic analysis at maximum total base shear .................................................................66

Figure FF: Model 25 base shear distribution from nonlinear dynamic analysis at

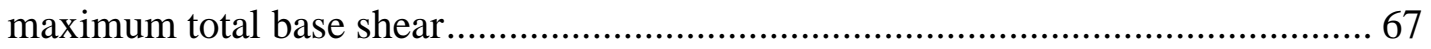

Figure GG: Comparison of median values at maximum total base shear....................... 67

Figure HH: Comparison of median values at maximum dynamic MF base shear .......... 69

Figure II: Model 15 nonlinear dynamic maximum total story shear demands ................ 73

Figure JJ: Model 25 nonlinear dynamic maximum total story shear demands................ 74 
Figure KK: Model 40 nonlinear dynamic results for maximum total story shear demands

Figure LL: Comparison of nonlinear dynamic median results for maximum net story

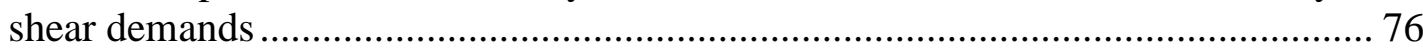

Figure MM: Model 15 nonlinear dynamic results for maximum moment frame story

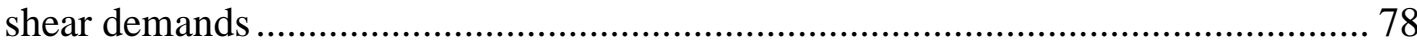

Figure NN: Model 25 nonlinear dynamic results for maximum moment frame story shear demands

Figure OO: Model 40 nonlinear dynamic maximum moment frame story shear demands .80

Figure PP: Comparison of median nonlinear dynamic results for maximum MF story shear demands 81

Figure QQ: Nonlinear Dynamic Ductility Ratios .................................................... 83

Figure RR: Nonlinear Dynamic Maximum Roof Displacement .................................. 85

Figure SS: Nonlinear dynamic story drift results for Models 15, 25, and 40 ................ 87

Figure TT: Building plan referenced for load takeoff and design .............................. 96 


\section{LIST OF NOMENCLATURE}

$\mathrm{a}=\mathrm{RBS}$ dimension as defined per AISC 341

$a=$ Rotational limit as defined per ASCE 41-06

$A_{s}=$ Steel core area in BRB

$b=$ Rotational limit as defined per ASCE 41-06

$\mathrm{b}=\mathrm{RBS}$ dimension as defined per AISC 341

$\beta=$ Adjustment factor for compression strength of a buckling restrained brace

$\mathrm{c}=\mathrm{RBS}$ dimension as defined per AISC 341

$c=$ Rotational limit as defined per ASCE 41-06

$C_{\max }=$ Maximum compressive capacity of a buckling restrained brace

$\mathrm{C}_{p l}=$ Strain hardening factor for reduced beam section

$C_{0}=$ Target displacement modification factor per ASCE 41-06

$C_{1}=$ Target displacement modification factor per ASCE 41-06

$C_{2}=$ Target displacement modification factor per ASCE 41-06

$D L=$ Rotational or displacement limit at the onset of strength degradation defined in Perform 3D

$D U=$ Rotational or displacement limit at maximum strain hardening defined in Perform $3 \mathrm{D}$

$D R=$ Rotational or displacement limit at maximum strength degradation defined in Perform 3D

$D X=$ Ultimate rotational or displacement limit defined in Perform 3D

DY $=$ Yield displacement or element rotation defined in Perform 3D

$\delta_{\mathrm{i}}=$ Lateral displacement at level, $i$, caused by story force, $F_{i}$

$E=$ Modulus of elasticity

$\mathrm{FY}=$ yield capacity of the element

$F_{y}=$ Yield strength of steel core

$F_{y e}=$ Expected yield strength

$F_{i}=$ Story force at level, $i$

$g=$ Acceleration due to gravity $\left(\mathrm{in} / \mathrm{s}^{2}\right)$

$I=$ Element moment of inertia

$\underline{K}=$ Stiffness matrix for the structure

$K E=$ Elastic stiffness

$L=$ Element length

$\mathrm{L}_{\mathrm{BRB}}=$ Length of buckling restrained brace

$\mathrm{L}_{\mathrm{ny}}=$ Length of non-yielding portion of buckling restrained brace

$\mathrm{L}_{\mathrm{y}}=$ Length of yielding portion of buckling restrained brace

$M=$ Mass matrix for the structure

$M U=$ Ultimate moment capacity of element after strain hardening

$M Y=$ Yield moment

$N=$ Total number of damped modes used for analysis

$\Phi_{n}=$ Mode shape

$S_{a}=$ Response spectrum acceleration for target displacement calculation

$\mathrm{T}=$ Building fundamental period

$T_{e}=$ Effective fundamental period used for target displacement calculation 
$T_{\max }=$ Maximum tensile capacity of a buckling restrained brace

$T_{n}=$ Modal period

$\mathrm{m}=$ Ductility Factor, displacement demands normalized by yield displacement

$V=$ Base shear, kips

$W=$ Total weight tributary to half the structure, kips

$w_{i}=$ Total seismic weight of floor level, $i$

$\omega=$ Adjustment factor for strain hardening of a buckling restrained brace

$\mathrm{Z}_{\mathrm{x}}=$ Plastic section modulus of the gross section beam, reduced beam section, or column

$\xi_{n}=$ Modal damping ratio 


\section{LIST OF ACRONYMS}

AISC $=$ American Institute of Steel Construction

ASCE $=$ American Society of Civil Engineers

ATC $=$ Applied Technology Council

$\mathrm{BF}=$ Braced Frame

$\mathrm{BRB}=$ Buckling-Restrained Brace

$\mathrm{BRBF}=$ Buckling-Restrained Braced Frame

BRBFDS $=$ Buckling-Restrained Braced Frame Dual System

$\mathrm{CUREe}=$ California Universities for Research in Earthquake Engineering

$\mathrm{CP}=$ Collapse Prevention

$\mathrm{CQC}=$ Complete Quadratic Combination

$\mathrm{DCR}=$ Demand to Capacity Ratio

$\mathrm{EQ}=$ Earthquake

$\mathrm{ESFP}=$ Equivalent Static Force Procedure

FEMA = Federal Emergency Management Agency

$\mathrm{IO}=$ Immediate Occupancy Limit State

LS= Life Safety Limit State

$\mathrm{MF}=$ Moment Frame

$\mathrm{MRF}=$ Moment Resisting Frame

$\mathrm{ND}=$ Nonlinear Dynamic

NEHRP $=$ National Earthquake Hazards Reduction Program

RBS $=$ Reduced Beam Section

RSA $=$ Response Spectrum Analysis

SAC $=$ Structural Engineers Association of California, Applied Technology Council, and

California Universities for Research in Earthquake Engineering

$\mathrm{SCWB}=$ Strong Column Weak Beam

$\mathrm{SEAOC}=$ Structural Engineers Association of California

$\mathrm{SIE}=$ Seismic Isolation Engineering Inc.

$\mathrm{SMRF}=$ Special Moment Resisting Frame

$\mathrm{UBC}=$ Uniform Building Code

USGS= United States Geological Survey

VA= Veteran's Affairs 


\subsection{INTRODUCTION TO DUAL SYSTEMS}

Dual systems have been used for more than a century as a way to give structural integrity to a building during an earthquake. Currently, ASCE 7-05 permits a variety of structural systems for use in combination as a dual system, yet the design requirements are limited to the following statement: "For a dual system, the moment frames shall be capable of resisting at least $25 \%$ of the design seismic forces. The total seismic force resistance is to be provided by the combination of the moment frames and the shear walls or braced frames in proportion to their rigidities" (ASCE and SSEC 2006). This thesis looks at the implications of the $25 \%$ rule and the affect on a dual system of designing a moment frame to more than, and less than the described $25 \%$ limit.

Today dual systems consist of a primary system of braced frames or concrete shear walls used in combination with a secondary steel moment resisting frame. Specifically, dual systems comprised of steel moment frames (MFs) and bucklingrestrained braced frames (BRBFs) provide benefits from both an architectural as well as a structural standpoint. While the use of MFs maintain space flexibility and architectural openness, the BRBFs help provide stiffness and control story drifts in mid- to high-rise structures (more than $160 \mathrm{ft}$ ), that may be seen in a fully MF structure (SEAOC Seismology Committee 2007). This drift control by the BRBFs is particularly apparent in the lower levels. In the upper levels, the MFs will be a more effective system for drift control since moment frame systems usually see a higher displacement demand at the 
lower levels. This behavior is shown below in Figure A below, in which the resultant displaced shape is linear with respect to the building's height (Maley et al. 2010).

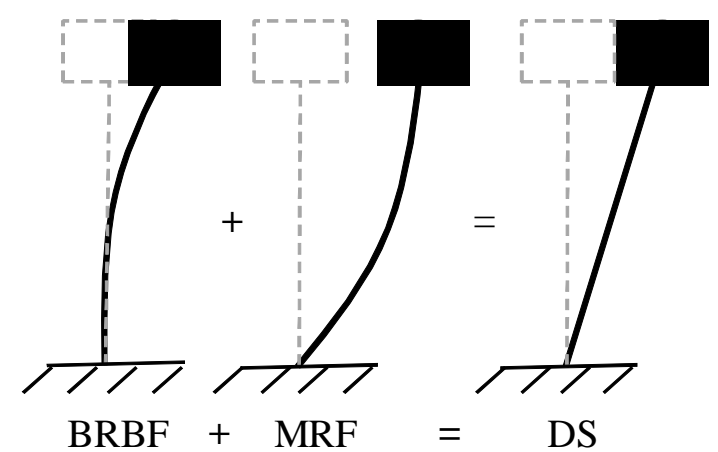

Figure A: Simplified displaced shape of respective systems in tall buildings Source: Author, Using Excel

Buckling-restrained braces (BRBs) also provide damping to a structure in the event of the earthquake due to their low post-yield stiffness and hysteretic behavior. Typically, while dissipating energy, this behavior causes large residual displacements after a large earthquake, which may result in significant damage to the nonstructural components of the building. Providing a MF to remain elastic until after the BRBF yields allows force re-distribution from the BRBFs to the MFs to restrict these large displacements and protect the structure. The combined behavior includes the advantages of serviceability (reduced residual displacement) and ductility (hysteretic behavior of BRB is still engaged).

In general, the design intentions of a dual seismic force resisting system composed of a BRBF and MF are the following:

- BRBFs yield and dissipate energy during an earthquake; and 
- MF limits story displacements by providing stiffness when the braces yield.

Using both MFs and BRBFs together in a dual system allows the benefits of both systems to be used and the short comings of the BRBF and MF to be mitigated by the benefits other system (Degenkolb 1994).

\subsection{History of Code Requirements}

Requirements for dual systems were first written into code in the 1959 Blue Book and the 1961 UBC. The primary system was required to be capable of resisting all lateral forces independent of the provided secondary system (UBC 1961). In addition to the primary system, the secondary system was required to be sufficient for a value of $25 \%$ of the same lateral forces. As described in the 2000 commentary by the National Earthquake Hazards Reduction Program (NEHRP), this $25 \%$ value was "judgmentally selected" and not based on any advanced analysis rationale (FEMA 369).

Later, the 1988 UBC no longer required the primary system to have full capability for lateral resistance because it was recognized that the secondary system would naturally share a fraction of the initial lateral load. Rather, the 1988 UBC specified that "the two systems shall be designed to resist the total lateral load in proportion to their relative rigidities," while the secondary system was still required to have $25 \%$ capacity (UBC 1988). With the available technology in the structural engineering industry in the late eighties, a structural designer could capture a more realistic behavior of the structural 
systems as well as the interaction between the primary and secondary systems (SEAOC Seismology Committee 2007).

The NEHRP expressed a concern in the 2000 commentary in regard to the reduced design capacity of the primary system. If the primary system is no longer adequate for the full seismic load, then the secondary system serves as a critical contributor to the full seismic resistance and the original intent of providing a backup system has been lost. While current code allowances for dual systems may still be sufficient and safe, the concept behind the dual system has been altered by reducing the overall strength of the dual system, allowing the design of the primary system to be based on relative rigidity. In response to this concern, the SEAOC Seismology Committee is expressing an interest in pursuing advanced analysis methods for the design of dual systems, which this thesis intends to address.

\subsection{Purpose}

The SEAOC Seismology committee concludes in the Seismic Design Recommendations Blue Book article suggesting "a rational approach to the definition of the $25 \%$ strength basis for the secondary system needs to be established. For some combinations of [dual] systems a greater or lesser strength basis may be beneficial or warranted or a nonlinear analysis may be needed to justify use of the system" (SEAOC Seismology Committee 2007). In order to be able to develop a more rational approach for the $25 \%$ rule, structural engineers must understand how this $25 \%$ rule affects the performance of dual systems. 
This thesis will assess the current $25 \%$ requirement for dual systems with respect to buckling-restrained braced frames $(\mathrm{BRBF})$ and special moment resisting frames (SMRF) with reduced beam sections (RBS) for a 20-story building. As In tall buildings, high rotations in moment connections may be seen as a result of higher mode effects, which in turn induce higher demands on moment frames of tall structures. Higher demands in a DS MF are critical because the MFs at these upper levels are intended to remain elastic and provide stiffness. From the illustration in Figure A above showing a first mode response, the MRF relieve the BRBFs imposed deformations. If higher mode effects occur during a seismic event, high rotational demands might damage the moment connections and cause large displacements in the BRBFs. Also, if the backup MF system is designed to take a fraction of primary lateral forces yet fails prematurely, the system may not perform to the anticipated level and the intent of the dual system is not met; This suggests that the design standards may need to be modified and that the assumed $25 \%$ moment frame design rule for all dual systems may not be appropriate. In this thesis, a response history analysis was conducted and the effect of designing a secondary system for $15 \%$ (not meeting code requirements), $25 \%$, and $40 \%$ (exceeding code requirements) lateral force capacity were examined, resulting in conclusions on the effects of the backup system strength on the behavior and intent of a the dual system (SEAOC Seismology Committee 2007). 


\subsection{Literature Review}

Many studies validate dual systems as being effective in reducing drift and resisting large earthquakes. However, the consequences of the $25 \%$ rule have not been directly addressed nor has the rule's effect on the overall dual system behavior been determined by advanced nonlinear structural analysis.

The article "Reducing Residual Drift of Buckling-Restrained Braced Frames" discussed the behavior and advantages of BRBFs in dual systems. A 3-story and 6-story dual system was designed according to the 1997 UBC for a downtown Los Angeles location of Site Class D. Maximum and residual drift ratios for each floor level showed that the addition of the backup moment frame system greatly decreased the amount of residual drift in the buildings. This thesis examines similar results as they apply to a 20story building for varying moment frames strengths (Kiggins and Uang 2006 ).

Jin et al. (2000) conducted a similar study, "Performance Based Analysis and Modeling of a Dual Seismic Force-Resisting System" with a 13-story dual system of eccentrically braced frames (EBFs) and MRFs. The building was designed for the 1995 Taiwan building codes and the 1994 UBC. Two dimensional models were used to represent the building in Drain2DX. Both Static Pushover Analysis as well as Response History Analysis showed the dual system maintained a consistent maximum drift ratio of approximately $1 \%$ and $1.5-2 \%$ at each floor of the building, based on a serviceability earthquake (SE) and maximum earthquake (ME), respectively. The authors concluded that strength and ductility of the studied dual system met the desired requirement for both serviceability and maximum earthquakes. The MFs were able to perform as a backup 
system while the EBFs reached their capacity in the maximum earthquake analysis; This is the intent of the design of a dual seismic-force resisting system. This thesis will examine how the $25 \%$ rule that was followed in this study may have affected these results (Jin et al. 2000).

Many well-known structures around the world have dual systems as their lateral force-resisting systems. The Taipei 101, completed in 2004 in Taiwan was designed by Thornton Thomasetti with a braced frame structural core for high shear stiffness and outriggers to engage corner super columns. MRFs, designed to the code $25 \%$ design strength, line the perimeter. In this case, the designers chose a dual system in order to control drift during major earthquakes when the core braced frames are loaded beyond elastic limits (Poon et al. 2002).

Another high rise structure in Taiwan also uses a combined braced and moment frame lateral system for other reasons. A signature 47-story Taichung Tower holds offices, hotel space, retail and a club facility for the city of Taichung, Taiwan. The tower demonstrates a unique layout and architectural program in addition to being located in a high seismic zone similar to UBC's Seismic Zone 3. The island of Taiwan is also at risk for typhoons, resulting in high wind design loads. The developer desired large open spaces in office floors, maximum window space, and minimized column interference at the exterior. Weiskopf \& Pickworth (W\&P), structural engineers, chose a dual lateral force-resisting system with an off-center EBF core and an exterior special MRF. The irregular plan posed an added challenge where the stiffness of the EBF and MRF systems 
became a balancing act at the office levels in which open space needed to be maintained; however, the moment frames allowed for openness while the EBF $+\mathrm{MF}$ together as a dual system still formed a high performance and redundant system (Argiris 1995).

Dual systems are also seen in Mexico; Mexico City's 57-story Torre Mayor, designed by Enrique Martinez-Romero, S.A. Consulting Engineers, Mexico City, required full operation, safety, and damage control after an earthquake under strict Mexico City Building Codes. A dual system was chosen as the optimum system, using a steel braced frame with concrete encased columns at the lower levels for additional stiffness, strength and economy. The dual system, with the addition of viscous dampers, reduces the overall displacements and story drifts protecting the structure (Rahimian and Martinez-Romero, 2003).

In the $21^{\text {st }}$ century, hospitals are being designed to remain fully operational after an earthquake. Degenkolb Engineers has designed a variety of hospitals for different clients using different systems to meet stringent code requirements and improve earthquake performance for hospital structures. A dual system of EBFs with a full backup steel MRF was chosen for the Veteran's Affairs (VA) Palo Alto replacement hospital after the VA Medical Center's main hospital was heavily damaged in the 1989 Loma Prieta earthquake. Since the facility is located within 10 miles of the San Andreas Fault, it was designed to some of the world's strictest seismic guidelines, which had been under development since the 1971 San Fernando Earthquake. The VA liked the idea of MRF for spatial planning and flexibility, but the single system was not adequate given the drift 
limitations that had to be met. Since concrete shear walls were too functionally limiting, a braced frame system was used. Jim Malley, Senior Principal and project manager says in an interview with the author of the article entitled "Future Hospital Design: Focusing on Performance" in Modern Steel Construction, "We wanted a lateral system that would provide sufficient ductility, toughness and redundancy to resist the large expected ground motions (Soulages and Rubbo, 1998)." Energy can be dissipated through yielding of the EBF link beam and the backup MFs allow for lateral resistance at every frame line of the structure. It was expressed in Modern Steel Construction (Soulages and Rubbo, 1998) that the use of dual systems is not appropriate for non-critical buildings, however, the added expense was justified given the necessity for continued operation.

A final example of dual systems in use is the Fox Tower: a 27-story high rise in Portland, Oregon. A concrete shear wall core system in combination with a perimeter moment frame system was chosen by KPFF Consulting Engineers to meet a fast-track construction schedule and allowed an unobstructed building perimeter to view Mount Hood. While the core was being constructed, the mill order for the moment frame steel was being filled. Having the core walls completed before steel erection allowed Hoffman Construction to proceed without temporary bracing of the steel frames until the connections were secured (Ambrose, 2001). In the case of the Fox Tower, the dual lateral force resisting system allowed for a faster construction time ultimately saving the owner money. 
The design procedure discussed in Magnusson's article "Earthquake-Resisting Dual Systems and the 25\% Rule" is consistent with ASCE 7-05 and was followed for the models in this thesis. The procedure is paraphrased by Magnusson as follows:

1. Design the primary system to resist the full lateral forces without the aid of the backup or secondary system,

2. Design the backup system to resist $25 \%$ of the design forces without the aid of the primary system, and

3. Design the combined system, or "real" system, for the full lateral forces (Magnusson 1997).

The design description of the three prototype models (Model 15, model 25 and Model 40) is presented in this thesis in the three step procedure described here. 


\subsection{ANALYTICAL MODELS}

BRBFs have been chosen along with SMRFs as the dual system for this thesis. More information on BRBFs and their behavior is given below in Section 3.0 of this document. These frames are considered to have non-moment resisting connections since ASCE 7-05 does not require this type of detailing. SMRFs were chosen as the secondary system for this project as appropriate for the seismic characteristics of building site. More information on the design of SMRFs in this project is given below in Section 3.0.

\subsection{Building Description}

A 20-story, rectangular building was chosen to be examined for this study as a part of a two-dimensional analysis. The typical bay sizes in the direction of interest were $24^{\prime}-0^{\prime \prime}$ with story heights of $13^{\prime}-0^{\prime \prime}$ and an $18^{\prime}-0^{\prime \prime}$ first floor lobby. Floor framing layout and loading criteria are provided in Table 18 and Figure TT at the end of this document (Appendix A). The moment frame line that is modeled is represented on gridlines $\mathrm{B}$ or $\mathrm{C}$, and the braced frame is located on the exterior of the building on gridlines A or E.

For the purposes of this thesis, only the lateral resisting elements were modeled for half of the overall building. The braced frame and moment frame were modeled in parallel connected by a rigid diaphragm. An elevation of the model reviewed for this thesis is shown below in Figure B. The alternating pattern of the braces on the building elevation helps reduce column sizes by coupling the tension and compression braces. In Figure B, phantom lines in the MF represent gravity framing that has not been modeled for the analysis in this thesis. 

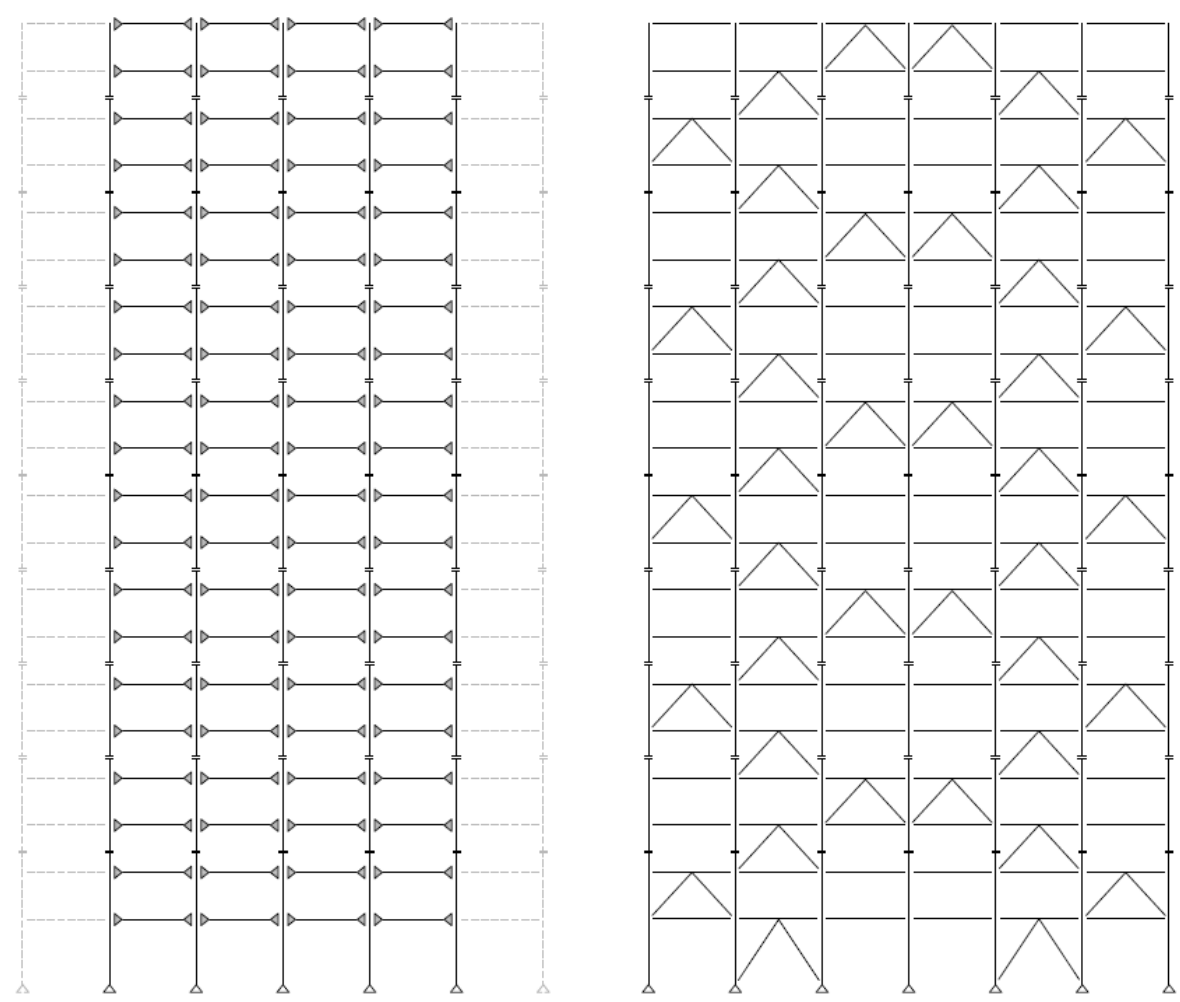

Figure B: Elevation of dual system

Source: Author, Using AutoCAD

Similar gravity loading criteria to the 20 -story building model in the SAC (Structural Engineers Association of California (SEAOC), Applied Technology Council (ATC), and California Universities for Research in Earthquake Engineering (CUREe) ) project for assessment of moment frames in response to the 1994 Northridge Earthquake was used (FEMA 355C 2000).

\subsubsection{Site Information}

The SAC project focused on theoretical structures located in Los Angeles, CA, Boston, MA, and Seattle, WA. Researchers found during the design of the 20-story moment frame structures that seismic forces governed the design of the Los Angeles 
structure, while wind was anticipated to govern the design of the lateral system for Boston and Seattle. Since the focus of this thesis is seismic analysis, Los Angeles, California was chosen as the theoretical location for the buckling-restrained braced frame dual system structures in this thesis project (FEMA 355 2000).

The design of these structures was site specific, based on the United States Geological Survey (USGS) design values for latitude and longitude (34 3' 36", $-118^{\circ} 15^{\prime}$ 0") on stiff soil (Site Class C). The theoretical structures were located by the designer in the financial district of Los Angeles; the response spectrum provided by USGS based on these defined parameters is shown in Figure $\mathrm{C}$ below. This graph shows that the maximum spectral acceleration seen at the site is approximately $2 g$ (where $g$ is the acceleration due to gravity) for short period buildings, and attains around $0.4 \mathrm{~g}$ at a period of 2.0 seconds.

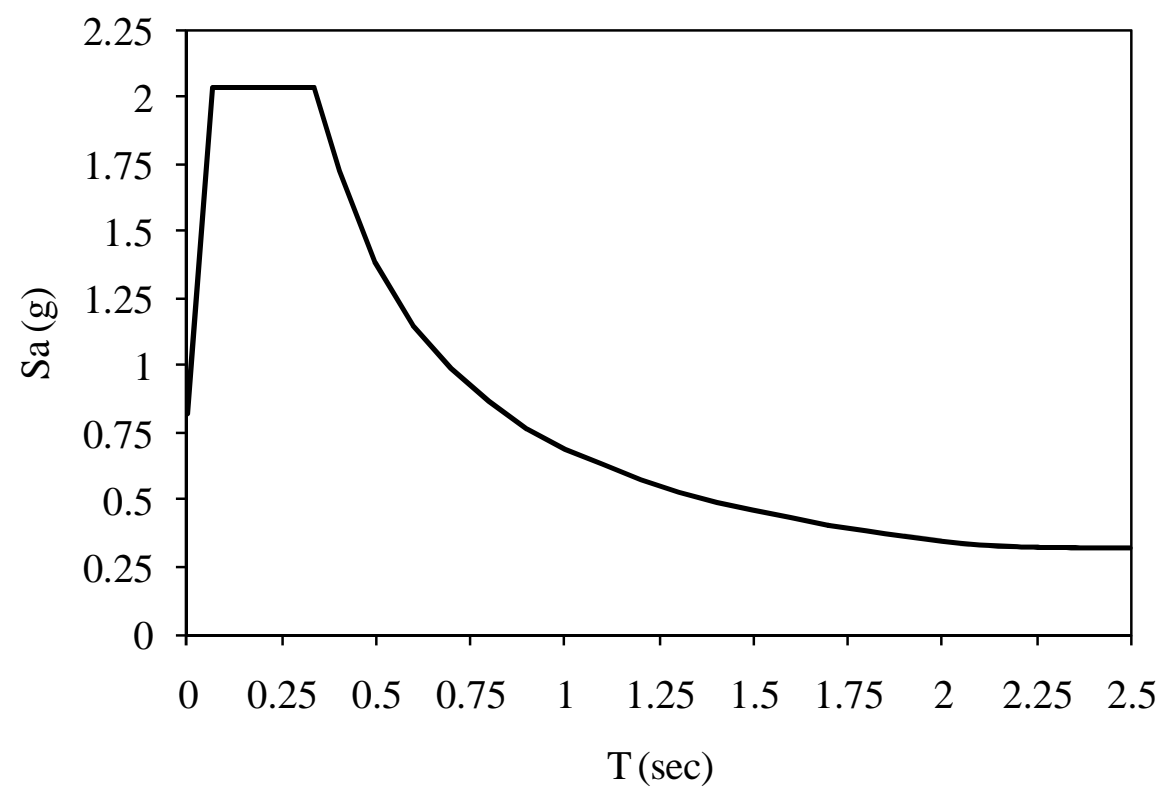

Figure C: Design Spectrum, Sa vs T Source: Author, Using Excel, Data from USGS

ASCE 7-05 Design Rule for Relative Strength in a Tall BRBF 


\subsubsection{Design Criteria}

ASCE 7-05 (including Supplements 1 and 2) was referenced for the calculations of seismic demands. The structural system is a dual system of buckling-restrained braced frames with special moment resisting frames. Braced frame connections are not detailed specifically for moment resistance and so are classified as non-moment-resisting connections. From ASCE 7-05 Table 12.2-1 the Response Modification Factor, Overstrength factor, and Displacement Modification Factors were used and provided below in Table 1. Full seismic calculations for using the equivalent lateral force procedure are provided in Table 2 (a) on page Error! Bookmark not defined..

\begin{tabular}{|c|c|}
\hline \multicolumn{2}{|c|}{ Seismic Design Values For BRBF Dual Systems } \\
\hline $\mathrm{R}=$ & 8 \\
\hline$\Omega_{0}=$ & 2.5 \\
\hline $\mathrm{C}_{\mathrm{d}}=$ & 5 \\
\hline
\end{tabular}

Table 1: Seismic design values for BRBF dual systems with non-moment-resisting connections per ASCE 7-05 Table 12.2-1

Source: Author, Using Excel

\subsubsection{Prototype Models}

Three separate buildings were designed for this analysis. The baseline model is a dual system based on the code requirements that have already been defined with a backup special moment-resisting frame (SMRF) designed for $25 \%$ capacity of the seismic demands on the structure. The remaining two models will have a backup SMRF designed to $15 \%$ strength and $40 \%$ strength. By providing analysis results of a similar structure that uses a stronger and weaker backup system, the effect of the $25 \%$ rule can be examined. For the analysis portion of this thesis, the models with $15 \%, 25 \%$, and $40 \%$ 
moment frame strength will be referred to as Model 15, Model 25, and Model 40 respectively.

For each of the three models, each BRBF will show some variation since the design of the BRBF system was based on the relative stiffness contribution of the respective moment frame

\subsection{Buckling-Restrained Braced Frame}

Buckling-restrained braces (BRBs) are manufactured with a steel core encased in a mortar-filled steel tube. The steel is coated with a material which restricts any bonding between the steel and mortar fill, allowing the core to elongate and compress as needed without a concern for buckling. This buckling restraint allows the brace tension and compression capacity to be nearly equal. The tension and compression capacity of a BRB have been considered using the following relationships (Clark et al. 1999):

$$
\begin{array}{ll}
C_{\text {max }}=\beta \omega A_{s} F_{y} & \text { Eq. } 1 \\
T_{\text {max }}=\omega A_{s} F_{y}, & \text { Eq. } 2
\end{array}
$$

where $\quad \beta$ is the adjustment factor for compression strength (dimensionless), $\omega$ is the adjustment factor for strain hardening (dimensionless), $A_{s}$ is the steel core area in BRB $\left(\mathrm{in}^{2}\right)$, and $F_{y}$ is the yield strength of steel core (ksi).

Near symmetry of tension and compression capacities induces a small unbalanced loading on the braced frame beams. Manufacturing information for braces was per Nippon Steel Corporation, Japan and testing data for brace properties was provided by Seismic Isolation Engineering Inc. (SIE). A general diagram of the components of a BRB 
is shown in Figure D below, along with a qualitative partial hysteresis loop of a brace in cyclic loading.

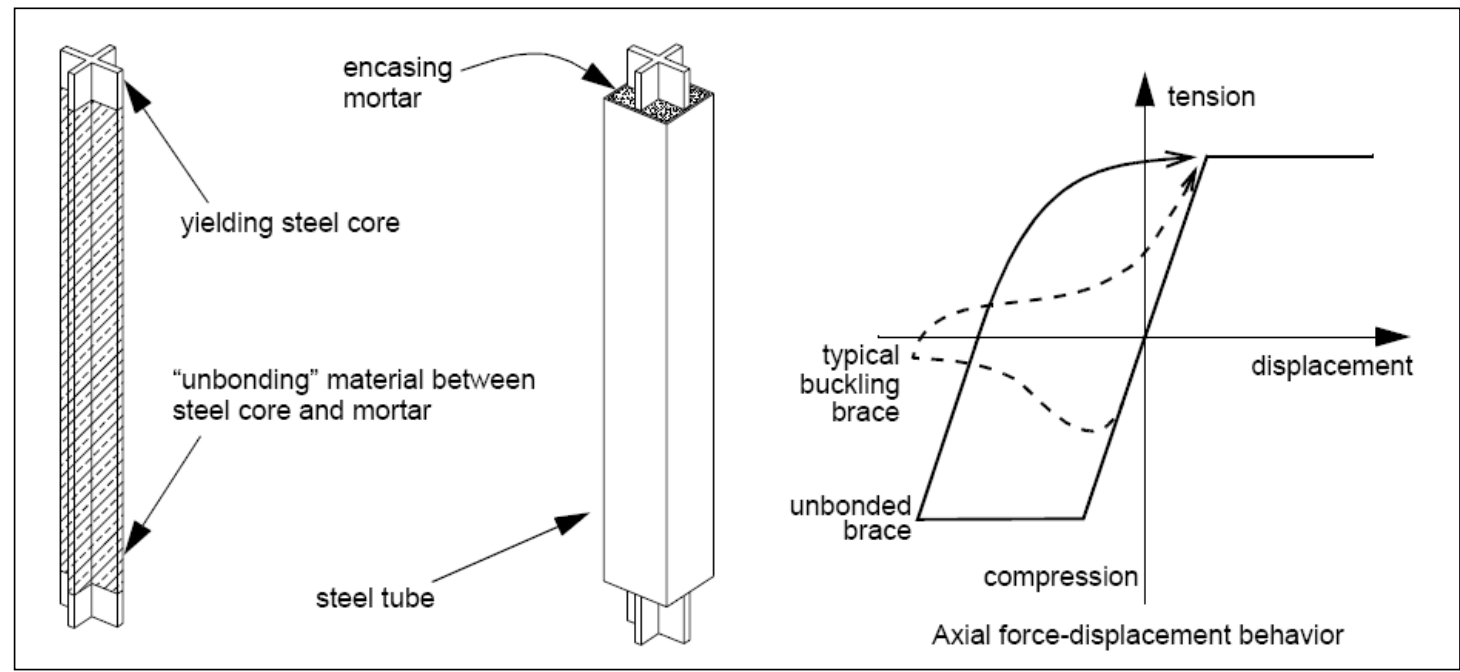

Figure D: Conceptual diagrams of Buckling-Restrained Brace elements Source: Clark et al. 1999

Above, Figure D shows the low post yield stiffness of the BRBF. In a dual system, the effect of low, post-yield BRBF stiffness on the building can be reduced with an elastic moment frame.

\subsection{Design Procedure}

The three step design procedure described in the article "Earthquake-Resisting Dual Systems and the 25\% Rule” by Magnusson was followed to design the BRBFDS for each model. Seismic forces were calculated using ASCE 7-05, and the minimum allowable base shear described in the supplement 2 revision of ASCE 7-05 was adopted. Seismic Calculations are provided below in Table 2 below. For preliminary force calculations, the maximum allowable period $\mathrm{T}_{\max }$ defined in ASCE 7-05 §12.8.2 (shown 
in Table 2) was used for the calculation of lateral forces. After the design was complete, this assumption was verified by the fundamental periods reported in ETABS. For all three models, the fundamental period exceeded $\mathrm{T}_{\max }$. The tributary seismic weight to the frames considered for the structure was half the total building weight, since only two of the four frame lines were modeled. As shown in Table 2 below, the design base shear force, $V$, is $0.06 \mathrm{~W}$ or 864 kips. 
2.0 Analytical Models 18

\begin{tabular}{|c|c|c|c|c|c|c|}
\hline \multicolumn{7}{|c|}{ Seismic Base Shear Calculations } \\
\hline \multicolumn{2}{|l|}{ Zip Code $=90012$} & \multicolumn{3}{|c|}{ Site Latitude $=\mathrm{N} / \mathrm{A}$} & \multicolumn{2}{|c|}{ Site Longitude $=\mathrm{N} / \mathrm{A}$} \\
\hline \multicolumn{7}{|c|}{ East-West Direction per ASCE 7-05 Minimum Design Loads for Buildings and Other Structures } \\
\hline \multicolumn{2}{|c|}{ Factor } & \multicolumn{3}{|c|}{\begin{tabular}{|c|} 
Description \\
\end{tabular}} & Value & Reference \\
\hline \multicolumn{2}{|l|}{ Total Building Height (ft) } & & 265 & \\
\hline Importance Factor & $\mathrm{I}$ & \multicolumn{3}{|c|}{ Occupancy Category II } & 1.0 & Table11.5-1 \\
\hline Response Factor & $\mathrm{R}$ & \multicolumn{3}{|c|}{ BRBF, Dual System } & 8.0 & Table $12.2-1$ \\
\hline Short Period Response Acceleration (s) & $\mathrm{S}_{\mathrm{S}}$ & & & & 2.243 & \multirow{2}{*}{$\begin{array}{l}\text { USGS Ground } \\
\text { Motion Paramete } \\
\text { Calculator }\end{array}$} \\
\hline 1 Second Response Acceleration & $\mathrm{S}_{1}$ & & & & 0.825 & \\
\hline Seismic Design Category & & & & & $\mathrm{D}$ & \begin{tabular}{|l|} 
Table $11.6-1,2$ \\
\end{tabular} \\
\hline Site Coefficient & $\mathrm{F}_{\mathrm{a}}$ & & $\mathrm{S}_{\mathrm{S}} \geq 1$ & & 1.0 & Table 11.4-1 \\
\hline Site Coefficient & $\mathrm{F}_{\mathrm{v}}$ & & $\mathrm{S}_{1} \geq$ & & 1.5 & Table 11.4-2 \\
\hline Max Considered Short Earthquake & $\mathrm{S}_{\mathrm{MS}}$ & & $\mathrm{S}_{\mathrm{MS}}=$ & & 2.243 & Equation 11.4-1 \\
\hline Max Considered 1 Second Earthquake & $\mathrm{S}_{\mathrm{M} 1}$ & & $\mathrm{~S}_{\mathrm{M} 1}=1$ & & 1.238 & Equation 11.4-2 \\
\hline Spectral Response Acceleration & $\mathrm{S}_{\mathrm{DS}}$ & & $\mathrm{S}_{\mathrm{DS}}=2$ & & 1.495 & Equation 11.4-3 \\
\hline Spectral Response Acceleration, $1 \mathrm{sec}$. & $\mathrm{S}_{\mathrm{D} 1}$ & & $\mathrm{~S}_{\mathrm{D} 1}=2$ & & 0.825 & Equation 11.4-4 \\
\hline Period Parameter 1 & $\mathrm{C}_{\mathrm{t}}$ & \multirow{2}{*}{\multicolumn{3}{|c|}{ All other Structural Systems }} & 0.02 & Table $12.8-2$ \\
\hline Period Parameter 2 & $\mathrm{x}$ & & & & 0.75 & Table $12.8-2$ \\
\hline Approximate Fundamental Period (sec) & $\mathrm{T}_{\mathrm{a}}$ & & $T_{a}=$ & & 1.31 & Equation $12.8-7$ \\
\hline Coefficient of Upper Limit & $\mathrm{C}_{\mathrm{v}}$ & & $\mathrm{S}_{\mathrm{D} 1} \geq$ & & 1.4 & Table 12.8-1 \\
\hline Upper Limit Fundamental Period & & & $\mathrm{T}_{\max }=$ & & 1.84 & Section 12.8 .2 \\
\hline Actual Building Period & $\mathrm{T}$ & *Use ? & $\mathrm{T}_{\mathrm{a}}$ as permit & by $\S 12.8 .2 *$ & 1.31 & Section 12.8 .2 \\
\hline Short Building & $\mathrm{T}_{\mathrm{S}}$ & & $T_{s}=$ & & 0.55 & Section 11.4 .5 \\
\hline Long Building Transition Period (sec) & $\mathrm{T}_{\mathrm{L}}$ & & $* *$ Using 9 & $12 * *$ & 12.0 & Figure $22-15$ \\
\hline Period (sec) & $\mathrm{T}$ & & & & 1.77 & Section12.8.2 \\
\hline & $\mathrm{C}_{\mathrm{Smax}}$ & & & $\frac{D 1}{\left(\frac{R}{I}\right)} \quad$ for $\mathrm{T} \leq \mathrm{T}_{\mathrm{L}}$ & 0.06 & Equation 12.8-3 \\
\hline & $\mathrm{C}_{\mathrm{Smax}}$ & & $C_{s}=$ & $\frac{T_{2}}{\left(\frac{R}{T}\right)}$ for $\mathrm{T}>\mathrm{TL}$ & 0.40 & Equation $12.8-4$ \\
\hline & $\mathrm{C}_{\mathrm{smin}}$ & & $\mathrm{C}_{\mathrm{S}}=0$ & & 0.01 & Equation $12.8-5$ \\
\hline Seismic Response Coefficient & $\mathrm{C}_{\mathrm{smin}}$ & & & & 0.05 & Equation 12.8-6 \\
\hline & $\mathrm{C}_{\mathrm{S}}$ & & & & 0.19 & Equation $12.8-2$ \\
\hline & $\mathrm{C}_{\mathrm{S}}$ & & $\mathrm{C}_{\mathrm{Smin}} \leq \mathrm{C}_{8}$ & Smax & 0.06 & Section 12.8.1.1 \\
\hline Building Fundamental Period & & $\mathrm{T}=$ & 2.13 & sec & $\mathrm{ASCE} 7-$ & $5(12.8-12)]$ \\
\hline Seismic Period exponent & & $\mathrm{k}=$ & 1.67 & & ASCE 7- & $5(12.8-12)]$ \\
\hline Seismic Response Coefficient & & $\mathrm{C}_{\mathrm{s}}=$ & 0.060 & & {$[\mathrm{ASCE} 7$} & 05 12.8.2] \\
\hline Tibutary Building Weight & & $\mathrm{W}=$ & 14452 & kips & Per Load & ig Summary] \\
\hline Base Shear & $\mathrm{V}=\mathrm{C}$ & $* \mathrm{~W}=$ & 864 & kips & {$[\mathrm{ASCE} 7$} & $05(12.8-1)]$ \\
\hline
\end{tabular}

Table 2: Seismic calculations for Model 25

Source: Author, Using Excel

ASCE 7-05 Design Rule for Relative Strength in a Tall BRBF 


\subsubsection{Magnusson Procedure Step 1: Design of BRBF}

Design recommendations from AISC Steel Tips: Seismic Design of BucklingRestrained Braced Frames were followed for the design of the BRBF since AISC 341 (AISC and SSEC 2006) does not cover the design procedure of BRBFs. The BRB core areas were sized based on

- axial demands of the full equivalent static forces calculated using ASCE 7-05 $\S 12.8$, based on the maximum building period as defined in ASCE 7-05 $\$ 12.8 .2$ for a dual system;

- gravity loads using a minimum anticipated core yield capacity of $38 \mathrm{ksi}$ steel. Demand to capacity ratios (DCR) were allowed to reach $95 \%-100 \%$ at levels 15 $20,85 \%-95 \%$ at levels $8-14$, and $80 \%-85 \%$ at the lower 8 floors. This is a technique chosen by the designer to prevent soft story collapses by providing the most reserve capacity at the lower levels, encouraging the order of failure events to occur from top to bottom (Null and Sabelli 2001).

Exterior braced frame column demands were calculated considering tributary gravity and seismic loads. The columns were designed to resist the brace capacities based on the maximum expected yield strength, $F_{y e}$, of $46 \mathrm{ksi}$ for the braces as an overstrength demand for earthquake forces. Columns were designed with a yield strength, $F_{y}$, of 50 ksi. Since the braces were arranged in an X-pattern (see Figure B above), the interior column forces are reduced by the tension and compression couple which results from a tension and compression brace sharing a column, demonstrated in Figure E below and a 
net vertical force close to zero on the interior columns. Since a single brace reaction must be fully resolved in the column, columns on the exterior were designed for the highest seismic demands.

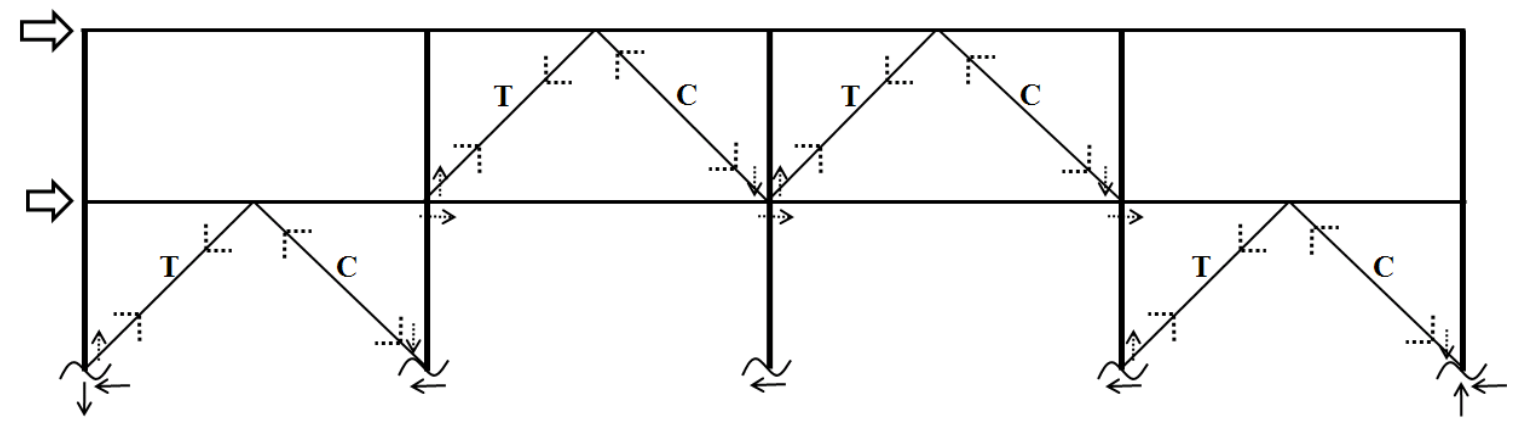

Figure E: Free body diagram for typical braced frame loading due to seismic loads Source: Author, Using Excel

Demand capacity ratios of the exterior columns were kept below $85 \%$ for all columns; the highest DCRs occur at the upper levels, and most conservative (lowest DCR) designs occur toward the bottom. Figure F below demonstrates the applied gravity forces to the columns. Based on tributary area, interior columns receive double the demands due to gravity loads causing axial shortening. As a result of axial shortening, the interior columns would settle more than the exterior causing a sag in the frame line and inducing large forces into the braces. To avoid shortening, the interior columns were sized with approximately twice the cross sectional area as the exterior columns to allow a more regular interaction of elements and force vertical deformation compatibility across the column line.

Similar to the columns, beams in the braced frame were also designed for axial, flexural and shear demands, based on the maximum force that can be delivered by the 
braces, assuming the maximum expected yield strength, $F_{y e}$. All beam-to-column connections were assumed to have pinned connections with the exception of gusset plate locations. Where gusset plates are welded to the beams and columns, the connections were assumed to have rotational fixity.

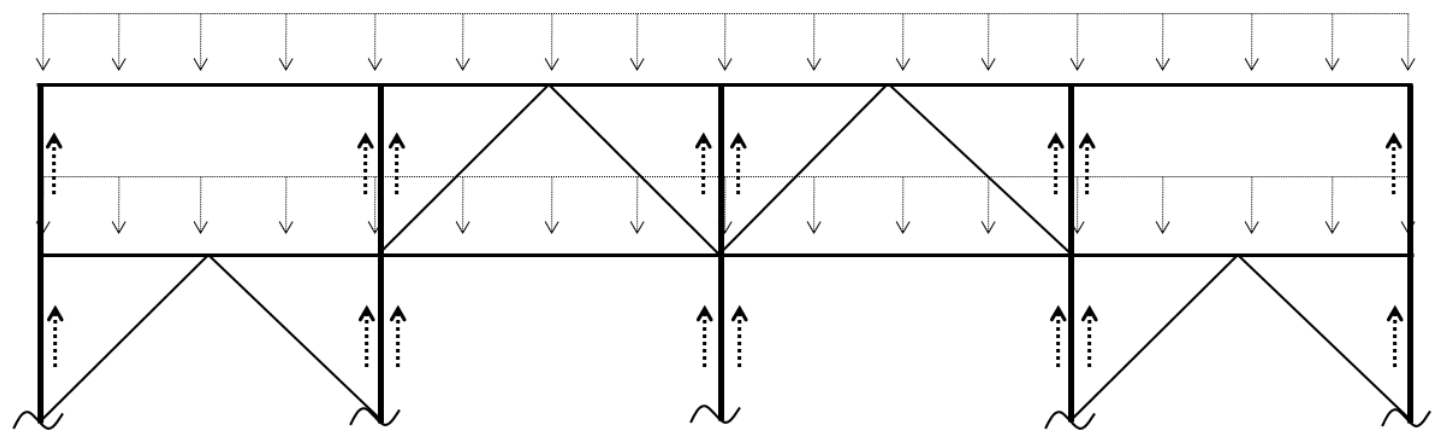

Figure F: Free body diagram for typical braced frame loading due to gravity loads Source: Author, Using Excel

The preliminary braced frame design (based on static forces) was checked with ETABS using response spectrum analysis (RSA) and the complete quadratic combination (CQC) method to combine the effects of multiple modes for the USGS mapped spectra from Figure $\mathrm{C}$ above. The analysis included the first three modes to capture a minimum of 90 percent mass participation as recommended by ASCE 7-05 $\$ 12.9$. The response spectrum analysis yielded lower force demands, and the brace and column member sizes were reduced.

Gusset plates were sized based on the ultimate brace capacity forces to ensure that the connections will remain elastic during an earthquake. The design was governed by gross section yielding, block shear and net section rupturing. A yield strength and 
ultimate capacity of $50 \mathrm{ksi}$ and $65 \mathrm{ksi}$ respectively was used for the gusset material. All gusset plates were $3 / 4^{\prime \prime}-1$ " thick and $3 / 4^{\prime \prime}-1$ " diameter A360 bolts were used to connect the braces to the gussets.

\subsubsection{Magnusson Procedure Step 2: Design of SMRF}

The preliminary design for the moment frames used the portal method to distribute earthquake forces using $15 \%, 25 \%$ or $40 \%$ of the calculated equivalent static base shear. MRF beams have four bays of fixed rotation on each end; see Figure B above.

Reduced beam sections were sized per requirements of the Seismic design Manual (also referred to as AISC 341) and Steel Tips: Design of Reduced Beam Section (RBS) Moment Frame Connections (Moore and Feng 2011). The beam-column interaction was checked for strong column-weak beam interaction (SCWB) at each level and doubler plates were added to panel zones where necessary; since doubler plates were provided, the effect of panel zone yielding, or inelastic panel zone deformation, was neglected in this analysis. DCRs for reduced beam sections were designed near $100 \%$ at the upper levels and more conservatively at the lower levels, ranging from 75\%-90\%, based on forces from the calculated response spectrum analysis by ETABS (as opposed to the linear static) forces along with dead and live loads. Since BRBF yielding occurs in the upper levels of the braced frame first, an effort was made to also control the moment frame failure order. Under a large earthquake, when braces exceed their capacity, the load is anticipated to shift into the moment frame. If the moment frame prematurely loses stiffness from yielding, farther excitation will result in further lateral displacement and 
collapse may occur. With this in mind, it is important to direct initial yielding at the top of the building and allow yielding to work its way from the top of the building down to avoid a soft story collapse.

\subsubsection{Magnusson Procedure Step 3: Adjustments for Dual System Interaction}

By combining the MF system with the BRBF in ETABS, the interaction between the two systems based on stiffness allowed a reduction (about 10\%-20\%) in the brace sizes for both the $25 \%$ and $40 \%$ MF dual system models. For Model 15, braces were reduced at most $0.25 \mathrm{in}^{2}$ and for most floors, no reduction was made at all since the braced frame was significantly stiffer than the moment frame. Member sizes are provided in Table 19, Table 20 and Table 21 at the end of this document (Appendix A) and can be compared for reference of the size reduction. Since the $15 \%$ moment frame model brace design is close to the original braced frame design, the reduction of brace sizes can be seen in the remaining two models. For this procedure, the demands from the ETABS RSA were used including the behavior of the first three modes to capture at least $90 \%$ mass participation. The modal responses were combined using the CQC method.

The highest reduction in braced frame strength was made to the $40 \%$ moment frame model. In the case of each model, the forces attracted by the moment frame based on the relative stiffness between the MF and BF did not exceed the capacity of the moment frame system. Regardless of the strength of the moment frame system, the models showed the moment frame to attract less base shear than the total shear it was 
designed for, since the BRBF system is inherently much stiffer. Results of the elastic shear distribution and frame interaction is shown in Section 2.4 to follow.

\subsection{Elastic Analysis}

Despite the varying relative stiffnesses between the three models, all three structures showed little variance in modal frequencies and mass participation. The reduction in brace sizes was slight for each model with the addition of the moment frame. Adding a moment frame caused an increased stiffness consistent with the increased moment frame strength. Modal information has been shown for each model in Table 3 below.

\begin{tabular}{|l|c|c|}
\hline Model 15 & Period (s) & $\begin{array}{c}\text { \% Mass } \\
\text { Participation }\end{array}$ \\
\cline { 2 - 4 } Mode 1 & 2.24 & 74.5 \\
\hline Mode 2 & 0.79 & 15 \\
\hline Mode 3 & 0.46 & 4.9 \\
\hline & Sum: & $\Sigma 94.4$ \\
\hline
\end{tabular}

\begin{tabular}{|c|c|c|c|}
\hline \multirow[t]{5}{*}{ Model 25} & & Period (s) & $\begin{array}{c}\% \text { Mass } \\
\text { Participation }\end{array}$ \\
\hline & Mode 1 & \begin{tabular}{|l|}
2.23 \\
\end{tabular} & 74.4 \\
\hline & Mode 2 & 0.8 & 15.1 \\
\hline & Mode 3 & 0.47 & 4.8 \\
\hline & & & $\Sigma 94.3$ \\
\hline
\end{tabular}

\begin{tabular}{|c|c|c|c|}
\hline \multirow[t]{5}{*}{ Model 40} & & Period (s) & $\begin{array}{c}\text { \% Mass } \\
\text { Participation }\end{array}$ \\
\hline & Mode 1 & 2.19 & 75.2 \\
\hline & Mode 2 & 0.79 & 14.5 \\
\hline & Mode 3 & 0.46 & 4.6 \\
\hline & & & $\sum 94.3$ \\
\hline
\end{tabular}

Table 3: ETABS periods and mass participation for dual system models Source: Author, Using Excel 
The fundamental period for each structure was verified using the Raleigh Ritz approximation as suggested in ASCE 41-06 and shown in Equation 3 below.

$$
T=2 \pi \sqrt{\frac{\sum w_{i} \delta_{i}^{2}}{g \sum F_{i} \delta_{i}}}
$$

where $\mathrm{T}$ is the building fundamental period (seconds), $w_{i}$ is the weight of floor level $i$ (kips),

$\delta_{\mathrm{i}}$ is the lateral displacement at level $i$ caused by story force $F_{i}$ (in), $F_{i}$ is the story force at level $i$ (kips), and $g$ is acceleration due to gravity $\left(\mathrm{in} / \mathrm{s}^{2}\right)$

Results of Raleigh Ritz approximation of Equation 3 closely match the fundamental periods reported by ETABS and are displayed below in Table 4.

\begin{tabular}{|l|c|}
\hline & $\begin{array}{c}\text { Fundamental } \\
\text { Period (s) }\end{array}$ \\
\hline Model 15 & 2.23 \\
\hline Model 25 & 2.22 \\
\hline Model 40 & 2.19 \\
\hline
\end{tabular}

\section{Table 4: Raleigh Ritz Approximation}

Source: Author, Using Excel

Since a minimum strength ( $25 \%$ of design forces) is required by code for a secondary moment frame in a dual system, the base shear demands were examined in the moment frames of each elastic model. The MF story shear demands for each model are shown in Figure $\mathrm{G}$ below, along with the total system design story shears calculated per ASCE 7-05 using the equivalent static force procedure (ESFP). Despite the differences in fundamental periods and modal participation, the elastic analysis data below is reported using a fundamental period of 2.2 seconds and the corresponding linear static story shears. 


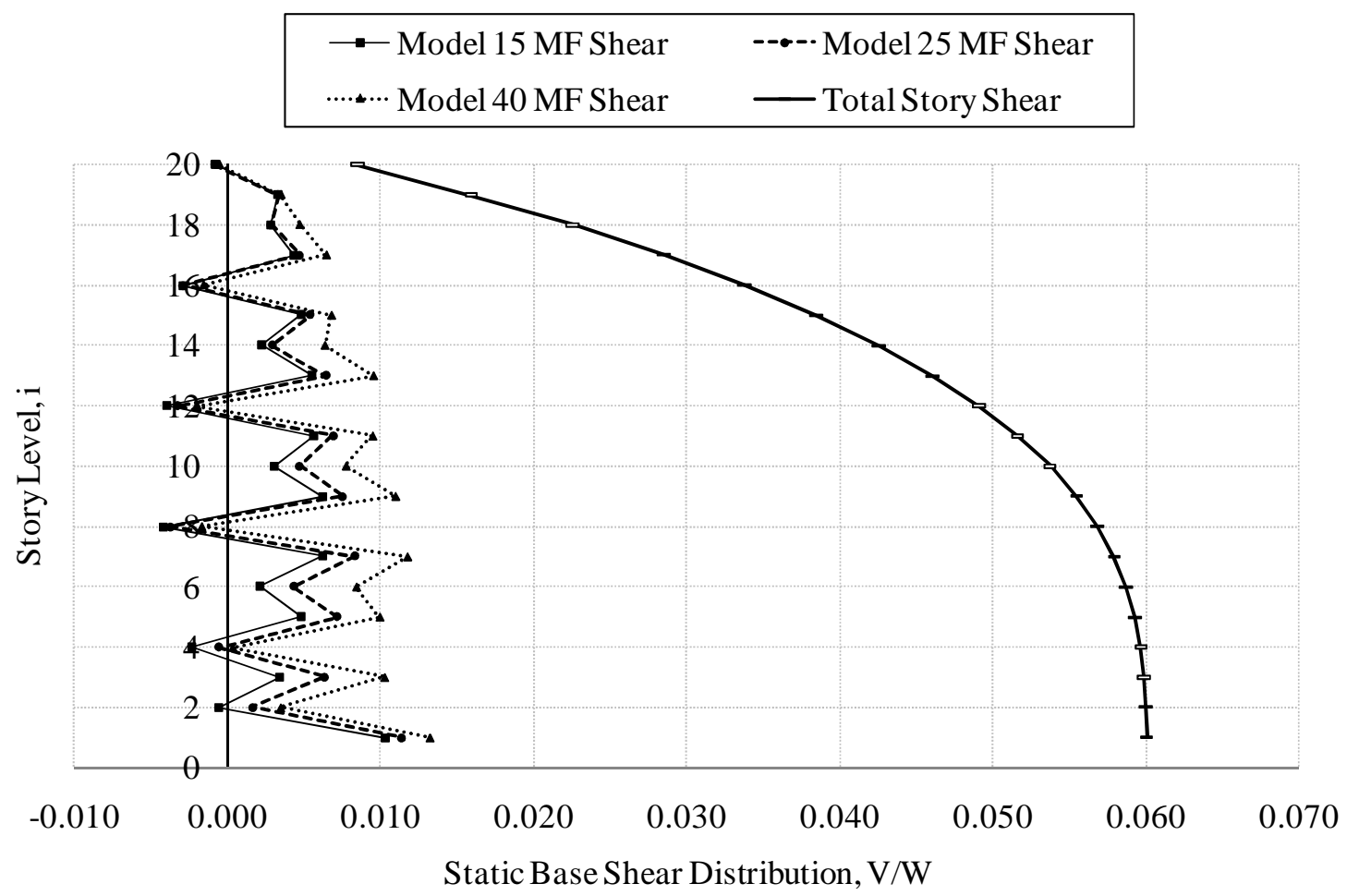

Figure G: Elastic Shear calculated by ESFP showing relative stiffness of MF to BF for Model 15, Model 25 and Model 40

Source: Author, Using Excel

Model 15 demonstrates reverse story shear at story 4, 8, 12, 16 and 20 (roof) and similar behavior is seen in Models 25 and 40 at story 8,12, and 20 as shown above in Figure G. This particular behavior corresponds with the levels where braces occur in adjacent bays and the stiffness of the adjacent braces is much stiffer than the moment frame. Because of the increased stiffness of adjacent braces, the braces attract over $100 \%$ of the story shear and the moment frame acts in resistance to the braced frame. The highest shear demands in the moment frame are apparent when the braces are separated by two center bays which occur on alternating levels. See Figure B for reference of brace configuration and the corresponding levels. The shear distribution trend seen here is 
particularly representative of the X-pattern brace configuration that was chosen for this thesis. From the linear static analysis, a maximum story shear ratio in the moment frame in Model 15 as well as Model 25 is $21 \%$, which occurs in level 19, and 23\% at level 17 in Model 40.
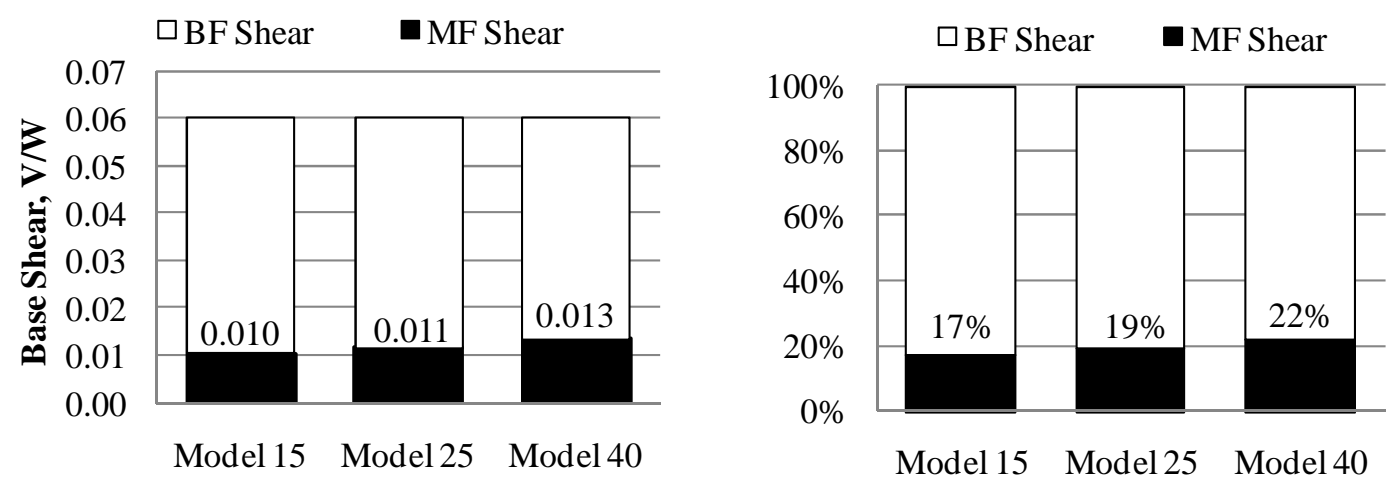

Figure H: Elastic base shear distribution as absolute and relative base shear quantities for Models 15, 25 and 40

Source: Author, Using Excel

The total base shear and base shear ratio for each model from the linear static analysis is shown above in Figure H. Results of the linear analysis show Model 40, designed for $40 \%$ of the expected base shear, received $22 \%$ of the total base shear (or $0.013 \mathrm{~W})$. A total of $19 \%$ of the expected base shear, or $0.011 \mathrm{~W}$, was attracted by the Model $25 \mathrm{MF}$, and $17 \%$ of the base shear, or $0.010 \mathrm{~W}$, was attracted by the Model 15 moment frame. These results suggest that the difference in strength of the MF has limited effect on the relative distribution of base shear between the MF and BRBF; a $25 \%$ design strength increase (between Model 15 and Model 40 ) only resulted in a 5\% (22\%-17\% shown in Figure $\mathrm{H}$ ) change in relative stiffness between the MF and BRBF. 


\subsection{MODELING FOR NONLINEAR ANALYSIS}

Before a nonlinear analysis was carried out for the models that have been presented in this thesis, a simplified model was used to demonstrate whether the modeling techniques and assumptions for the dual system analysis would represent real life behavior of a steel building frame system.

\subsection{UC Berkeley Testing on Single BRBF}

A report by Lopez et al. entitled "Lessons Learned from Large-Scale Tests of Unbonded Braced Frame Subassemblages" was published in 2002 documenting the results of cyclic testing of an unbonded braced frame (buckling-restrained braced frame). The tests were ordered by Rutherford and Chekene as a verification of analytical performance for the lateral force resisting system of a new laboratory building on the UC Berkeley campus. One of three tests was a cyclic testing of a concentrically modeled unbonded (buckling-restrained) braced frame, as shown below in Figure I. Dimensions and member sizes were provided by the published document and the test set-up is shown in Figure I below. Rutherford and Chekene used OpenSees to analytically model the behavior of the frame. The frame was also modeled in Perform 3D to calibrate the modeling assumptions of this thesis to be consistent with true life performance (Lopez et al. 2002). 


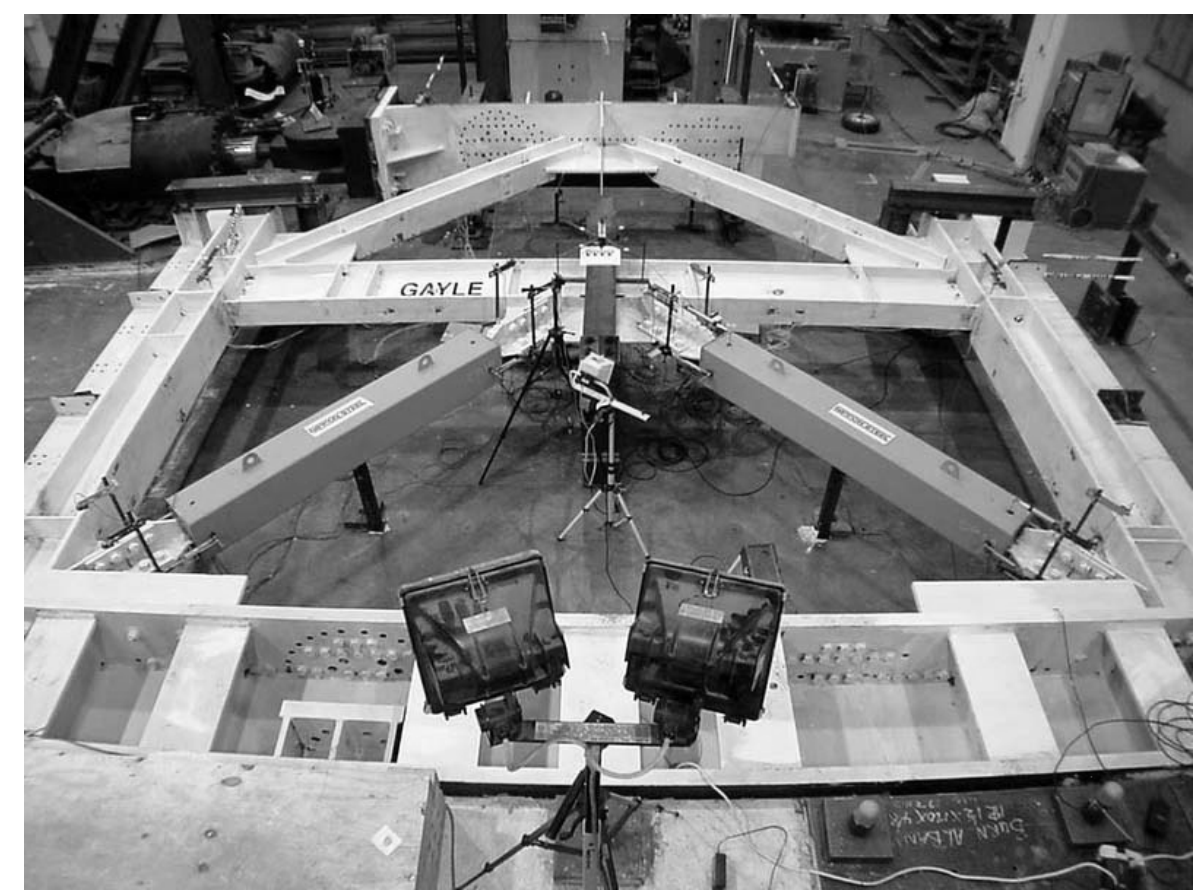

Figure I: Test setup for UC Berkeley Unbonded Braced Frame Source: Lopez et al. 2001

The core area of the unbonded brace in this test, manufactured by Nippon Steel Corporation, was $6.33 \mathrm{in}^{2}$; braces examined in this thesis range from $2 \mathrm{in}^{2}$ to $10.5 \mathrm{in}^{2}$. The test used bolted brace connections with welded gusset plates which were verified using the design checks and methods mentioned in Section 2.3.1. In Perform 3D, moment rotation hinges were assigned with beam properties at a distance of half the beam depth from the gusset at the top of the frame and moment rotation hinges with axial interaction were placed at a distance equal to half the column depth from the gusset on each side at the base of the frame. Beams and columns were assumed to be rigid where they were welded to the gusset plates. The nonlinear BRB element in Perform 3D was used and is further discussed in section 3.2 of this document (Lopez et al. 2002). 
Lateral displacements up to $2 \%$ story drift (approximately $2.5^{\prime \prime}$ ) were imposed in the test; the cyclic response of the frame is shown below in Figure $\mathrm{J}$ along with the pushover curve from the same frame modeled in Perform 3D using the calibrated assumptions in the thesis.

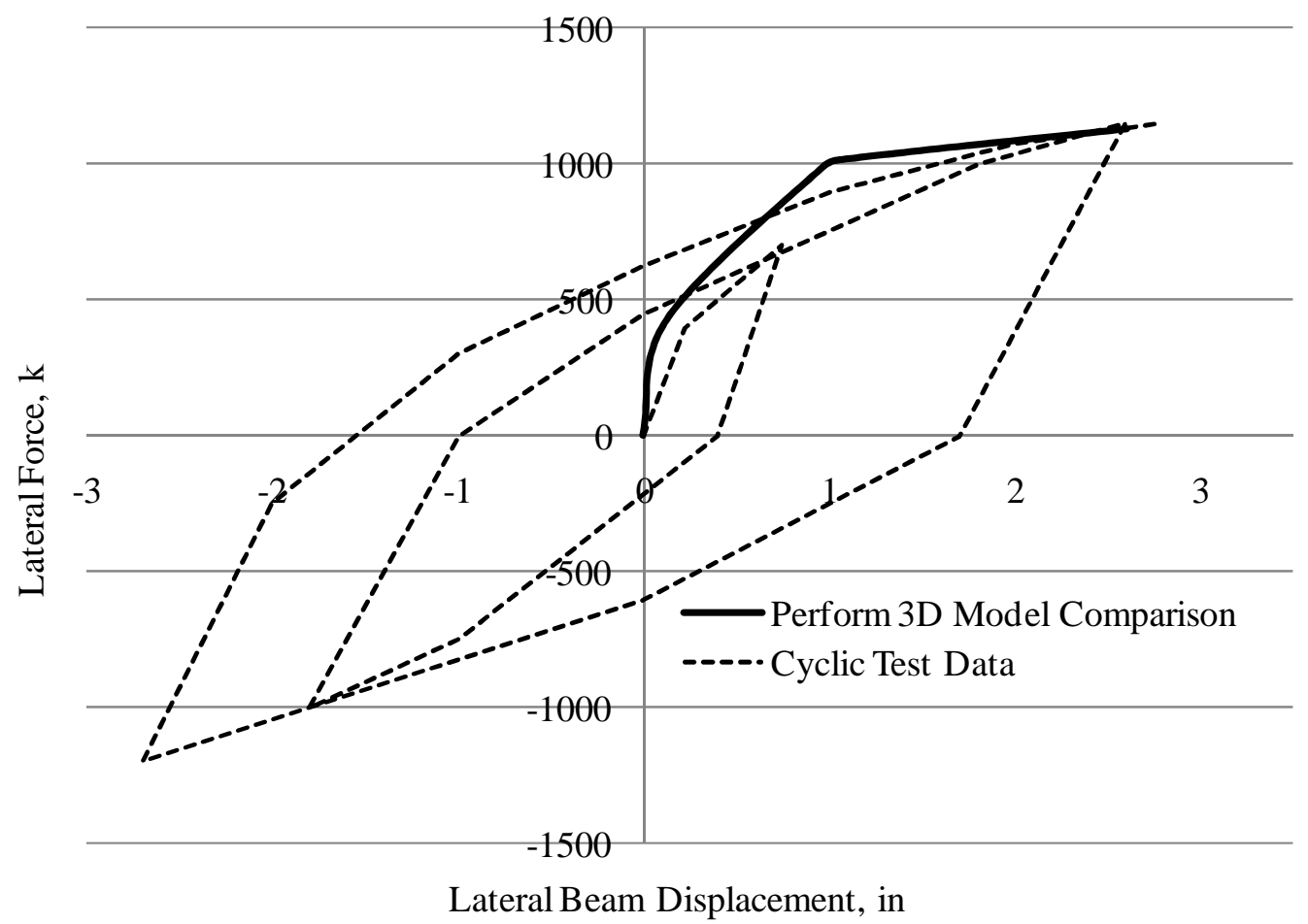

Figure J: Testing data compared to analytical modeling in Perform 3D Source: Test data by Lopez et al. 2002, replotted by Author, using Excel

Since the Perform 3D prediction closely matched the real behavior of the test frame, the assumptions for this thesis have been considered appropriate for further analysis of the dual systems. 


\subsection{Modeling Assumptions}

All analyses were done using Perform 3D based on expected strength properties for materials rather than design values since the goal of this thesis is to capture the realistic interaction and behavior of this particular dual system under nonlinear seismic analysis. Expected yield strengths, $\mathrm{F}_{\mathrm{ye}}$, for each member were used for analysis and are shown in Table 5 below, along with the nominal yield strength, $\mathrm{F}_{\mathrm{y}}$, and the modulus of elasticity, E.

\begin{tabular}{|c|c|c|c|}
\hline Member & $\mathrm{F}_{\mathrm{y}}(\mathrm{ksi})$ & $\mathrm{F}_{\mathrm{ye}}(\mathrm{ksi})$ & Modulus of Elasticity, E (ksi) \\
\hline Beams & 50 & 55 & 29000 \\
\hline Columns & 50 & 55 & 29000 \\
\hline Braces & 38 & 46 & 29000 \\
\hline
\end{tabular}

Table 5: Material Properties

Source: Author, Using Excel

2D models were used in Perform 3D to analyze the dual system interaction between the braced frame and moment frames. The building model elevation from above in Figure B shows how the structure was represented in 2D by considering one exterior braced frame line and one interior moment frame line, i.e. half of the building's lateral system in series. The two frames were connected by assigning equal lateral displacements (rigid diaphragm) to all nodes at a given level. Out of plane translation and rotation were restricted. Beam and column hinges were modeled according to ASCE 41-06 Table 5-6. Experimental testing data were used to define the BRB properties as BRBs are not addressed by the ASCE 41-06.

ASCE 41 makes a distinction between primary and secondary elements, and separate performance criteria are assigned to an element based on its classification as 
primary or secondary. Throughout this document, the moment frame is referred to as a secondary system to the braced frame. ASCE 41 defines a secondary system as one that does not contribute to the lateral behavior of the building and only supports vertical loads. Since all elements (moment frame and braced frame) are acting together as a single dual system and all are contributing to the primary resistance of lateral forces, performance criteria for primary elements have been assigned to all nonlinear components. Secondary systems (MF) as previously discussed for dual systems are modeled using ASCE 41 performance criteria for primary elements.

A typical braced frame is shown below in Figure $\mathrm{K}$ along with a simplified stick model demonstrating the locations of linear and nonlinear elements.

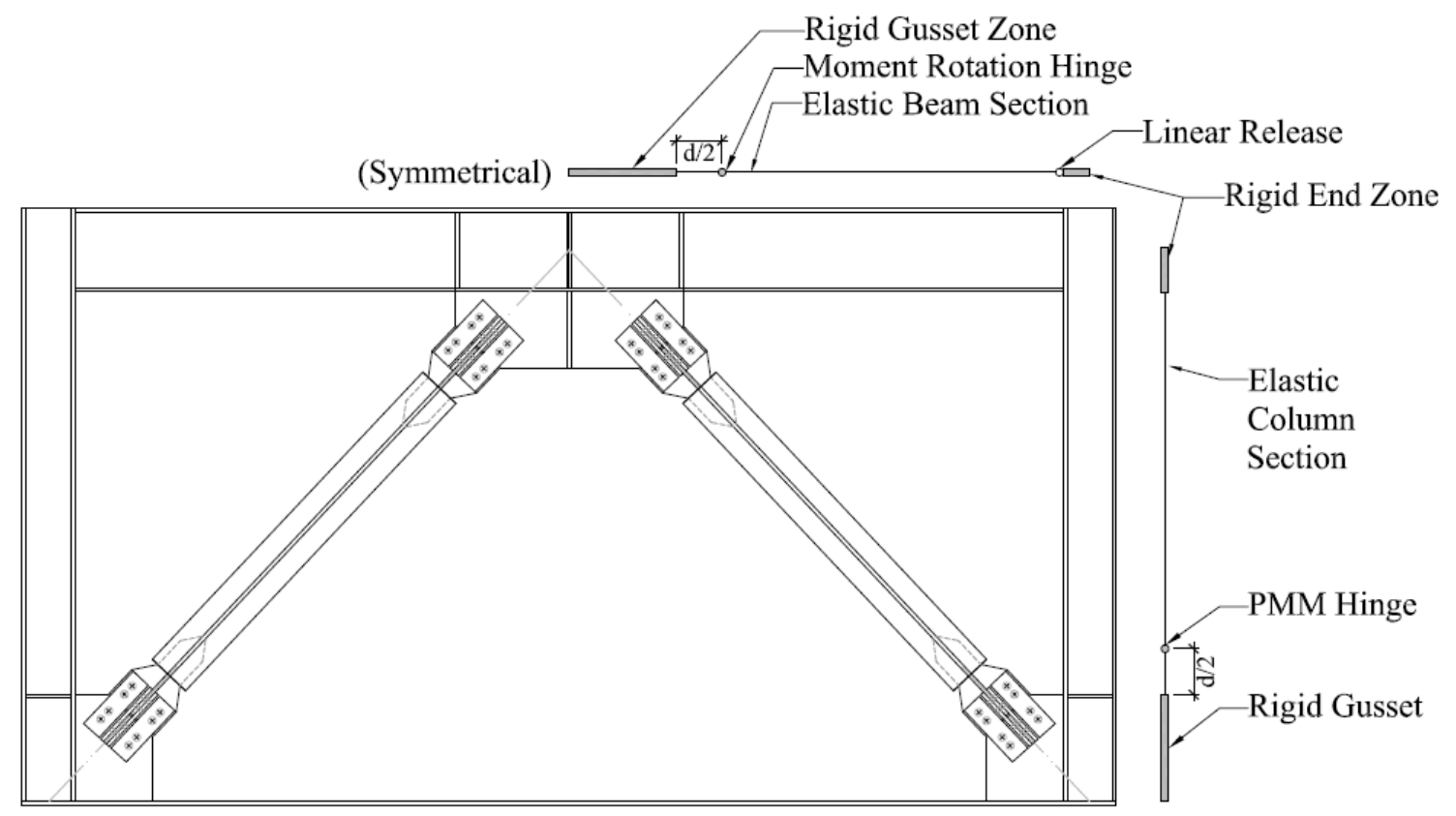

Figure K: Analytical interpretation of typical braced frame Source: Author, Using Excel 
Column hinges are placed at a distance $d / 2$ above the gusset or beam connection where $d$ is the depth of the column or beam the hinge is placed on. Gusset regions are considered relatively rigid and modeled with a stiffness of 10 times the stiffness of the elastic section. Beams and columns are also assigned as rigid for $d / 2$, where $d$ is the depth of the corresponding column or beam in the connection as shown in Figure K.

BRB compound elements make up the braces and gusset region in the brace work point length, which is further described by Figure $M$ on page 35. In addition, the beams of the braced frame are assigned a linear hinge release at the ends since the connections are not relied upon for moment-resistance. An analytical linear hinge release at the beam column connection causes a potential hinge location at a distance of half the beam depth outside the gusset at beam mid-span. Specific properties of individual nonlinear elements discussed in more detail in the remainder of this section.

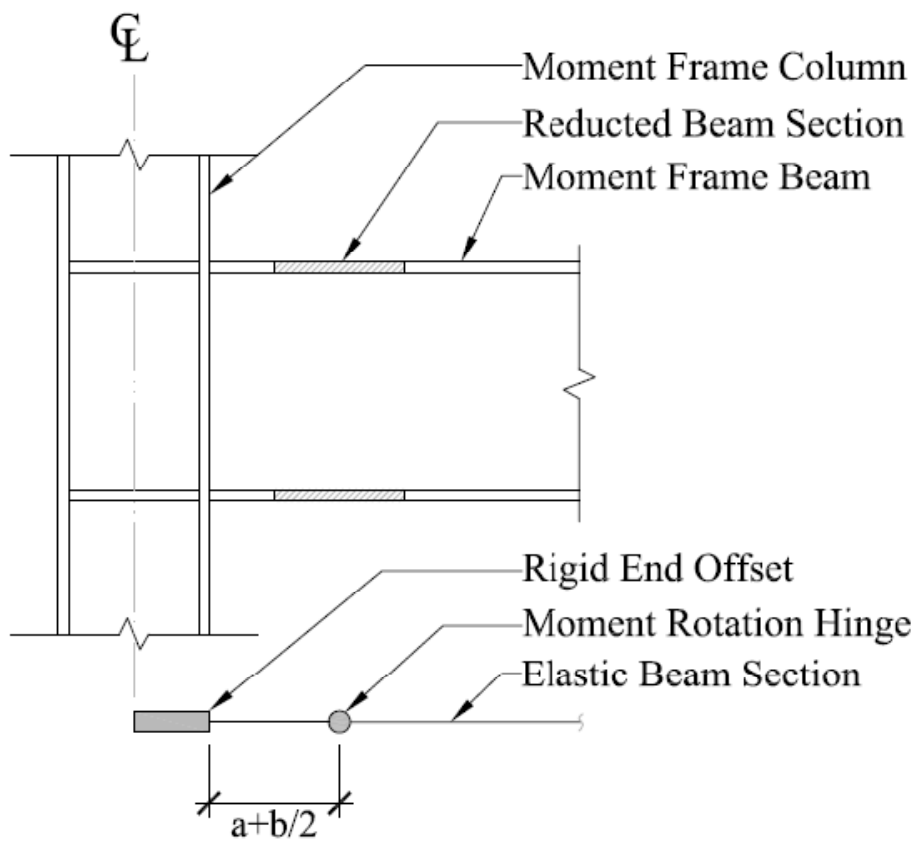

ASCE 7-05 Design Rule for Relative Strength in a Tall BRBF 


\section{Figure L: Analytical Interpretation of RBS Moment Connection}

Source: CSI 2006a, redrawn by author using AutoCAD

Moment rotation hinges are placed at the centerline of the RBS cut in the beam flanges as shown in Figure L where $a$ and $b$ are defined by AISC 341 in the design of reduced beam sections. The remaining length of the beam in the model is given elastic properties while the beam column interface is assumed rigid.

\subsubsection{BRB Perform 3D Element Compounds}

A schematic diagram of a brace element is shown below in Figure M. The nonlinear BRB element in Perform 3D was used with a yield length (Ly) of approximately $75 \%$ of the overall brace length (Ly+2Lny). The remaining $25 \%$ of the brace (2Lny) is modeled as a linear elastic bar with a stiffness of ten times the yield length stiffness. The remaining work point length is also modeled as rigid to account for the beam or column interface region as well as the gusset connection since it is expected to be far more stiff than the yield region of the brace. These proportions are based on preliminary suggested assumptions by Nippon Steel Corporation and are considered adequate for analysis. In projects facing construction, the structural designer must work closely with the brace manufacturer as the unbonded yield length may vary depending on the demands and the length of the connection required. 

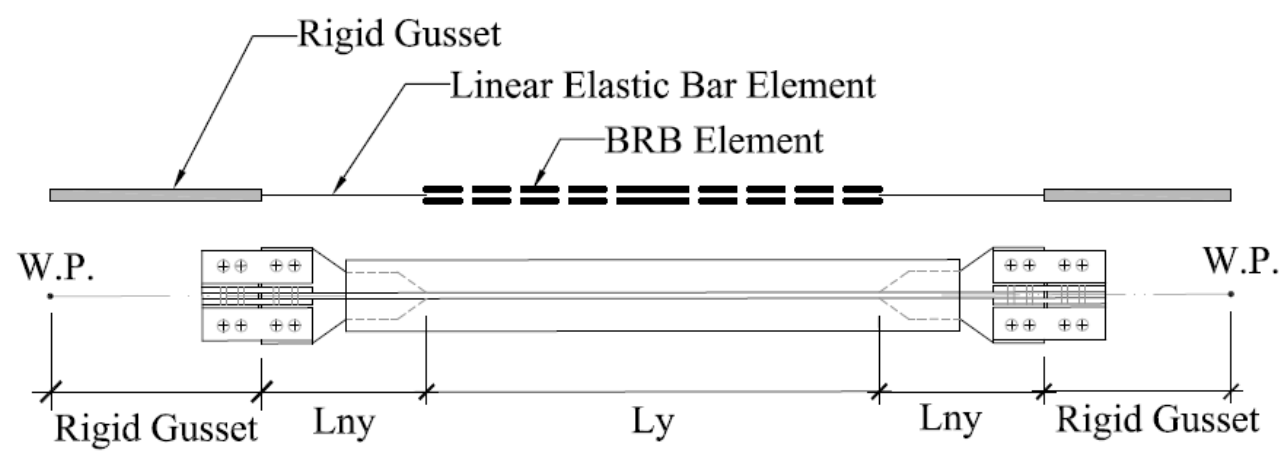

Figure M: Diagram of Buckling-Restrained Brace

Source: Author, Using AutoCAD

Since BRB elements are not addressed by ASCE 41, the force-displacement

behavior for the BRB elements in this thesis are based off testing data for a variety of

brace capacities. Testing of BRBs by SIE specific to braces manufactured by Nippon

Steel were referenced for modeling BRB properties. A typical hysteresis plot is shown in

Figure $\mathrm{N}$ along with the linear approximation used in Perform 3D. 


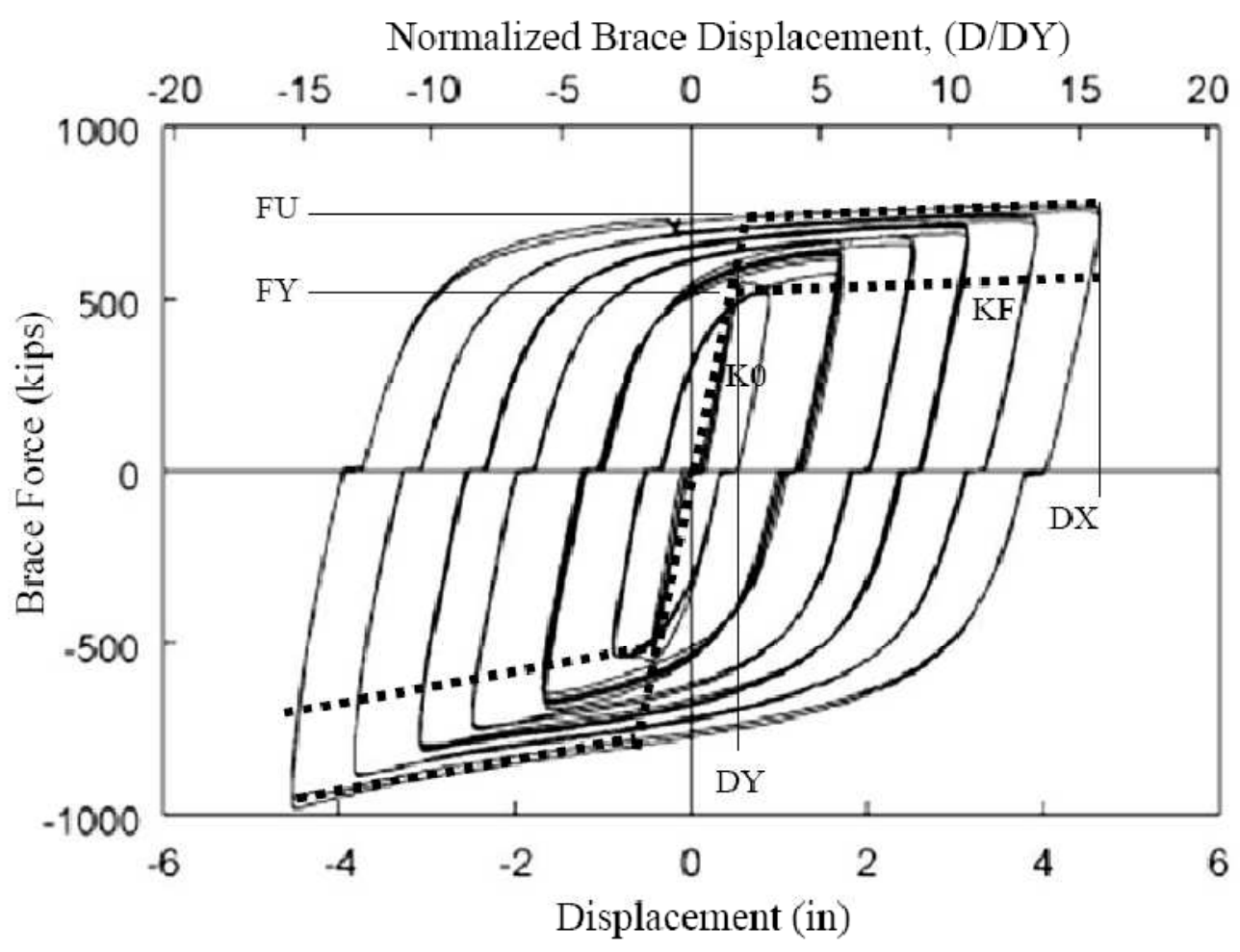

Figure N: Hysteresis response of Buckling-Restrained Brace Source: Black et al. 2004, Normalized curves added by Author

Testing results of various brace sizes were normalized by the yield force and yield displacement and scaled up by the yield capacity and displacement for each BRB in the model. While the maximum tension and compression forces are typically unequal by the $\beta$ adjustment factor for compression, test results were nearly symmetrical and this adjustment factor was assumed to be close to one for this design and the BRB behavior was modeled to have symmetrical tension and compression behavior. For each brace the yield force (FY) was calculated as $\mathrm{A}_{\text {core } *} \mathrm{~F}_{\mathrm{ye}}$, where the yield displacement (DY or $\Delta_{\mathrm{y}}$ ) is considered the axial elongation of the yield length at FY based on the first cycle of loading. Testing shows a hysteretic strain hardening behavior of BRB elements which is 
modeled in Perform 3D by an additional input force, FU to represent the last cycle yield capacity.

As shown above in Figure N, cyclic tests reached a maximum demand of $3 \%$ strain in the steel core (approximately 15 times the yield strain). This limit is considered the maximum desired capacity of a BRB; however, it may be possible for the core to yield further. In "Component Testing, Seismic Evaluation and Characterization of Buckling-Restrained Braces" failure mechanisms such as plastic buckling of the inner core and eventual cracking of the concrete or mortar may occur at high axial demands but have not been seen in a laboratory setting of brace only testing; demands this high could break testing equipment. These potential failure mechanisms have not been included for this thesis because the deformations of this magnitude would likely cause failures elsewhere in the structure before the braces.

In order to classify a structure's performance, ASCE 41-06 provides the following limit states; Collapse Prevention (CP), Life Safety (LS), and Immediate Occupancy (IO) are defined below in Table 6 below in terms of yield deformation, $\Delta_{\mathrm{y}}$.

\begin{tabular}{|c|c|c|c|}
\multicolumn{2}{c}{ CP } & LS & IO \\
\hline $\begin{array}{c}\text { Buckling Restrained } \\
\text { Brace }\end{array}$ & $15 \Delta_{\mathrm{y}}$ & $0.75 \mathrm{CP}=11.25 \Delta_{\mathrm{y}}$ & $0.67 \mathrm{LS}=7.54 \Delta_{\mathrm{y}}$ \\
\hline
\end{tabular}

\section{Table 6: Performance Criteria for BRB elements}

Source: Author Using Excel

Since ASCE 41 does not give modeling criteria specifically for BRB elements, the deformation limit for $\mathrm{CP}$ was used as a reference based on the available test data. The LS and IO limits were proportioned from the CP limit state with consideration of ASCE 
41 guidelines for other elements. The force displacement relationship modeled for BRB elements in perform is shown in Figure $\mathrm{N}$ on page 36.

\subsubsection{Moment Rotation Hinge}

Nonlinear behavior is designed to occur in the RBS of the moment frame and may also form outside the gusset sections in the braced frame. A force displacement relationship used for the moment rotation hinge properties is shown in the normalized diagram in Figure $\mathrm{O}$ where $Q$ represents the moment capacity as a function of the rotational displacement, $\theta$. The displacement values defined by ASCE 41 associated with points $\mathrm{B}, \mathrm{C}$ and $\mathrm{E}$ were used and the hinges were modeled as tri-linear to allow a strain hardening slope.

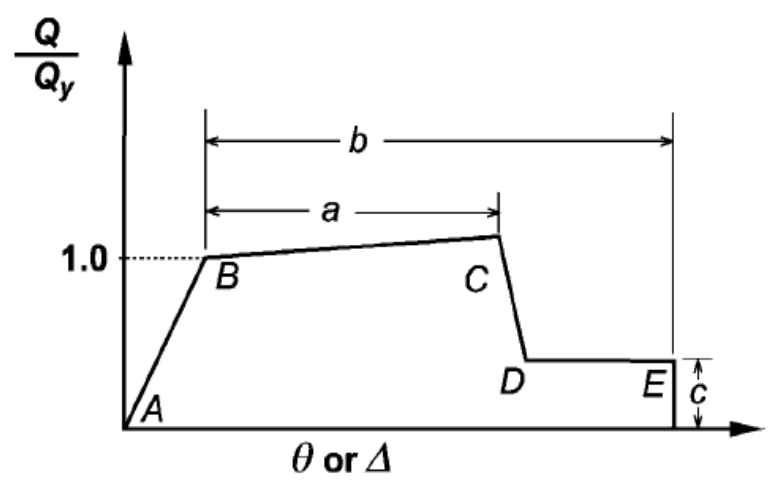

Figure O: Backbone Curve for nonlinear elements as defined in ASCE 41-06 Source: Perform 3D User Guide

Since Perform 3D assumes a rigid-plastic relationship, no rotation is calculated before the yield capacity is reached. Figure $\mathrm{O}$ is adapted to the Perform 3D inputs as shown in Figure $\mathrm{P}$ below. 


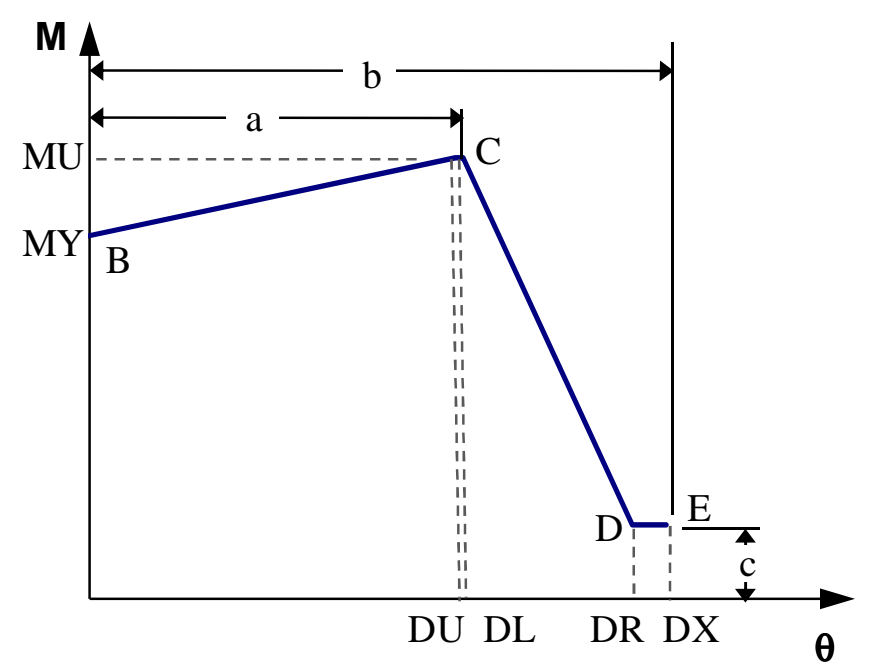

Figure P: Perform 3D inputs for moment rotation hinge

Source: Author, Using Excel

The yield point is defined as follows:

$$
\begin{aligned}
& M Y=Z_{x} F_{y e}, \\
& D Y=\frac{Z_{x} F_{y e} L}{6 E I},
\end{aligned}
$$

where $M Y$ is the beam yield moment (k-in),

$\mathrm{Z}_{\mathrm{x}}$ is the plastic section modulus of the beam or RBS $\left(\mathrm{in}^{3}\right)$,

$F_{y e}$ is the expected yield strength (ksi),

$L$ is the length of beam (in),

$E$ is the modulus of elasticity (ksi), and

$I$ is the beam moment of inertia $\left(\mathrm{in}^{4}\right)$.

Combining both Figure $\mathrm{O}$ and Figure $\mathrm{P}$ for rigid plastic behavior, the rotational limits of DL and DX are defined by ASCE 41-06 Table 5-6. Using the modeling parameters for rotational capacities of $a, b$, and $c$ for reduced beam sections and compact sections as appropriate. To meet the stability requirements for Perform 3D nonlinear analysis, DU is assumed to be $2 \%$ less than DL, and DR is assumed $5 \%$ less than DX based on Perform 3D criteria for a tri-linear backbone relationship. RBS strain hardening 
values were taken as the factor $\mathrm{C}_{\mathrm{pr}}$, also considered in design while all other moment rotation hinges were assumed to have a strain hardening ratio equal to $3 \%$ of the elastic stiffness.

Axial force interaction was not recorded during the analysis for beam deformations since the diaphragms are rigid. Since the beams were designed to resist demands based on the maximum force that can be delivered by the braces, and the brace capacities were explicitly modeled, the effect of the axial load on beams was considered to have minimal effect for the analysis.

\subsubsection{P-M2-M3 Rotation Hinge}

Since the columns have been designed to carry axial load, the moment-axial interaction was monitored using a PMM Rotation hinge. Axial elements with average compressive stresses in excess of $20 \%$ yet below $50 \%$ of the total axial buckling capacity are considered to be deformation controlled, while demands above $50 \%$ are considered to be controlled by strength. For this reason, hinge properties include section strength properties, the moment-axial interaction and the rotational limits according to ASCE 41 with a similar backbone relationship as shown above in Figure O. 


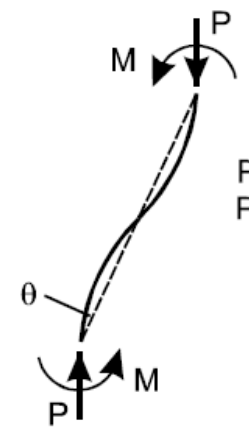

(a)

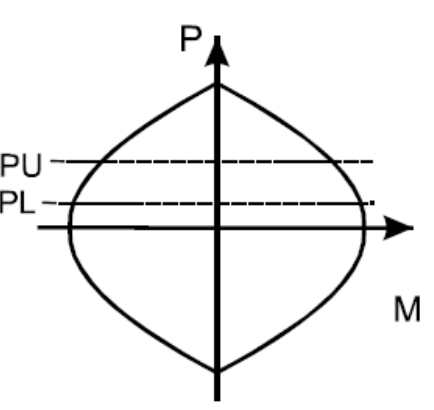

(b)

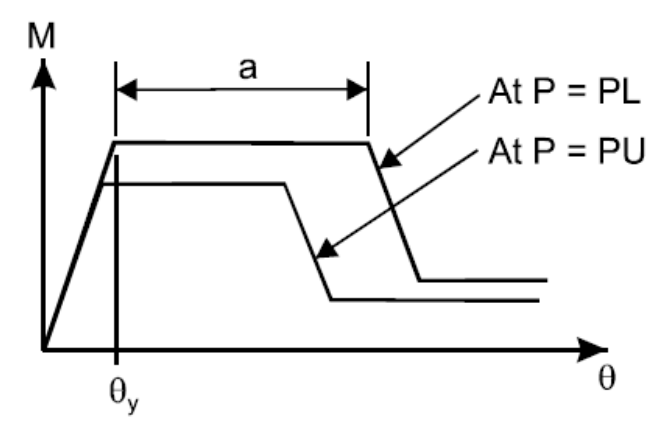

(c)

Figure Q: Axial interaction on moment rotation column hinges Source: Perform 3D User Guide

The yield point including axial effects is defined as follows:

$$
\begin{gathered}
M Y=1.18 Z_{x} F_{y e}\left(1-\frac{P}{P_{y e}}\right) \leq Z_{x} F_{y e}, \\
\theta_{y}=\frac{Z_{x} F_{y e} L}{6 E I}\left(1-\frac{P}{P_{y e}}\right),
\end{gathered}
$$

where all variables have previously been defined and $P / P_{y e}$ is calculated using with consideration of both the upper and lower axial compressive limit of the column section. A graphical display of this interaction and the resulting reduction in ductility based on higher axial loads is shown above in Figure Q.

\subsection{Perform Modal Analysis}

Previously, the first period for Model 15, Model 25 and Model 40 was reported in Table 3 as 2.24, 2.23, and 2.19 seconds respectively. Fundamental periods from Perform 3D are 4-5\% lower on average and the mass participation reported in Perform 3D averages $1 \%$ higher than those reported in ETABS. Values for the second and third modes are 3-4\% higher for each model in Perform 3D than those reported in Table 3 from 
ETABS, while mass participation factors are 2-4\% less in Perform than ETABS. These variations are within an acceptable difference since more detail was provided in Perform 3D for the nonlinear analysis.

\begin{tabular}{|c|c|c|c|}
\hline \multirow[t]{5}{*}{ Model 15} & & Period (s) & $\begin{array}{c}\% \text { Mass } \\
\text { Participation }\end{array}$ \\
\hline & Mode 1 & 2.12 & 75 \\
\hline & Mode 2 & 0.77 & 14.6 \\
\hline & Mode 3 & 0.45 & 4.8 \\
\hline & & Sum: & $\Sigma 94.4$ \\
\hline \multirow[t]{5}{*}{ Model 25} & & Period (s) & $\begin{array}{c}\% \text { Mass } \\
\text { Participation }\end{array}$ \\
\hline & Mode 1 & 2.13 & 74.8 \\
\hline & Mode 2 & 0.76 & 14.7 \\
\hline & Mode 3 & 0.45 & 4.8 \\
\hline & & Sum: & $\Sigma 94.3$ \\
\hline
\end{tabular}

\begin{tabular}{|c|c|c|c|}
\hline \multirow[t]{5}{*}{ Model 40} & & Period (s) & $\begin{array}{c}\% \text { Mass } \\
\text { Participation }\end{array}$ \\
\hline & Mode 1 & 2.09 & 75.6 \\
\hline & Mode 2 & 0.76 & 14.1 \\
\hline & Mode 3 & 0.45 & 4.5 \\
\hline & & Sum: & $\Sigma 94.2$ \\
\hline
\end{tabular}

Table 7: Perform 3D periods and mass participation for dual system models Source: Author, Using Excel

Looking at the fundamental period for each model, both ETABS and Perform 3D shows that the overall building stiffness increases with the increase of moment frame strength. Similar periods between models show the ASCE 7-05 approach of reducing the total braced frame strength based on the relative stiffness between the moment frame and braced frame has little impact on the overall elastic building stiffness. Results show that a structure with a dual seismic force resisting system will have an increased lateral strength 
directly related to the secondary moment frame strength, and the structure's lateral strength will be more than $100 \%$ of the design forces, even with the braced frame reduction allowed by ASCE 7-05.

\subsection{NONLINEAR ANALYSIS}

Nonlinear building response was assessed by means of nonlinear static (pushover) and nonlinear dynamic analyses. Both procedures were executed according to the ASCE 41. The following sections have been presented with reference to the SAC project and FEMA 355C.

\subsection{Preliminary Calculations}

Preliminary calculations have been provided below in order to predict and understand the interaction between a MF and BF. By simplifying the dual system, a single braced frame and moment frame of similar dimensions can be joined assuming equal lateral displacements.
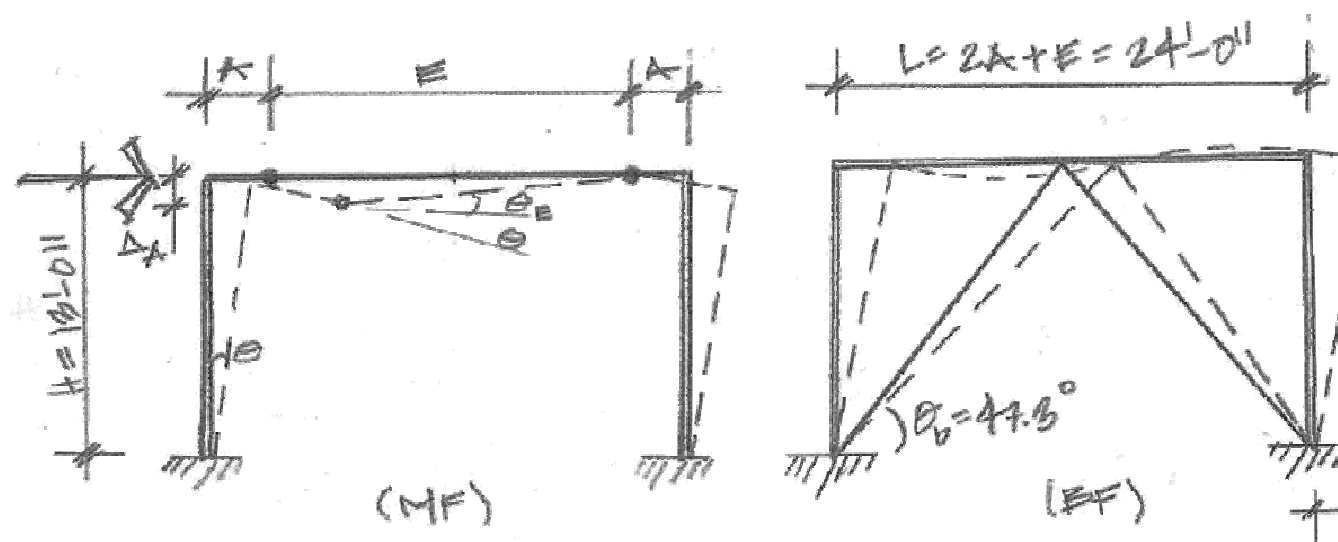

Figure R: Schematic relationship between BRBF and MRF in series Source: Author 
In Figure R above, dimensions have been chosen to represent the bay sizes used for the analysis of this thesis. Assume $A \approx 1^{\prime}-6^{\prime \prime}$ and $E \approx 21^{\prime}-0^{\prime \prime}$. If a lateral force is applied producing a lateral displacement, the following relationships are made based on the geometry of the frames: The column rotation angle, $\theta$, can be approximated by

$$
\theta=\frac{\Delta_{x}}{H}
$$

where $\Delta_{\mathrm{X}}$ is the lateral displacement of the frame (in), and $\mathrm{H}$ is the story height (in).

The vertical displacement of the RBS hinge is described by $\Delta_{A}$. Using the small angle theorem,

$$
\Delta_{A}=\theta_{A}=\frac{\Delta}{H} A
$$

where $\Delta_{\mathrm{A}}$ is the vertical displacement of the RBS (in), and

$\mathrm{A}$ is the distance from column center line to the centerline of the RBS (in).

The total RBS rotation, $\theta_{R B S}$, has two components: rotation due to column hinge rotation, and beam hinge rotation. The RBS rotation due to beam rotation, $\theta_{E}$, is assessed below,

$$
\theta_{E}=\frac{2 \theta_{A}}{E}=\frac{2\left(\frac{\Delta}{H} A\right)}{E}
$$

where $\mathrm{E}$ is the distance between center lines of RBS (in).

The total RBS rotation, $\theta_{R B S}$, is defined below in Eq. 11: 


$$
\theta_{R B S}=\theta+\theta_{E}=\frac{\Delta}{H}\left(1+\frac{2 A}{E}\right)
$$

From the calculations for nonlinear modeling, based on the typical yield length (Ly), a brace yields at an elongation, $D Y=0.157^{\prime}$ or a lateral frame displacement

$$
\Delta_{\text {Yield }, x}=\frac{D Y}{\cos \left(\theta_{b}\right)}=\frac{0.157 \mathrm{in}}{\cos \left(47.3^{\circ}\right)}=0.232 \mathrm{in}
$$

A typical RBS is expected to yield at a total RBS rotation angle,

$\theta_{\text {Yield }, R B S}=0.009$ radians. Using the equations above, when the brace yields, the RBS is still elastic since

$$
\theta_{R B S}=\frac{0.232 i n}{13 f t \times 12 i n / f t}\left(1+\frac{2(18 i n)}{23 f t \times 12 i n / f t}\right)=0.0017<\theta_{\text {Yield, RBS }} \cdot \quad \text { Eq. } 13
$$

BRB and RBS limit states have both been defined as a ductility factor or function of yield displacement or rotation. These limit states are given below in the Table 8 .

\begin{tabular}{|c|c|c|}
\hline Limit States & $\begin{array}{c}\text { BRB Ductility } \\
\mu_{B R B}=\Delta / \Delta_{\text {yield }}\end{array}$ & $\begin{array}{c}\text { RBS Ductility } \\
\mu_{R B S}=\theta / \theta_{\text {yield }, R B S}\end{array}$ \\
\hline Yield & 1.0 & 1.0 \\
\hline IO & 7.54 & 2.43 \\
\hline LS & 11.25 & 3.69 \\
\hline CP & 15.0 & 4.86 \\
\hline
\end{tabular}

Table 8: BRB and RBS Limit states defined by ductility Source: Author, Using Excel

When the brace yields, the RBS rotation and ductility is reported below:

$$
\theta_{R B S}=0.0017 \text { radians }, \text { or }
$$

Eq. 14 


$$
\mu_{R B S}=\frac{\theta_{R B S}}{\theta_{\text {Yield }, R B S}}=\frac{0.0017}{0.009}=0.19 \text {. }
$$

Since the BRB yields first, the RBS remains elastic at this stage, and ductility of the RBS is less than 1 . Taking the inverse ratio of the RBS ductility when the brace yields gives the expected BRB ductility when the RBS yields:

$$
\mu_{B R B}=\frac{\theta_{\text {Yield }, R B S}}{\theta_{R B S}}=\frac{0.009}{0.0017}=5.3
$$

If $\mathrm{BRB}$ reaches $I O$ at $7.54 D Y$

$$
\begin{array}{ccc}
\Delta_{x, I O}=7.54(0.157 \text { in })=1.75 i n(\text { or } 1.1 \% & \text { Drift }), & \text { and } \\
\theta_{R B S}=7.54(0.0017 \text { radians })=0.0128 & \left(\mu_{R B S}=\frac{0.0128}{\theta_{Y, R B S}}=1.42\right) & \text { Eq. } 18
\end{array}
$$

If $\mathrm{BRB}$ reaches $L S$ at $11.25 D Y$

$$
\begin{array}{cc}
\Delta_{x, I O}=2.61 \text { in }(\text { or } 1.7 \% \text { Drift }), \text { and } & \text { Eq. } 19 \\
\theta_{R B S}=11.25(0.0017 \text { radians })=0.0191\left(\mu_{R B S}=\frac{0.0191}{\theta_{Y, R B S}}=2.12\right) . & \text { Eq. } 20
\end{array}
$$

If $\mathrm{BRB}$ reaches $C P$ at $15 D Y$

$$
\begin{array}{cc}
\Delta_{x, I O}=15(0.157 i n)=3.48 \text { in }(\text { or } 2.2 \% \text { Drift }), \text { and } & \text { Eq. } 21 \\
\theta_{R B S}=15(0.0017 \text { radians })=0.0255\left(\mu_{R B S}=\frac{0.0255}{\theta_{Y, R B S}}=2.83\right) . & \text { Eq. } 22
\end{array}
$$

The limit states, yielding sequence and ductility relationship between the BRB and RBS along with the story drift angle calculated above are summarized below in Table 9. 


\begin{tabular}{c|c|c|c|}
\multicolumn{1}{c}{} & \multicolumn{1}{c}{$\mu_{\mathrm{BRB}}$} & $\mu_{\mathrm{RBS}}$ & $\theta$ \\
\cline { 2 - 4 } BRB Yields & 1 & $*$ Elastic* & $0.1 \%$ \\
\cline { 2 - 4 } RBS Yields & 5.3 & 1 & $0.8 \%$ \\
\cline { 2 - 4 } BRB IO & 7.5 & 1.4 & $1.1 \%$ \\
\cline { 2 - 4 } BRB LS & 11.3 & 2.1 & $1.7 \%$ \\
\cline { 2 - 4 } RBS IO & 12.9 & 2.4 & $1.9 \%$ \\
\cline { 2 - 4 } BRB CP & 15 & 2.8 & $2.2 \%$ \\
\cline { 2 - 4 } & & &
\end{tabular}

Table 9: Hand calculations for ductility factors and story drift angle Source: Author, Using Excel

Table 9 shows the order at which the limit states are expected to be reached by the dual system in Figure R. As shown, the BRB will yield first. Next, the RBS will yield at a brace ductility factor of 5.3. As displacements continue to increase, the BRB will reach IO and LS before the RBS reaches IO. Table 9 quantifies the lateral displacement required to force rotation on a RBS. Finally, if the BRB reaches $\mathrm{CP}$, the structure is at a drift limit similar to code limitations $\left(2 \%\right.$ or $\left.0.02 \mathrm{~h}_{\mathrm{sx}}\right)$. At BRB CP, the load is expected to move out of the BF since significant strength loss may have occurred in the yielding core of the BRB elements. Here the performance advantage of the DS is seen since the MF RBS sections remain in the IO range and fully capable of carrying load shed from the BRB that may no longer be fully functional. While the values of Table 9 are based on a single bay and typical member sizes, the relationship between the nonlinear events are consistent with the results presented in this thesis as it is based on relative strength and ductility of elements. 


\subsection{Nonlinear Static Analysis}

Both a modal and uniformly loaded pushover were executed to describe the relative behavior between the $\mathrm{BF}$ and $\mathrm{MF}$ for each model. Diagrams of the applied loading are shown below in Figure S. Equal story shears were applied to each level for the uniform loading, while the modal loading was applied based on the first mode force distribution in which story forces vary with respect to story elevation as calculated in the linear static procedure. The resultant force of the uniformly loaded structure is located at mid height while the resultant of the Modal pushover is located near 2/3 height.

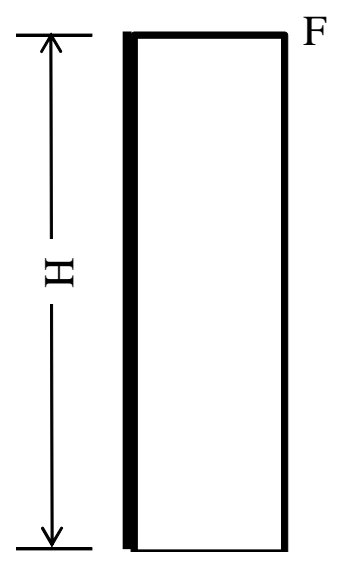

Uniform

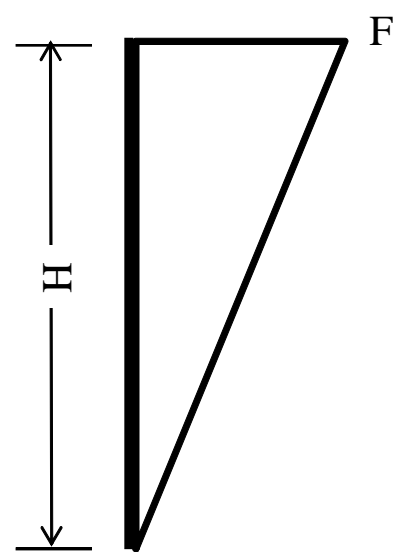

Modal

Figure S: Force distribution along building height for uniform and modal pushover Source: Author, Using Excel

The base shear in both the braced frame and moment frame were recorded separately as a function of the roof drift angle, and the sum of the BRBF and MF represents the force displacement relationship for the total system under the given load pattern. The results are shown below in Figure $\mathrm{T}$ and Figure $\mathrm{U}$ (page 51) for Model 15, Figure V and Figure W (page 52) for Model 25, and Figure X and Figure Y (page 54) for 
model 40. Figure $\mathrm{Z}$ (page 56) provides a comparison of the pushover plots along with the target displacement.

The base shear value that causes first yield (can be assumed approximately at the force magnitude where the initial elastic slope becomes nonlinear) is close to the design base shear of 0.06W (see Figure Z on page 56). In Figure T through Figure Y, yielding of the braces at the upper level causes the initial change in stiffness; however, the capacity continues to increase as the design was more conservative in the lower levels. The high system capacity shows the conservatism that was incorporated in the design of these structures consistent with current practices. First, the nominal material strengths were used for design along with $\Phi$ factors used in AISC. Next, realistic yet conservative design DCRs of the elements was used as previously discussed for braces and columns. For the nonlinear analysis, all the safety factors were removed from the element capacities in order to get a realistic behavior. As a result, after the braces yield, the braces strain harden and more elements are loaded up to their ultimate capacity until finally a lowerlevel column is loaded beyond its allowable axial-flexure interaction envelope. While this is not a desirable failure mechanism, the structure has been loaded well beyond its design force and has been displaced to almost two times the target displacement as described in ASCE 41-06.

Figures $\mathrm{T}$ through $\mathrm{Z}$ also show an ultimate system capacity significantly higher than the design base shear. Since nonlinear elements were given strain hardening properties, the overall capacity was increased. The maximum capacity shown in the 
pushover plots below is the point just before strength degradation occurs: the maximum base shear seen by the structures when all the braces are in the strain hardening region and many of the RBS sections have also yielded. The design force, however, is the magnitude of the base shear that causes the first element to yield based on nominal strengths and safety factors. Since all elements could not have been designed to yield concurrently, the pushover capacity is much higher than the design force. ASCE 7-05 requires drags and collectors among other elements that are desired to remain elastic to be designed for a demand level increased by the $\Omega_{0}$ factor ( 2.5 for BRBF dual systems). In this case, a factor of 2.5 brings the design base shear or design yield force (approximately $0.06 \mathrm{~W}$ for all models) up to $0.15 \mathrm{~W}$. This seems to be a realistic number as for all three models the ultimate capacity of the dual systems is $0.14 \mathrm{~W}-0.17 \mathrm{~W}$ for the uniform pushover and ranges from $0.12 \mathrm{~W}-0.14 \mathrm{~W}$ for the modal pushover.

Based on the pushover plots in pages 51 through 56, the MF has a lower elastic stiffness than the BRBF, and the strength is dependent on the load pattern. The change in stiffness seen by changing the load patterns is expected since the two force patterns induced different failure modes. The uniformly loaded structure has a resultant shear force at half the height of the structure; uniform loading will generate more of a shearlike failure in the building as high demands will be seen at low levels and lower displacements. The modal pushover causes more of a top-down failure sequence. Since the structure was designed for a loading with this pattern, a more ductile response is anticipated and is shown by the pushover plots. The results of the uniformly loaded 
pushover in Figure T, Figure V, and Figure X show that the capacity of the MF is higher than that of the BF. Here the braces at the lowest levels are pushed to their limits before the braces at the upper levels and the load moves into the moment frame when BRB elements go inelastic. Since the design DCRs were lowest in the MF at the bottom, the net lateral load required for failure is highest.

Figure U and Figure W show similar behavior for models 15 and 25 respectively subjected to the modal pushover load patter where the moment frame capacity just reaches the capacity of the braced frame in the nonlinear range. Figure Y shows the Model $40 \mathrm{MF}$ has a significantly higher capacity than the BF.

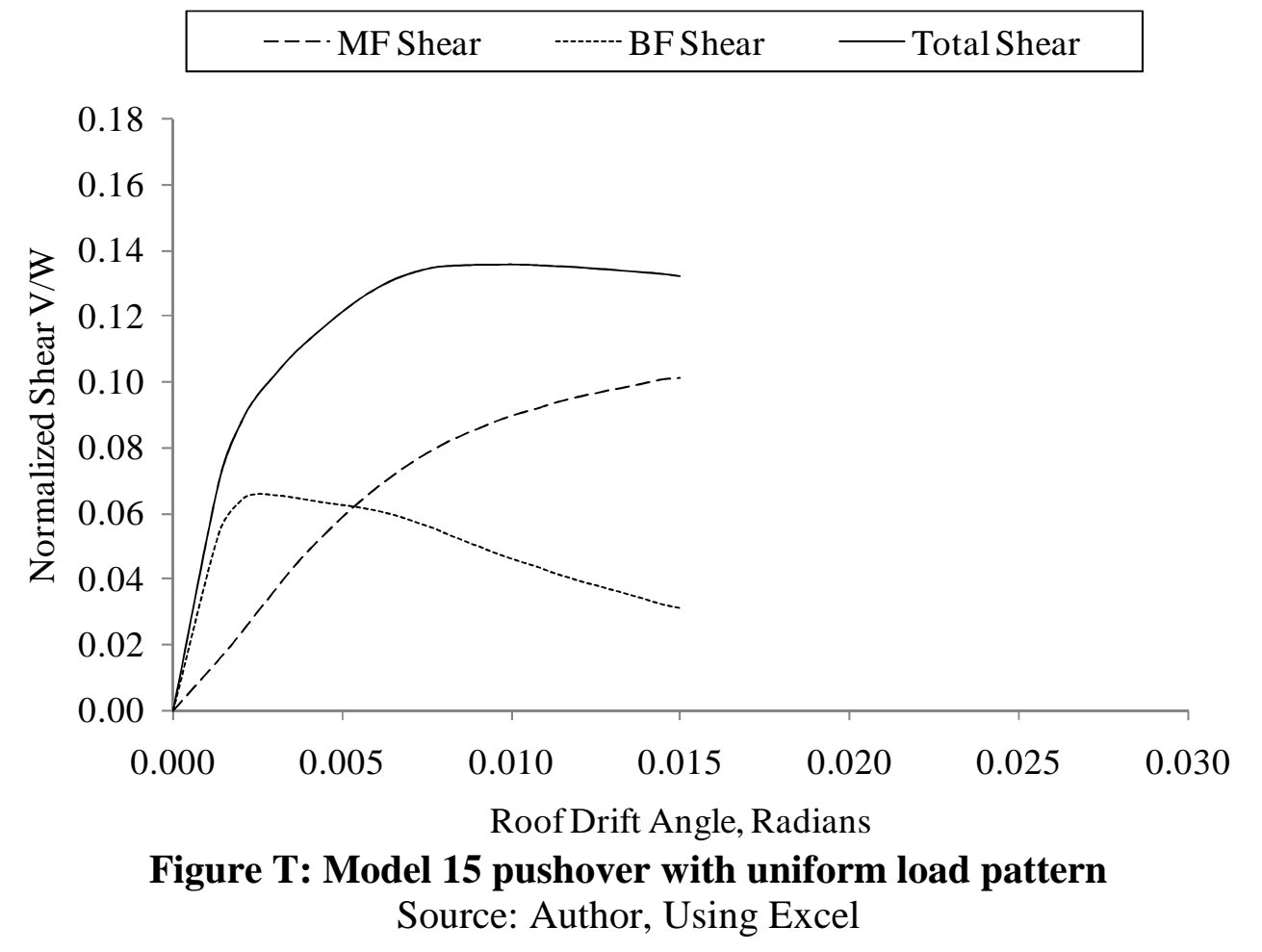




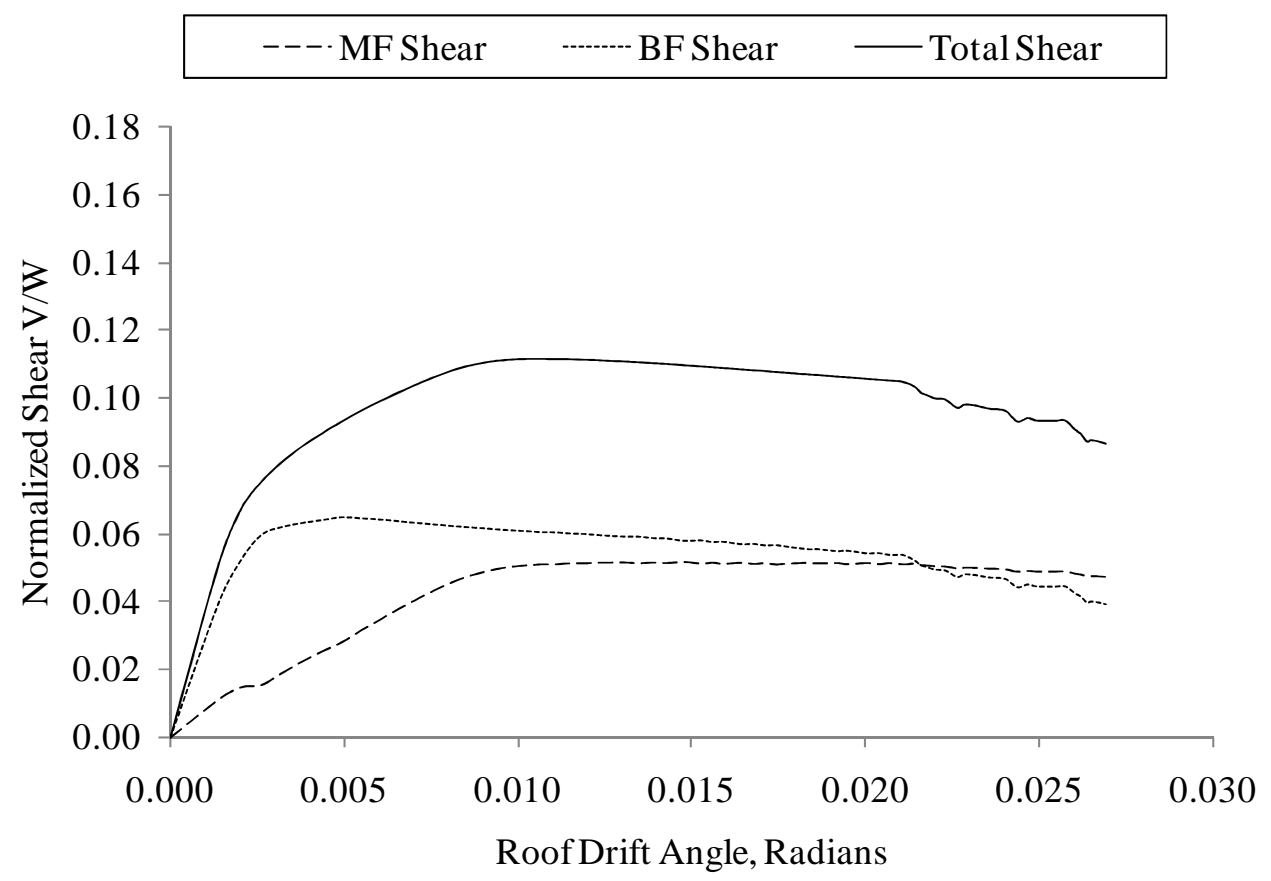

Figure U: Model 15 pushover with mode 1 load pattern

Source: Author, Using Excel

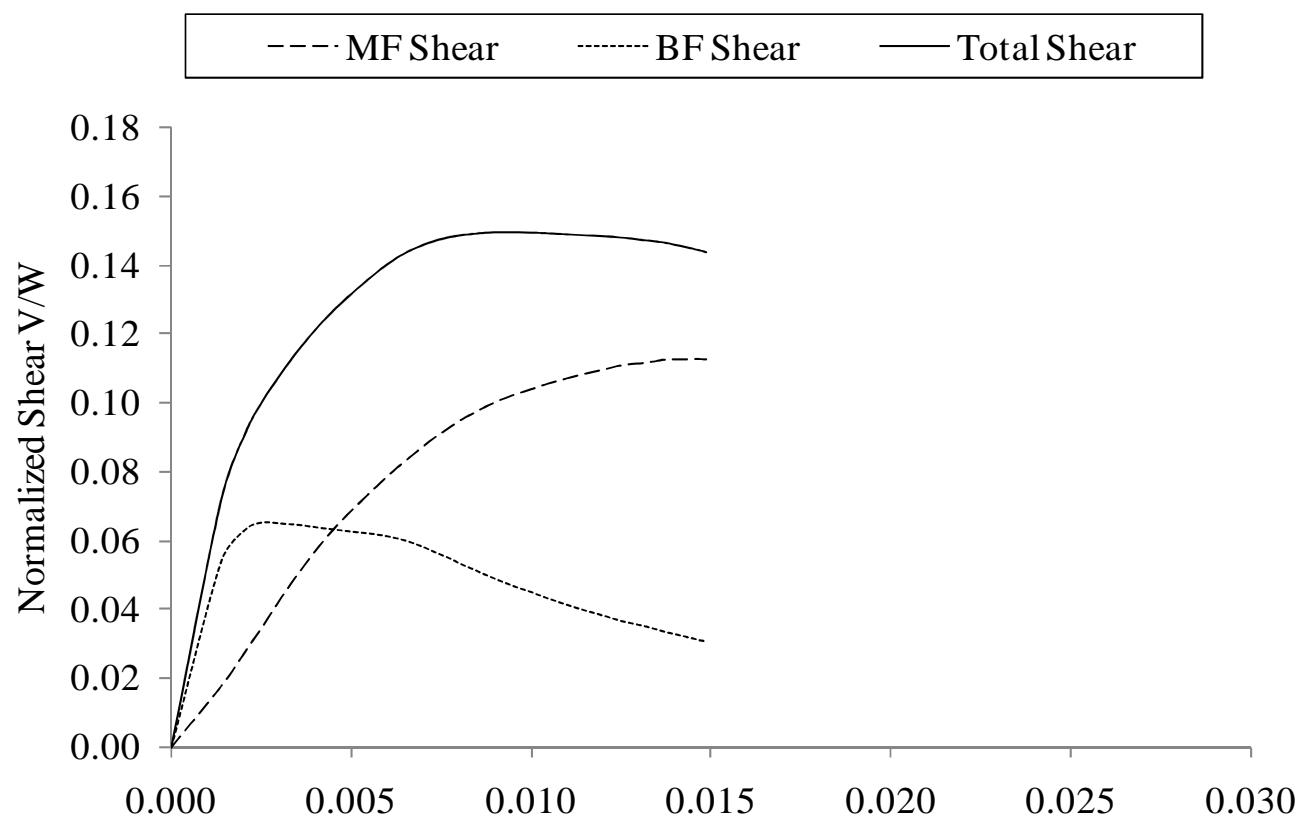

Roof Drift Angle, Radians

Figure V: Model 25 pushover with uniform load pattern

Source: Author, Using Excel 


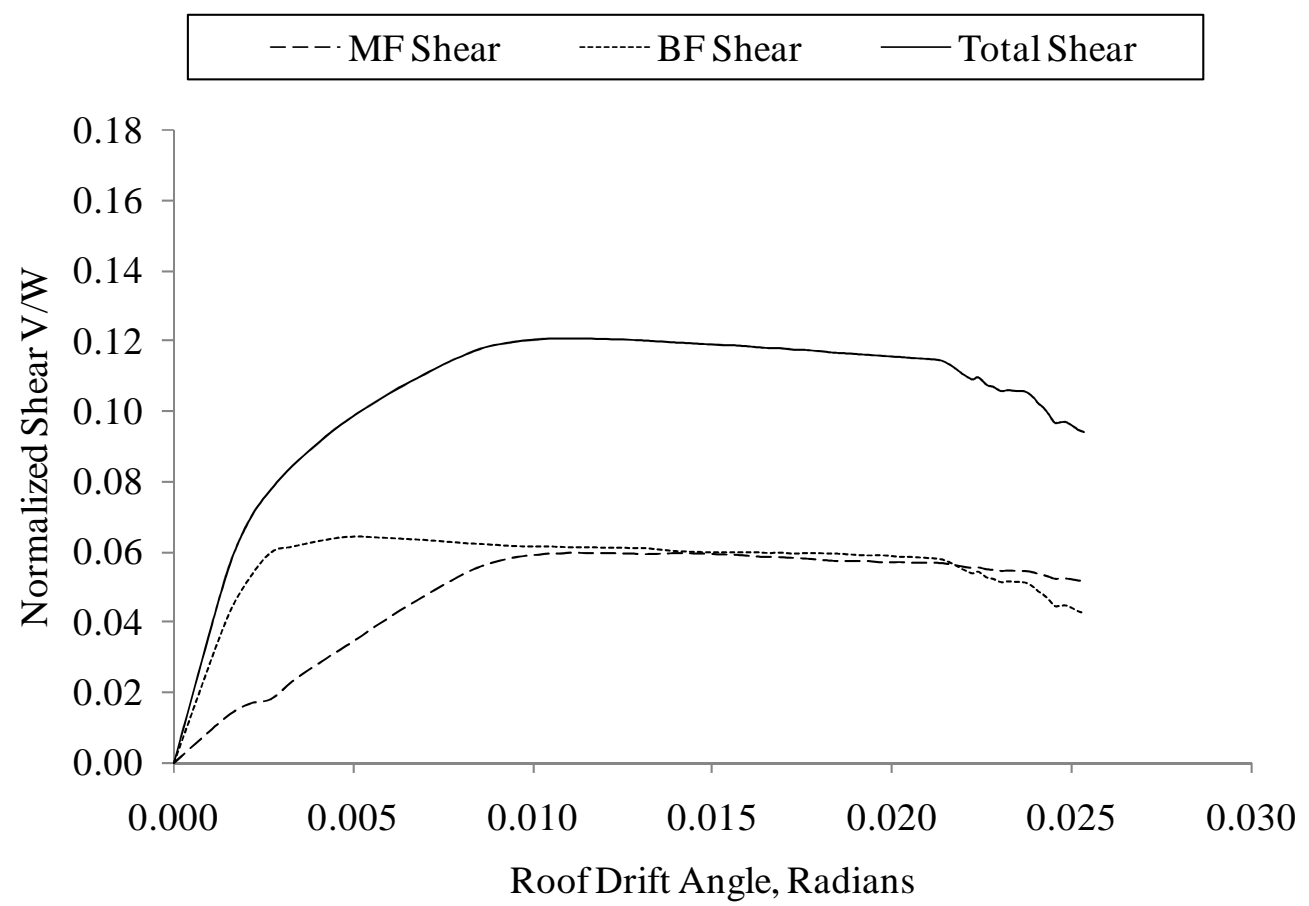

Figure W: Model 25 pushover with mode 1 load pattern Source: Author, Using Excel

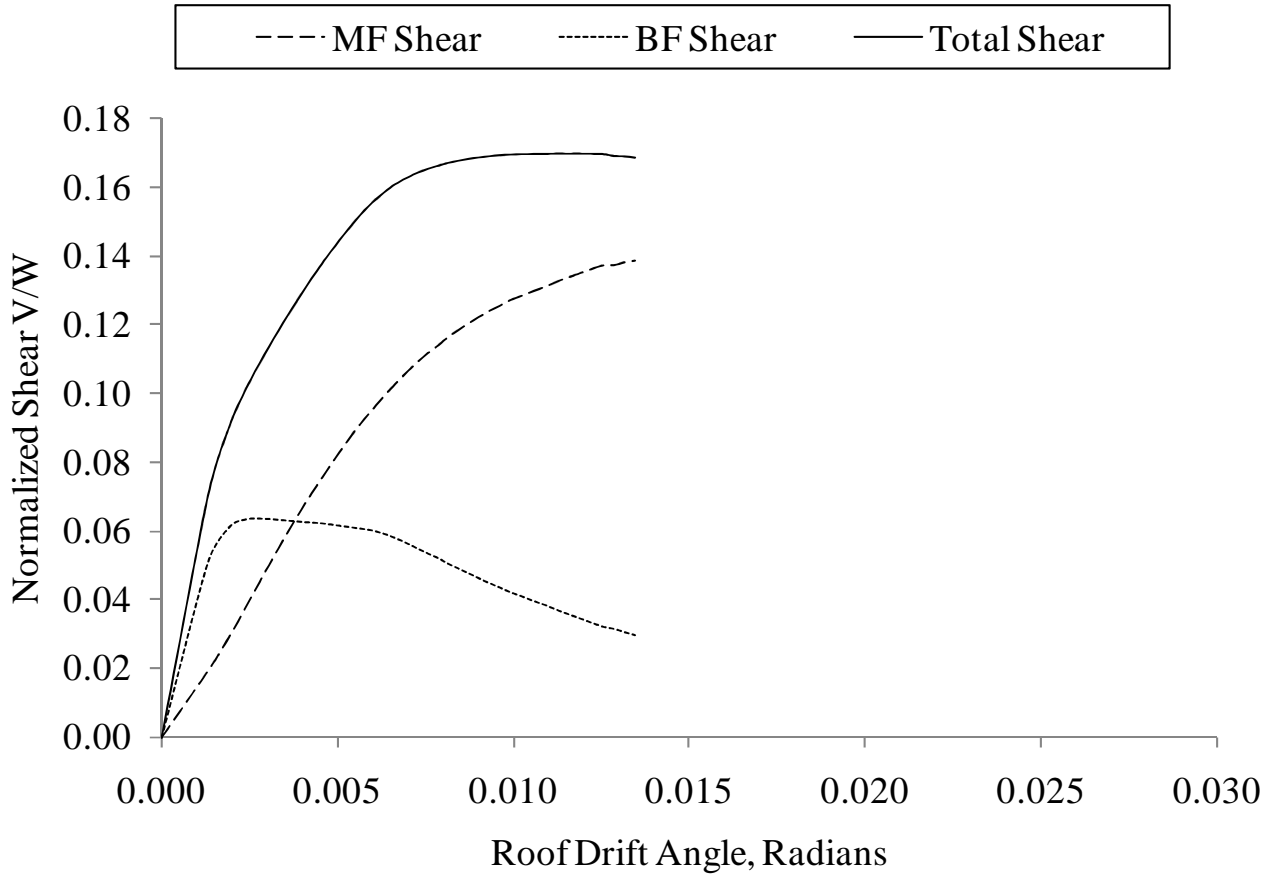

Figure X: Model 40 pushover with uniform load pattern Source: Author, Using Excel 


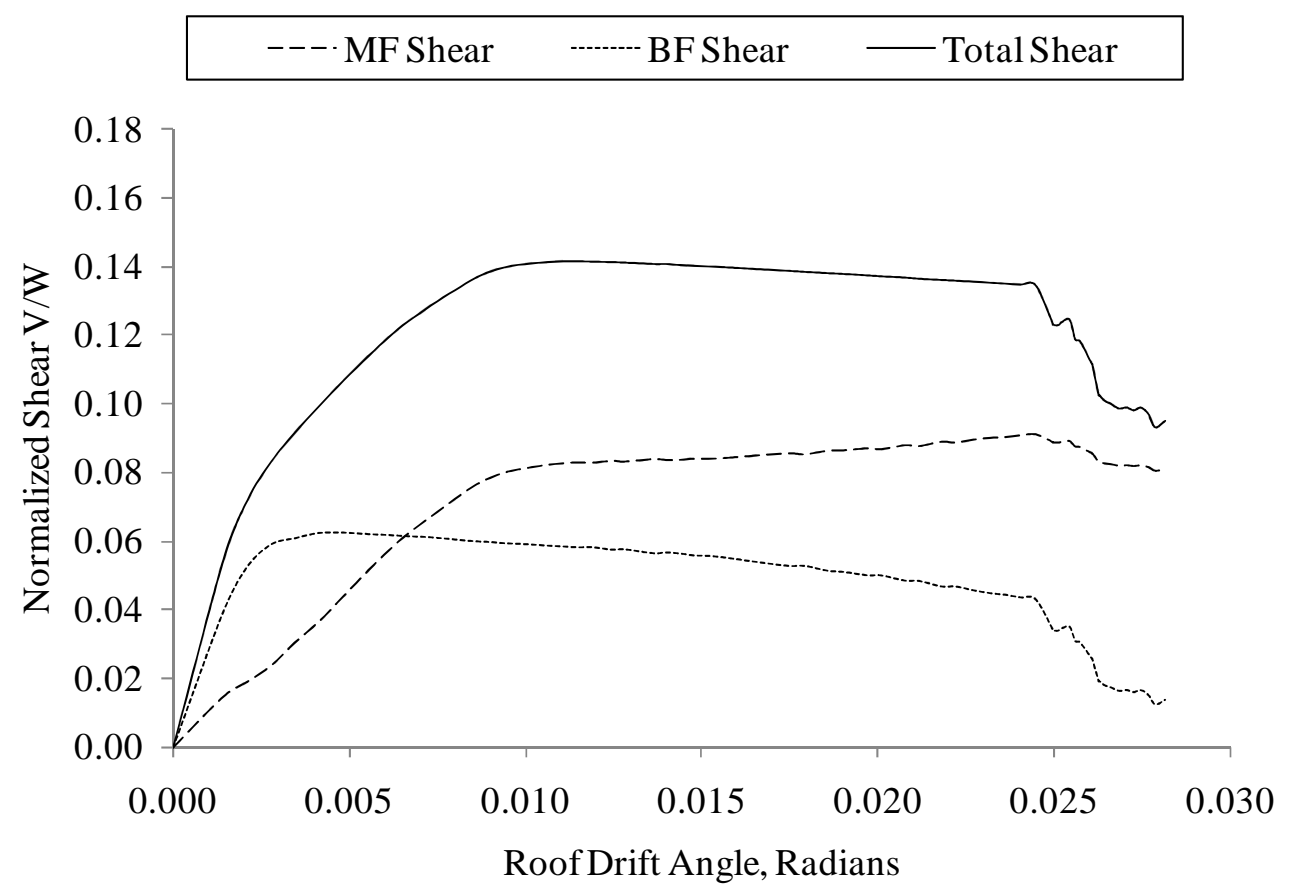

Figure Y: Model 40 pushover with mode 1 load pattern Source: Author, Using Excel

It is important to understand the interaction between the stiff braced frame system and the flexible moment frame. When the structure is displaced into the inelastic region and the forces are reversed in a nonlinear static cyclic pushover or a nonlinear analysis, the dual system will likely unload, resulting in a permanent residual deformation of the structure. Although there is zero total force in the structure, the "unloaded" MF and BF are most likely subject to a net force because the MF and BF have different unloading stiffness. This zero force point for the structure at a given deformation will demonstrate a residual force in the moment frame at that deformation. Furthermore, if the braced frame is unloaded into the negative force region, the moment frame may experience positive directional shear in opposition to the braced frame. This shear reversal is a result of the combination of a stiff and flexible lateral system. 
Since ASCE 7-05 allows a reduction in strength of the braced frame, the overall force displacement relationships of the different models were compared for each load pattern. Only small strength reductions were made to the braced frames due to the small relative stiffness of the $\mathrm{MF}$ to $\mathrm{BF}$. As a result, the largest difference in force-displacement relationship was seen as a result of the moment frame strength rather than the reduced braced frame strength. This can be observed in the graphs provided (Figure T through Figure Z), as each BRBF has approximately the same maximum strength equal to $0.06 \mathrm{~W}$. A comparison of the force displacement relationship between Models 15, 25, and 40 is shown below in Figure Z. Using the described design procedures, increasing the moment frame design force from $25 \%$ to $40 \%$ seismic capacity (a $15 \%$ increase) resulted in a increased system strength by approximately $15 \%(0.15 \mathrm{~W}$ to $0.17 \mathrm{~W})$. Similarly, reducing the moment frame design force from $25 \%$ to $15 \%$ resulted in approximately $10 \%$ system strength reduction $(0.15 \mathrm{~W}$ to $0.14 \mathrm{~W})$, which is displayed in Figure $\mathrm{Z}$. 


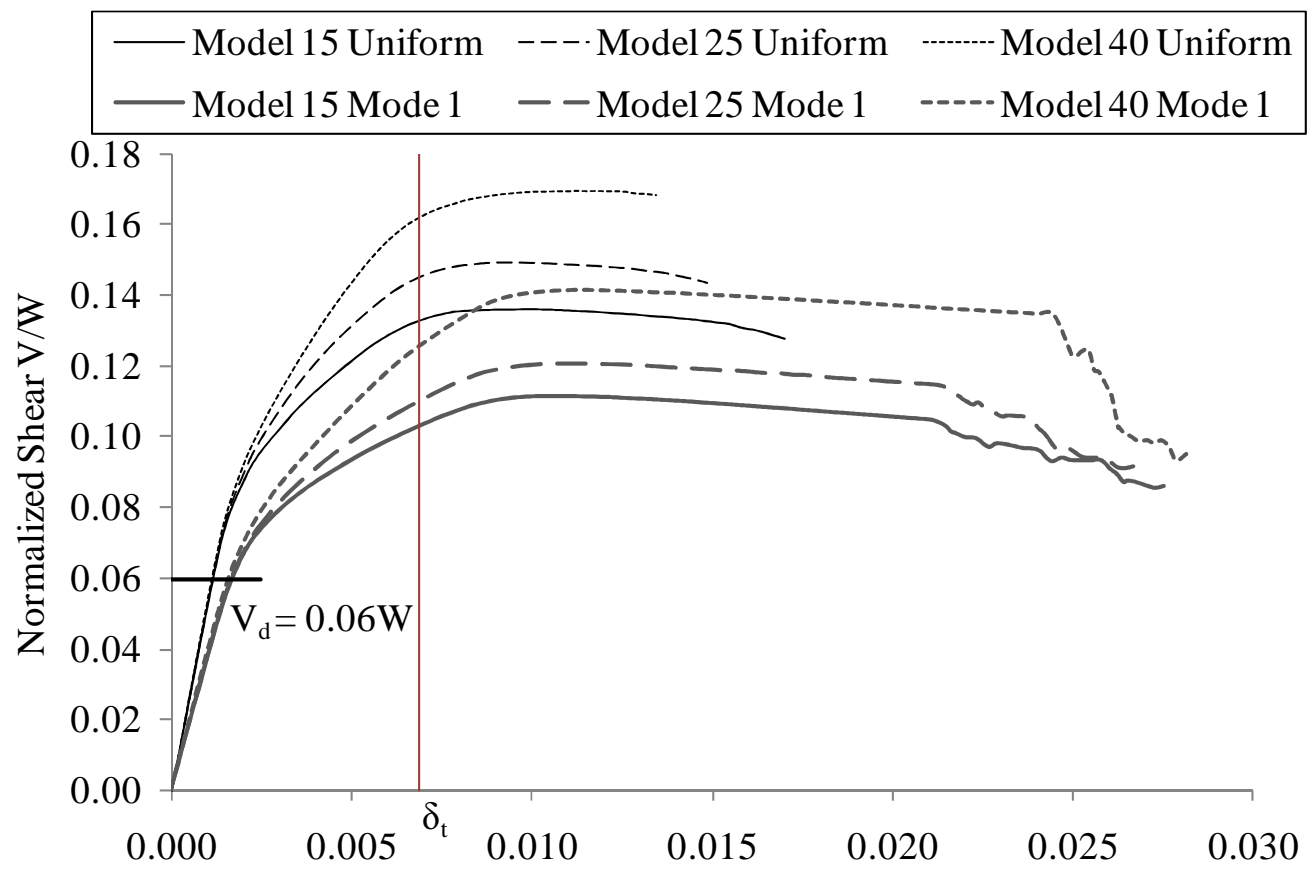

Roof Drift Angle, Radians

Figure Z: Pushover results for models 15, 25 and 40 with uniform and Mode 1 load pattern

Source: Author, Using Excel

For each model, the target displacement was calculated based on the modal

pushover analyses for the design earthquake values using ASCE 41-06 §3.3.3.3.2 and described in Eq. 23.

$$
\delta_{t}=C_{0} C_{1} C_{2} S_{a}\left(\frac{T_{e}^{2}}{4 \pi^{2}}\right) g,
$$

where $\delta_{t}$ is the Target Roof Displacement,

$C_{0}$ is a Modification factor per ASCE 41-06 (dimensionless),

$C_{1}$ is a Modification factor per ASCE 41-06 (dimensionless),

$C_{2}$ is a Modification factor per ASCE 41-06 (dimensionless),

$S_{a}$ is the response spectrum acceleration $(\% \mathrm{~g})$

$T_{e}$ is the effective fundamental period (seconds), and $g$ is gravity $\left(\mathrm{k} /\left(\mathrm{in} / \mathrm{s}^{2}\right)\right)$. 
The target displacements, as well as the target displacement normalized by building height, $\mathrm{h}$, for the three models, are summarized below in Table 10,

\begin{tabular}{|c|c|c|}
\hline & $\delta_{\mathrm{t}}$ (in) & $\delta_{\mathrm{t}} / \mathrm{h}$ (radians) \\
\hline Model 15 & 21.9 & 0.0069 \\
\hline Model 25 & 21.6 & 0.0068 \\
\hline Model 40 & 21.5 & 0.0068 \\
\hline
\end{tabular}

Table 10: Target displacements

Source: Author, Using Excel

To compare the nonlinear interaction between the $\mathrm{MF}$ and $\mathrm{BF}$ the relative story shear distribution at the target displacement for each structure is shown in Figure AA and Figure BB below. In Figure AA, the story shear demand in the moment frame varries with the brace configuration as seen in the elastic model. As expected, the MF in Model 40 sees the highest demands, while the MF in Model 15 sees the lowest. 


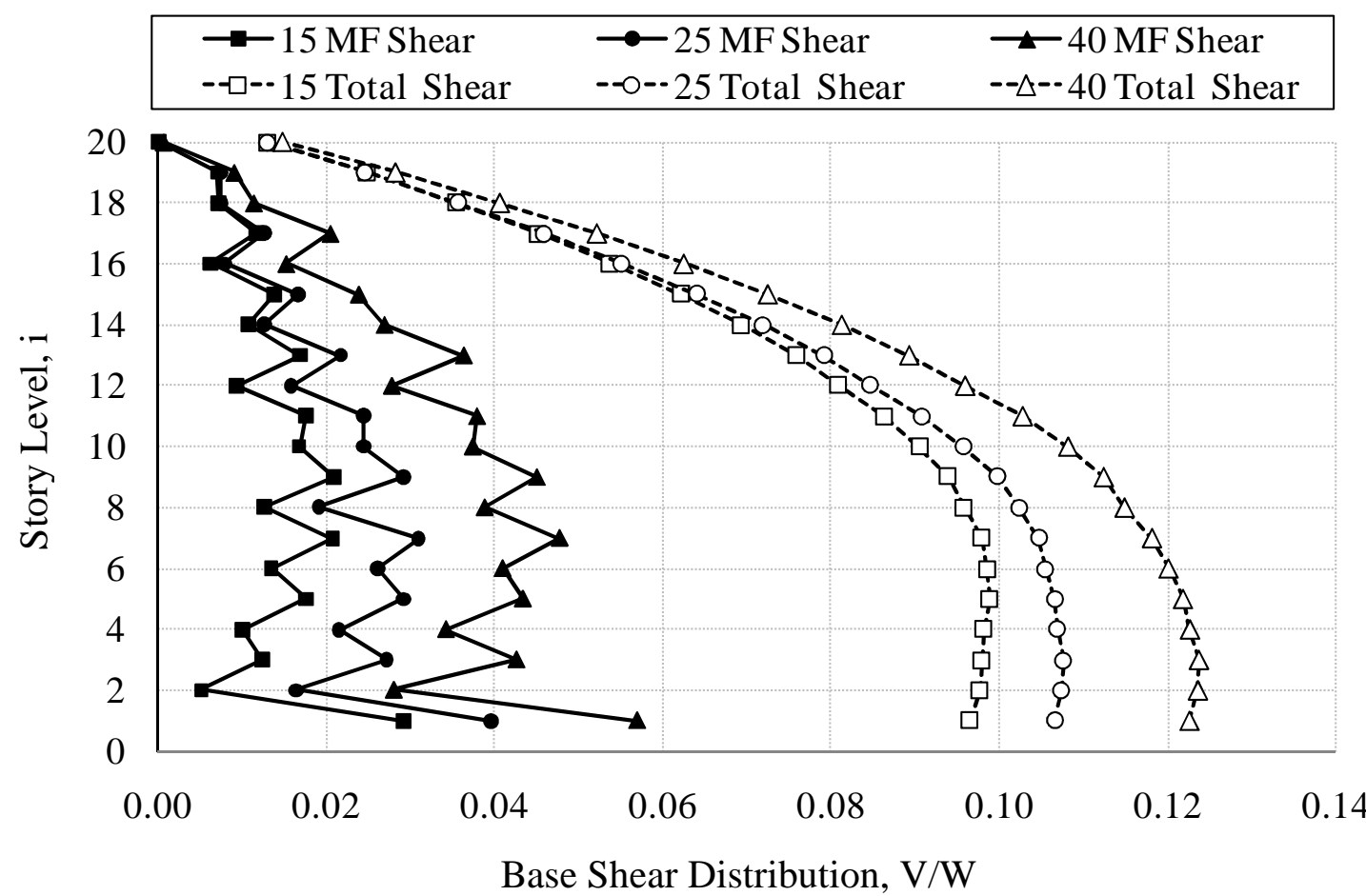

Figure AA: Shear distribution at $\delta_{t}$ based on mode 1 nonlinear pushover analyses Source: Author, Using Excel
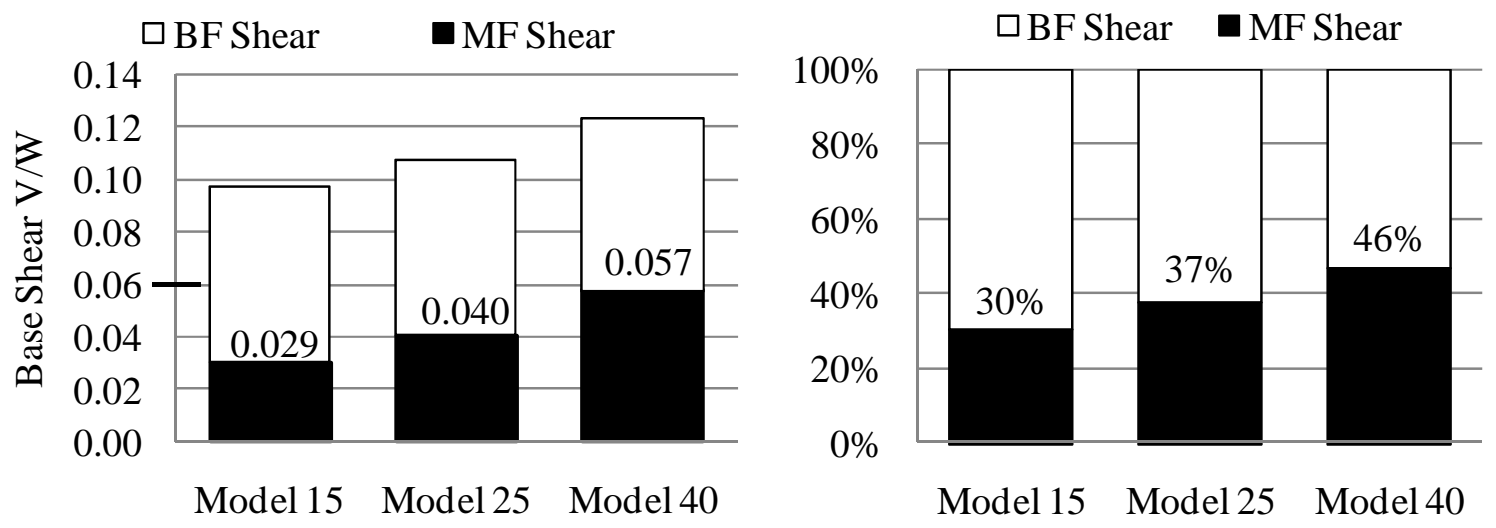

Figure BB: Nonlinear base shear distribution at $\delta_{\mathrm{t}}$ as absolute and relative base shear quantities for Models 15, 25 and 40

Source: Author, Using Excel 
The relative contribution to the listed lateral resistance from the moment frames at target displacement in the nonlinear pushover (30\%, 37\%, and 46\% for Models 15, 25, and 40 respectively) is higher than for the elastic model (17\%, 19\% and 22\% for Models 15, 25, and 40 respectively) as shown in Figure BB and Figure H (page 27). In Model 15, Model 25 and Model 40, the MF demands exceed the design base shear and appropriately shares more of the lateral load in the inelastic range greatly increasing the system strength as intended. The total system capacity shown in Figure BB is significantly higher than the design strength. Combining the BRBF and MRF system increased the strength to be greater than $100 \%$ of the design strength. Since the BRBF was only allowed a reduction in strength based on the relative rigidity between the BRBF and MRF, the added moment frame ultimately increases the capacity beyond the design strength. Aside from the additional strength provided by the moment frame, safety factors have been applied to the design as per design practice, and as displayed in Table 5 on page 31, expected material strengths were used in the nonlinear analysis rather than design strengths (typically a $10 \%$ increase).

\subsection{Nonlinear Dynamic Analysis}

To explore the structural response due to the variability of seismic ground motions, a suite of 7 earthquakes was selected. Median and $84^{\text {th }}$ percentile response quantities are reported. The Perform 3D model included vertical gravity loading on the structure in combination with the effects of these ground motions. 


\subsubsection{Ground Motions}

The 7-record suite was scaled to the design spectrum using an amplitude scaling procedure. This method of scaling was chosen in order to maintain the ground motion variability and to excite the buildings through a broader range of response. The ground motions were scaled according to ASCE 41 1.6.2.2. ASCE 41 recommends the average SRSS of periods between $0.2 \mathrm{~T}$ and $1.5 \mathrm{~T}$ is not to be taken less than 1.3 times the $5 \%$ damped design spectrum (where $\mathrm{T}$ is the fundamental period of the structure). A list of ground motions, their peak ground accelerations (unscaled) and the amplitude scale factors used for this analysis is shown in Table 11 and the response spectrum for the suite is shown below in Figure CC.

\begin{tabular}{|c|c|c|c|c|}
\hline & Earthquake & Record Station & $\begin{array}{c}\text { Peak Ground } \\
\text { Acceleration (g) } \\
\text { (unscaled) }\end{array}$ & Scale Factor \\
\hline EQ1 & Northridge & Canoga Park & 0.356 & 2.15 \\
\hline EQ2 & Loma Prieta & Capitola & 0.529 & 2.55 \\
\hline EQ3 & Imperial Valley & Bonds Corner & 0.775 & 2.03 \\
\hline EQ4 & Imperial Valley & El Centro & 0.352 & 2.18 \\
\hline EQ5 & Kalamata & Kalamata & 0.248 & 3.88 \\
\hline EQ6 & Coalinga & Pleasant Valley & 0.380 & 3.52 \\
\hline EQ7 & Northridge & Saticoy Station & 0.368 & 1.77 \\
\hline
\end{tabular}

Table 11: Earthquake record data

Source: Author, Using Excel 


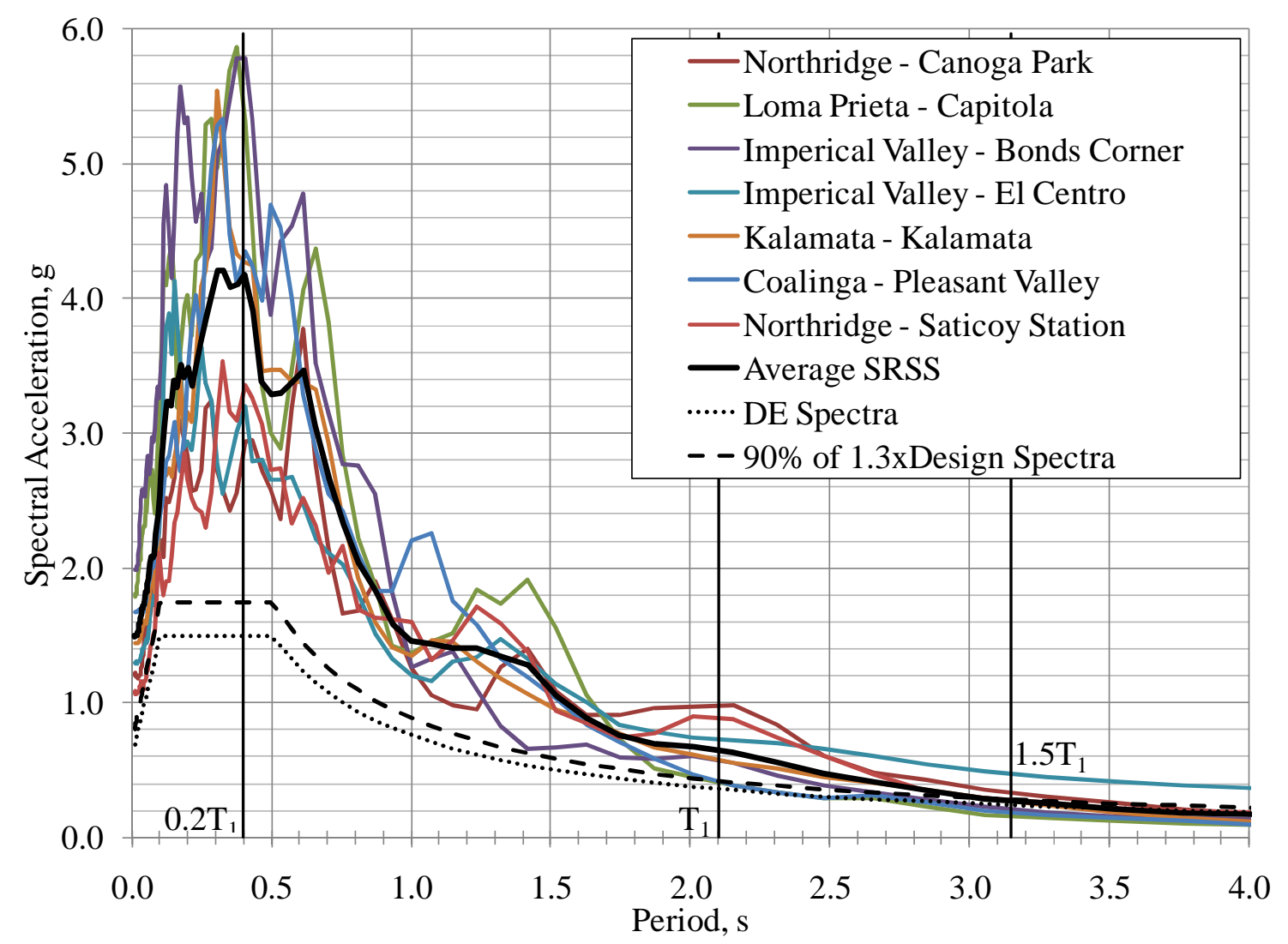

Figure CC: Earthquake spectral scaling for response spectrum

Source: Degenkolb Engineers, Using Excel

The response history analysis executed with Perform 3D to was terminated when any single nonlinear element reached its maximum inelastic displacement or rotation capacity (DX). When deformations are imposed beyond this limit, nonlinear elements have no analytical force displacement relationship assigned. For all three models, only the Imperial Valley - El Centro earthquake induced deformations high enough to terminate the analysis. This ground motion exhibited a large pulse around 6 seconds into the record, causing a large roof displacement and high ductility demands in the BRB elements until termination. For the results presented, all data from the Imperial Valley - 
El Centro record includes only building response data for the first 6.5 seconds. The remaining 6 records did not induce deformations beyond DX and the entire record was examined.

\subsubsection{Damping}

A large portion of the structural system damping has been accounted for by the hysteretic characteristic of the BRB elements which have been explicitly modeled with the BRB element compounds in Perform 3D. In addition to BRB yielding, yielding of the moment frame as well as damage to architectural features and cladding are expected throughout a seismic event and will also contribute an amount of damping to the building response. To account for MF yielding and nonstructural damage, modal damping and Raleigh damping have also been included in the nonlinear model.

Modal damping is defined by a damping matrix, $\underline{C}$ and is defined by the following equation (Perform User Guide):

$$
\underline{C}=\sum_{n=1}^{n=N} \frac{4 \pi}{T_{n}} \xi_{n} \frac{\underline{M} \phi_{n}}{\phi_{n}^{T} \underline{M} \phi_{n}},
$$

where $n$ is the mode for which damping is being calculated

(dimensionless),

$N$ is the total number of damped modes (dimensionless), and

$T_{n}$ is the period of mode $n$ ( $\left.\mathrm{sec}\right)$,

$\xi_{n}$ is the modal damping ratio of mode $n$,

$\underline{M}$ is the mass matrix for the structure, and

$\bar{\Phi}_{n}$ is the shape of mode $n$.

To reduced computational time, Perform 3D reduces this matrix to a banded matrix similar to the stiffness matrix of the structure which results in a slight energy unbalance in the analyses; however, the energy unbalance has been shown to be 
negligible. A modal damping of $1.9 \%$ has been implemented, although the effective damping achieved after the matrix is banded is unknown.

$$
\underline{\mathrm{C}}=\alpha \underline{\mathrm{M}}+\beta \underline{\mathrm{K}}
$$

where $\underline{\mathrm{K}}$ is the structure's stiffness matrix $(\mathrm{k}, \mathrm{in})$, $\alpha$ is a scalar adjusctment factor (dimensionless), and $\beta$ is a scalar adjusctment factor (dimensionless).

Raleigh damping which varies by period has also been added. This damping relationship is defined in Eq. 25 where $\alpha \underline{\mathrm{M}}$ (or $\alpha \mathrm{M}$ ) produces significant damping in long periods and $\beta \underline{\mathrm{K}}$ (or $\beta \mathrm{K}$ ) accounts for additional damping in short period modes.

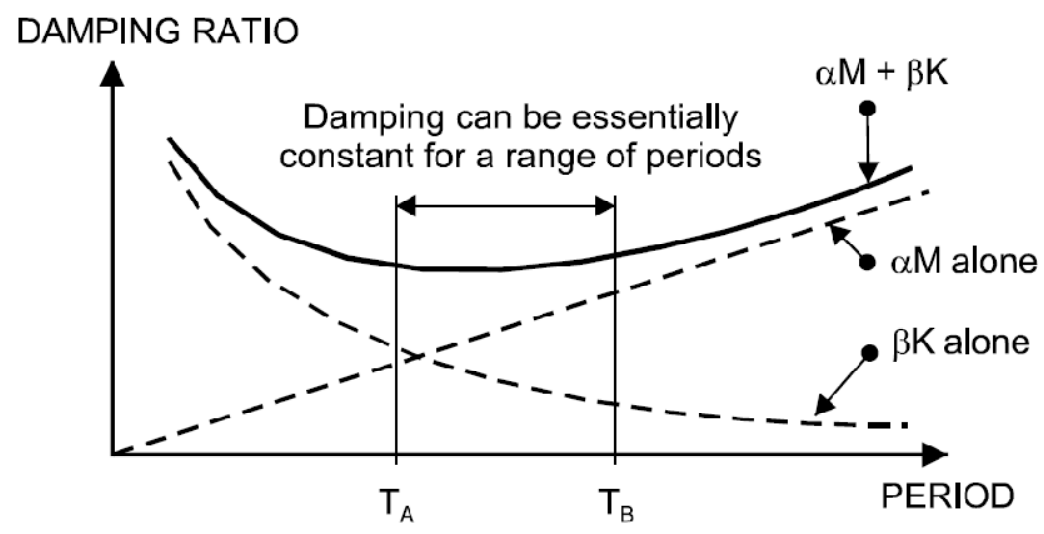

Figure DD: Raleigh damping ratio variation with period Source: CSI 2006a

The Raleigh damping model is displayed in Figure DD above. Where $T_{A}$ and $T_{B}$ have been assigned to $0.5 \mathrm{~T}_{1}$ and $1.5 \mathrm{~T}_{1}$ respectively where $\mathrm{T}_{1}$ is the fundamental period calculated by Perform 3D. The combination of $0.1 \%$ Raleigh damping and $1.9 \%$ Modal damping gives a total of $2 \%$ damping at $0.5 \mathrm{~T}_{1}$ and $1.5 \mathrm{~T}_{1}$ in addition to the hysteretic damping which results from BRB yielding. 


\subsubsection{Statistical Consideration of Results}

The buildings' response to seven ground motions has been examined for this thesis and the results for ductility, drift and displacement and story shear distribution have been displayed in tables and graphs of this section. Listing the results in increasing order of demands, the smallest earthquake response quantity would be considered as the first data point and the most severe response quantity would be the seventh data point. The median is reported as the value of the $4^{\text {th }}$ (or middle) data point, while the $84^{\text {th }}$ percentile result is approximated as data point 6 (since $6 / 7=0.86$ which is nearest 0.84 ). This method was used for the SAC project (FEMA 355).

\subsection{Response History Analysis Results}

Six of seven ground motions examined for the structures caused inelastic behavior; however, the structures did not reach collapse prevention (CP) limit state for any nonlinear element. One record, Imperial Valley, El Centro earthquake (EQ 4) induced brace ductility demands as high as $24 \Delta_{\mathrm{y}}$ at the lower levels which was caused by a large pulse in the first six to eight seconds of the record. Drift ratios resulting from this amount of displacement were significantly higher than the other six records considered. Since the accepted collapse prevention ductility for BRB elements is $15 \Delta_{\mathrm{y}}$ for this thesis, data was not collected beyond the time step at which $15 \Delta_{\mathrm{y}}$ was reached.

The following items have been studied for all three models based on the nonlinear dynamic (ND) behavior under the seven ground motions previously described:

- Maximum MF story shear demands; 
- Distribution of base shear demands in the MF at the instant of maximum MF story shear and a comparison to the $25 \%$ design rule in ASCE 7-05;

- Distribution of base shear demands in the MF at the instant of maximum net (MF $+\mathrm{BRBF}$ ) story shear and a comparison to the $25 \%$ design rule in ASCE 7-05;

- $\quad$ BRB and RBS maximum ductility ratios as multiples of the yield deformation or rotation;

- Drift profiles at maximum roof displacement; and

- Maximum story drift ratios.

\subsubsection{Base Shear}

The base shear distribution was considered for the point in time at which the base shear is at a maximum for each earthquake. The results of Model 25 are shown below in Figure EE. The data for EQ 4 included in the data of Figure EE shows the highest demands imposed onto the structure as a result of the Imperial Valley - El Centro ground motion record before a BRB reached the maximum ductility ratio. This record imposed the highest deformations in all three models. The data below in Figure EE demonstrates the highest base shear in the moment frame resulted from EQ 4; the MF was engaged and shared the lateral load as the BRBF went more fully nonlinear. The median MF base shear demand was $0.085 \mathrm{~W}$. Figure EE shows that the mean total base shear imposed on Model 25 exceeds the ultimate pushover capacity $(0.15 \mathrm{~W})$ shown by the uniform pushover in Figure V (page 52). This is because the force distribution imposed by the earthquake accelerations is unique to the record, causing the structure to be engaged 
differently. Also, the hysteretic behavior of the BRB elements has been modeled explicitly. As seen in testing and modeled, because of cyclic strain hardening, the capacity of the BRB elements increases as the members cycles back and forth. Previously Figure $\mathbf{J}$ showed an example of the hysteresis of a BRB element tested by Nippon Steel.

The shear distribution ratio in the $25 \%$ model for each ground motion is also provided for the instant of maximum total base shear below in Figure JJ. The median MF contribution is $51 \%$ of the maximum overall dynamic base shear demand. In the case of model 25, the median MF base shear and the median total base shear are not a result of the same ground motion. This is simply because the ground motions excite the building differently, engaging more and less of the MF.

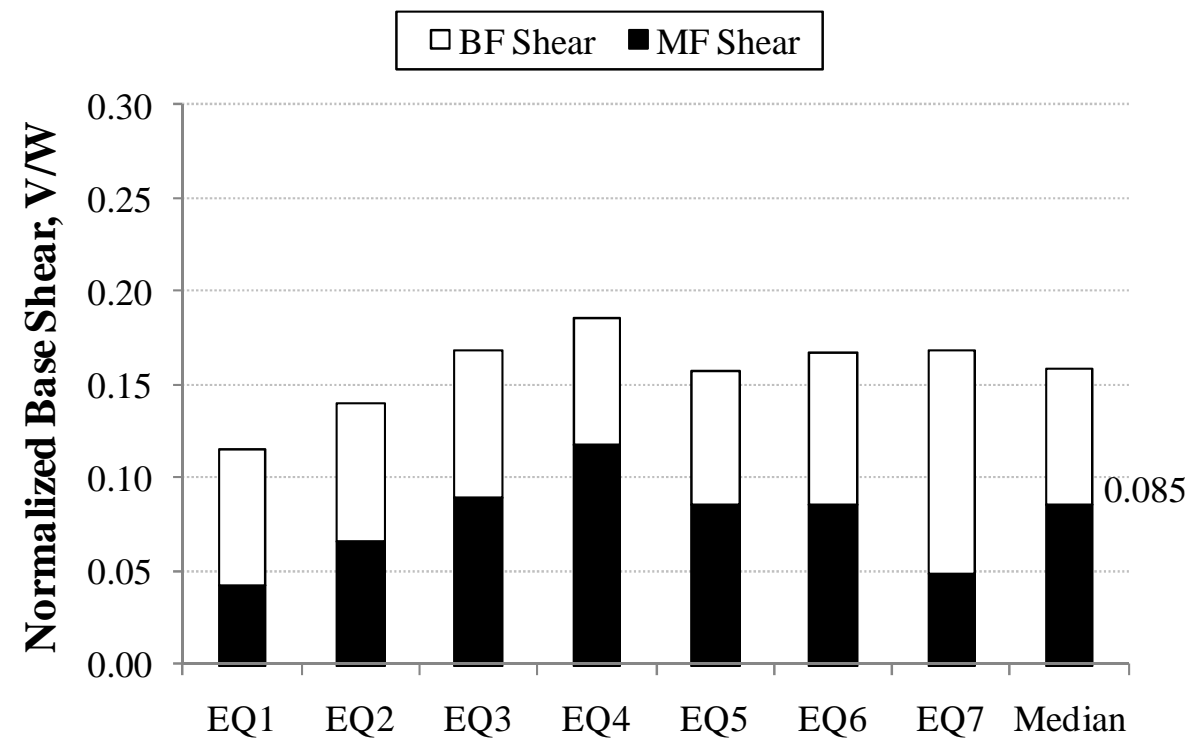

Figure EE: Model 25 normalized base shear demands from nonlinear dynamic analysis at maximum total base shear Source: Author, Using Excel 


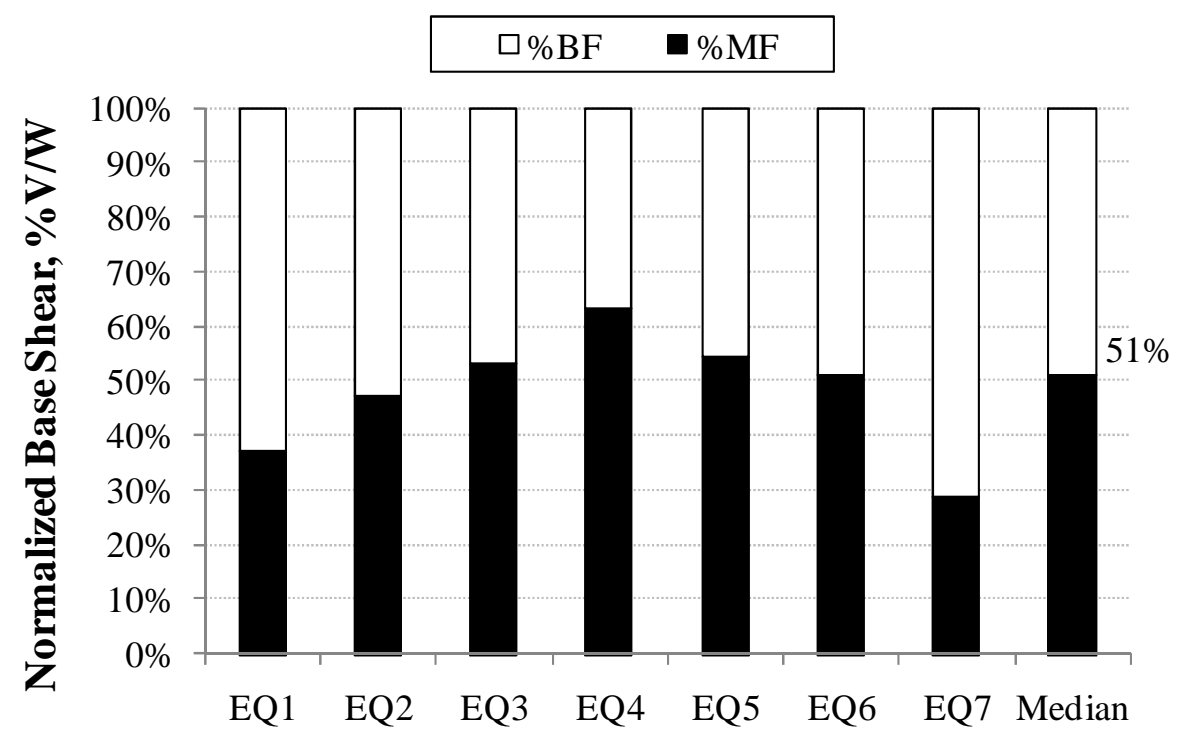

Figure FF: Model 25 base shear distribution from nonlinear dynamic analysis at maximum total base shear

Source: Author, Using Excel

A similar trend was seen for Models 15 and 40, and a comparison of the median base shear demands is shown below in Figure GG.
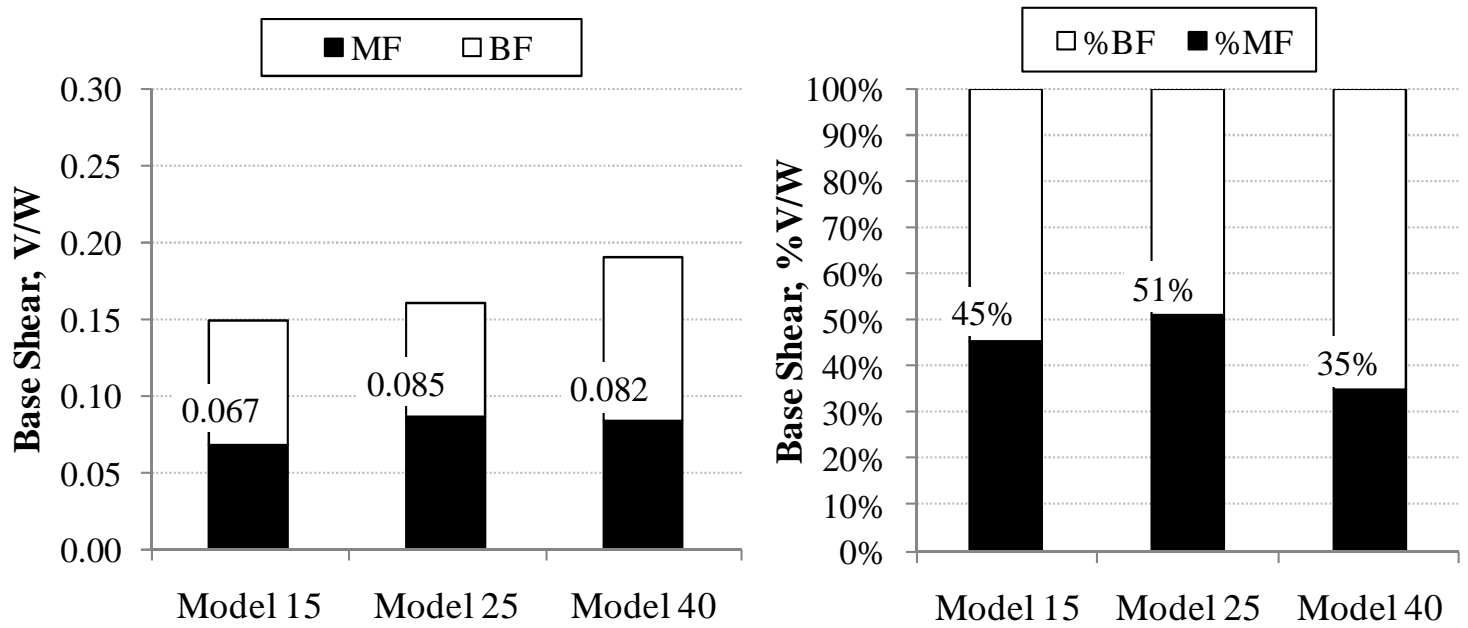

Figure GG: Comparison of median values at maximum total base shear Source: Author, Using Excel 
Recall, that the design base shear was calculated to be $0.06 \mathrm{~W}$ for all three structures using a response modification factor (R-factor), equal to 8, which has been defined in ASCE 7-05 with the understanding that the structure will behave in a ductile fashion during a major seismic event. For Model 25, the moment frame was designed for $25 \%$ of $0.06 \mathrm{~W}$, or $0.015 \mathrm{~W}$, where $\mathrm{W}$ is the total seismic weight of the structure.

Based on the results shown above in Figure GG, the median dynamic base shear in the moment frame varies only slightly between models 25 and 40; however, a higher force is induced in the $\mathrm{BF}$ in Model 40 leaving the relative contribution of the MF at $35 \%$ in Model 40 compared to 51\% in Model 25. The MF demands for Model 15 are $6 \%$ less than Model 25. The MF demands for all three models shown in Figure GG are compared to the design base shear below in Table 12.

Similar results have been considered for each earthquake at the instant during the earthquake at which the moment frame demand was the greatest. In some cases, the overall maximum base shear demand did not occur at the same time as the maximum moment frame base shear demand during the time history analysis. The median result for this state is shown below in Figure HH for each model. 

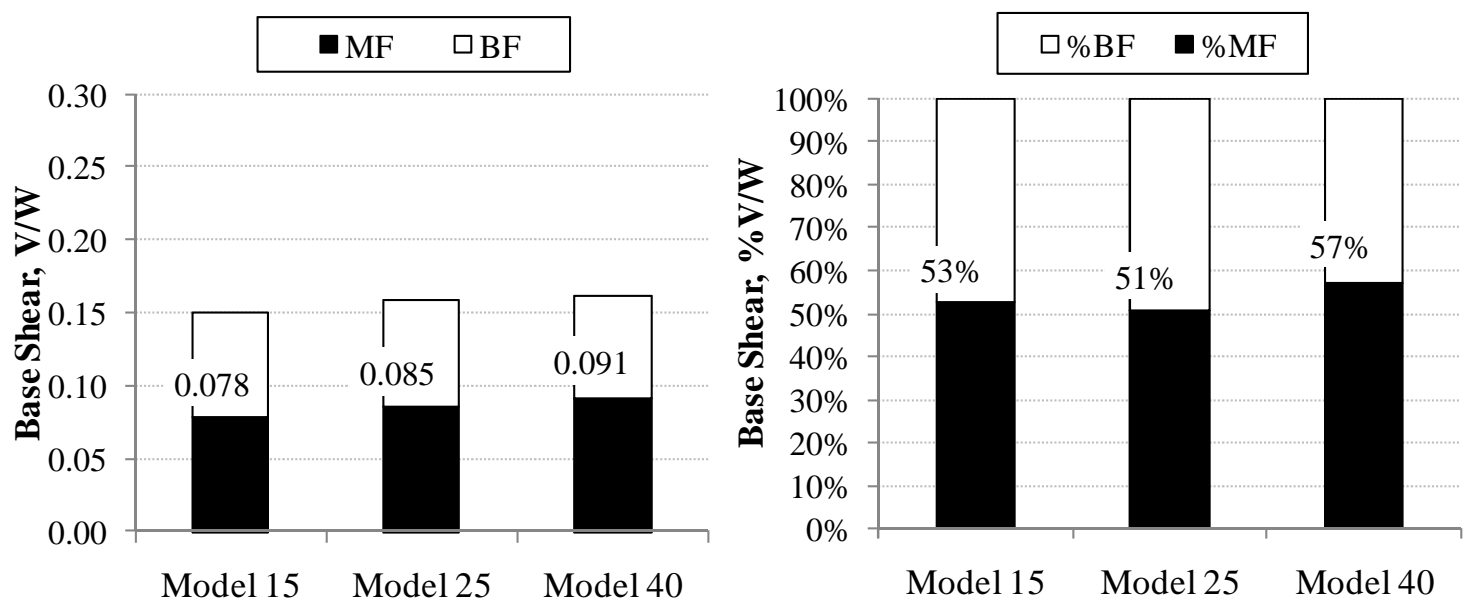

Figure HH: Comparison of median values at maximum dynamic MF base shear Source: Author, Using Excel

Figure $\mathrm{HH}$ shows a more regular trend as the MF base shear increases with MF strength between the models. Base shear is the minimum in the Model $15 \mathrm{MF}$, and a maximum in Model 40 when the overall MF demands are a maximum during the response history.

Below in Table 12, the ratio of nonlinear demands versus the design base shear is displayed. For Model 15, the MF base shear recorded from the RHA at the instant of maximum base shear as well as the instant of maximum net base shear is 7.4 times the design base shear. As the MF design strength increases, the comparison to the design base shear reduces. Model 25 reaches 5.7 times the design base shear, while Model 15 is 3.4 and 3.8 for the data recorded. These results show that increasing the design strength of the MF in Model 15 by $25 \%$ causes a $50 \%$ difference in comparison to the ASCE 7-05 design values. 
4.0 Nonlinear Analysis 70

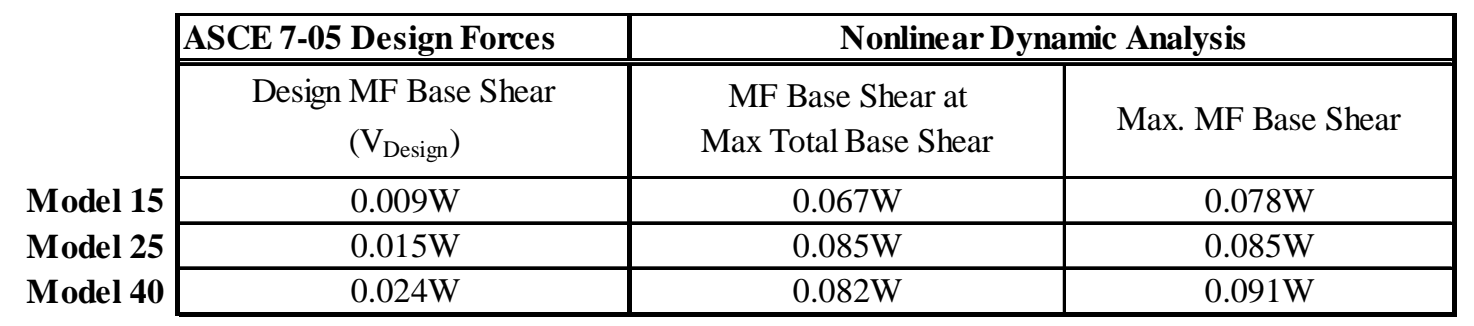

\begin{tabular}{l|c|c|}
\cline { 2 - 3 } & $\mathbf{V}_{\text {MF at Max Total }} / \mathbf{V}_{\text {Design }}$ & $\mathbf{V}_{\text {Max MF }} / \mathbf{V}_{\text {Design }}$ \\
\cline { 2 - 3 } Model 15 & 7.43 & 8.64 \\
\cline { 2 - 3 } Model 25 & 5.67 & 5.67 \\
\cline { 2 - 3 } Model 40 & 3.40 & 3.80 \\
\cline { 2 - 3 } & &
\end{tabular}

Table 12: Comparison of Median Nonlinear Dynamic MF base shear demands to ASCE 7-05 design base shear.

Source: Author, Using Excel

The median MF base shear results from the response history analysis have also been compared to the MF base shear demands at target displacement during the modal pushover. The modal pushover has been chosen over the uniform pushover since it demonstrates some uniqueness to the structure's first mode response. Similar to the results shown in Table 12, the MF base shear results have been included and the ratios to the pushover demands are displayed in the lower portion of Table 13. These results show that the MF base shear in the Response History Analysis is much higher than the demands at target displacement of the Modal Pushover. The MF demands are 2.3-2.7 times higher in Model 15, 2.1 times in Model 25 and 1.4-1.6 times higher than the pushover results in Model 40. Since a structure is expected to have capacity beyond the target displacement for life safety performance it is expected that when the dual system structure is subject to a significant earthquake, the MF will be stressed beyond what has been calculated at target displacement. 


\begin{tabular}{|c|c|c|c|}
\cline { 2 - 4 } & Nonlinear Modal Pushover & \multicolumn{2}{|c|}{ Nonlinear Dynamic Analysis } \\
\cline { 2 - 4 } & $\begin{array}{c}\text { MF Base Shear at Target } \\
\text { Displacement }\end{array}$ & $\begin{array}{c}\text { MF Base Shear at } \\
\text { Max Total Base Shear }\end{array}$ & Max. MF Base Shear \\
\cline { 2 - 4 } Model 15 & $0.029 \mathrm{~W}$ & $0.067 \mathrm{~W}$ & $0.078 \mathrm{~W}$ \\
\cline { 2 - 4 } Model 25 & $0.040 \mathrm{~W}$ & $0.085 \mathrm{~W}$ & $0.085 \mathrm{~W}$ \\
\cline { 2 - 4 } Model 40 & $0.057 \mathrm{~W}$ & $0.082 \mathrm{~W}$ & $0.091 \mathrm{~W}$ \\
\cline { 2 - 4 } & & &
\end{tabular}

\begin{tabular}{l|c|c|}
\cline { 2 - 3 } & $\mathbf{V}_{\mathbf{M F} \text { at Max Total }} / \mathbf{V}_{\text {at } \mathbf{~ t ~}}$ & $\mathbf{V}_{\text {MF at Max MF }} / \mathbf{V}_{\text {at } \mathbf{~} \mathbf{t}}$ \\
\cline { 2 - 3 } Model 15 & 2.31 & 2.68 \\
\cline { 2 - 3 } Model 25 & 2.13 & 2.13 \\
\cline { 2 - 3 } Model 40 & 1.43 & 1.60 \\
\cline { 2 - 3 } & &
\end{tabular}

Table 13: Comparison of Median Nonlinear Dynamic MF base shear demands to Modal Pushover MF demands at $\delta_{\text {t }}$.

Source: Author, Using Excel

The MF demands recorded from the nonlinear dynamic analysis can be compared to the overall capacity of the MF (maximum base shear) shown in the pushover curves displayed in Figure U, Figure W, and Figure Y. Table 14 below shows the results of this comparison. The capacities observed in the modal pushover are a result of the first mode only force distribution linearly increased, while the demands seen in the NDA include dynamic variability from the ground motions and effects of higher modes. While Model 15 and Model 25 show demands beyond their modal pushover capacities in the NDA, the base shear demands in Model 40 from the NDA are within $10 \%$. 


\begin{tabular}{|c|c|c|c|}
\hline \multirow{5}{*}{$\begin{array}{l}\text { Model } 15 \\
\text { Model } 25 \\
\text { Model } 40\end{array}$} & \multirow{2}{*}{$\begin{array}{c}\text { Nonlinear Modal Pushover } \\
\text { Max MF Capacity }\end{array}$} & \multicolumn{2}{|c|}{ Nonlinear Dynamic Analysis } \\
\hline & & $\begin{array}{c}\text { MF Base Shear at } \\
\text { Max Total Base Shear }\end{array}$ & Max. MF Base Shear \\
\hline & $0.051 \mathrm{~W}$ & $0.067 \mathrm{~W}$ & $0.078 \mathrm{~W}$ \\
\hline & $0.060 \mathrm{~W}$ & $0.085 \mathrm{~W}$ & $0.085 \mathrm{~W}$ \\
\hline & $0.090 \mathrm{~W}$ & $0.082 \mathrm{~W}$ & $0.091 \mathrm{~W}$ \\
\hline \multirow{4}{*}{\multicolumn{2}{|c|}{$\begin{array}{l}\text { Model } 15 \\
\text { Model } 25 \\
\text { Model } 40\end{array}$}} & $V_{\text {MF at Max Total }} / V_{\text {MF capacity }}$ & $\mathrm{V}_{\text {MF at Max MF }} / \mathrm{V}_{\text {MF capacity }}$ \\
\hline & & \begin{tabular}{|c|}
1.31 \\
\end{tabular} & $\begin{array}{r}1.52 \\
\end{array}$ \\
\hline & & 1.42 & 1.42 \\
\hline & & 0.91 & 1.01 \\
\hline
\end{tabular}

Table 14: Comparison of Median Nonlinear Dynamic MF base shear demands to Modal Pushover MF demands at $\boldsymbol{\delta}_{\text {t }}$.

Source: Author, Using Excel

The base shear ratios comparing the NDA to the ASCE 7-05 design base shear and nonlinear static base shear at target displacement maintain a similar trend as the NDA demands decrease as the strength of the MF increases.

\subsubsection{Story Shear}

The story shears displayed below in Figure II, Figure JJ and Figure KK represent the instance at which the total story shear is maximum during the response history for Models 15, 25, and 40 respectively with the median results indicated as previously defined. For the remainder of this section, the total story shear that is reported is the summation of the BF and MF story shear at the same instant in time throughout the earthquake records. The data points shown in the figures of this section demonstrate the distribution of data that was collected from the seven earthquake records. Results of the El Centro ground motion are included up to approximately 6.5 seconds where the BRB elements have exceeded their maximum ductility for all three models. In the graphs 
below, the open data points and solid lines represent the story shear demands in the moment frame, while the solid data points and dashed lines represent the total story shear or the sum of braced and moment frame shear forces.

In all three models, the median results of the maximum net story shears demonstrate a mostly smooth trend for the total story shear. The zigzag pattern, similar to that previously seen in the elastic and the pushover analysis, is a result of the brace pattern on the structure's elevation.

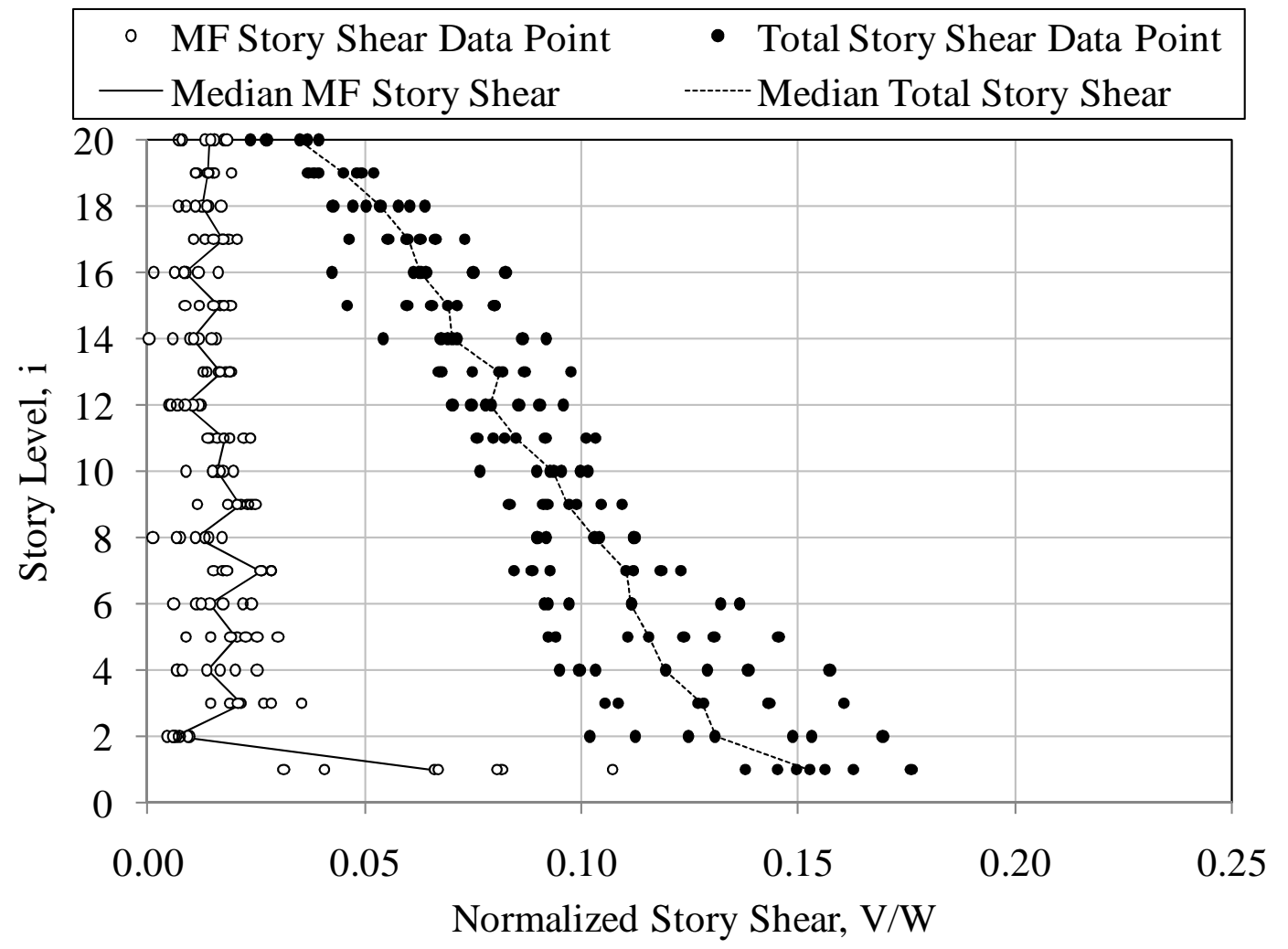

Figure II: Model 15 nonlinear dynamic maximum total story shear demands Source: Author, Using Excel

Figure II and Figure JJ show the story shear distribution at the instant at which the total story shear demands are a maximum. Model 25 distributes forces with a similar 
trend as Model 15. Near the $\mathrm{x}$-axis of the figure the overall maximum base shear is defined as the lowest data points at $\mathrm{y}=1$ (story shear at level 1).

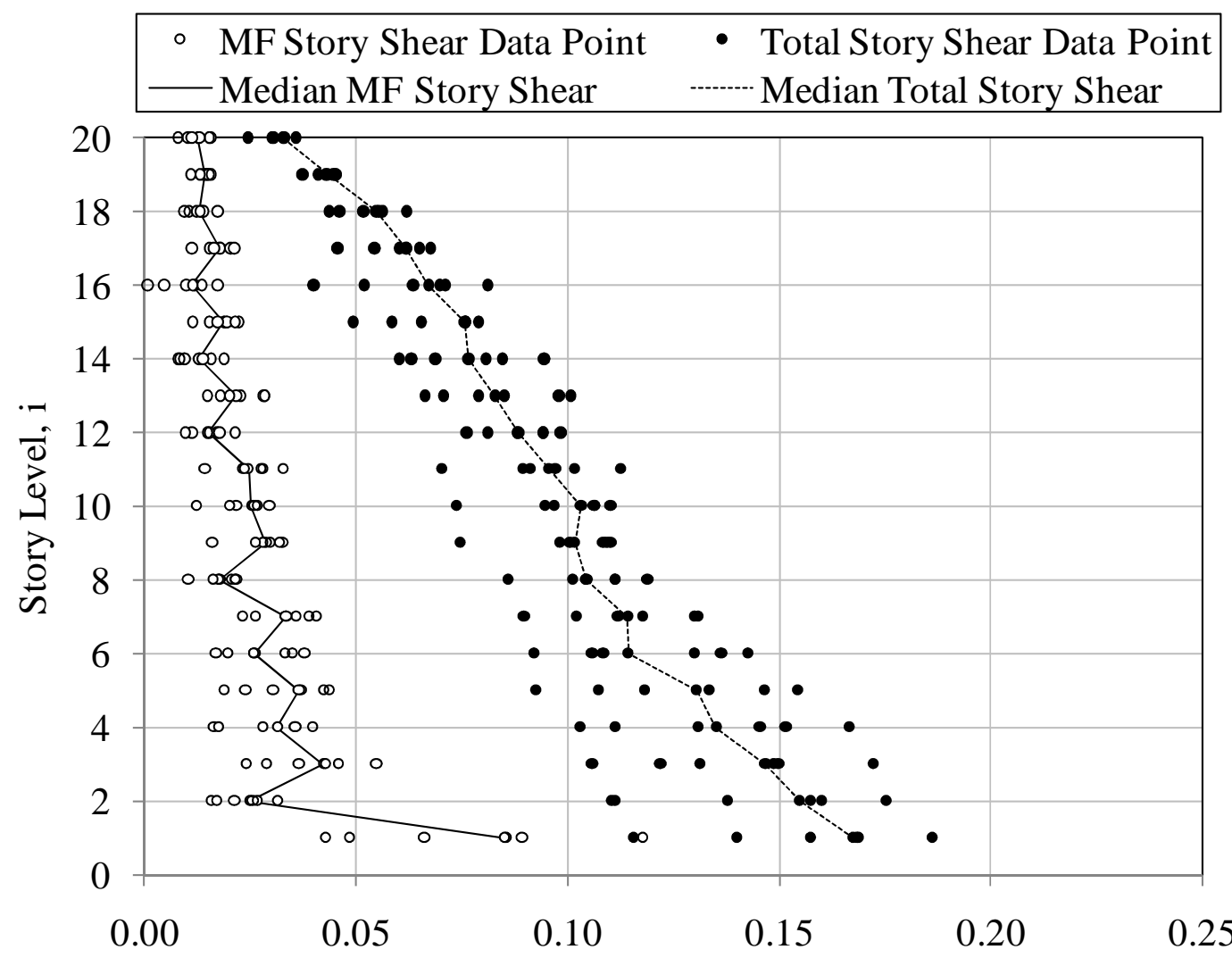

Normalized Story Shear, V/W

Figure JJ: Model 25 nonlinear dynamic maximum total story shear demands Source: Author, Using Excel

A slightly more irregular trend is observed in Figure KK for the overall story

shear; however, the moment frame story shears are nearly linear between levels 7 and 12 .

The MF base shear (the story shear at story level 1) is nearly equivalent between Model 25 and Model 40 (shown in Figure LL). Since the pitch of the first level brace is steeper, the maximum total base shear seen in a NDA is higher for all three models. 


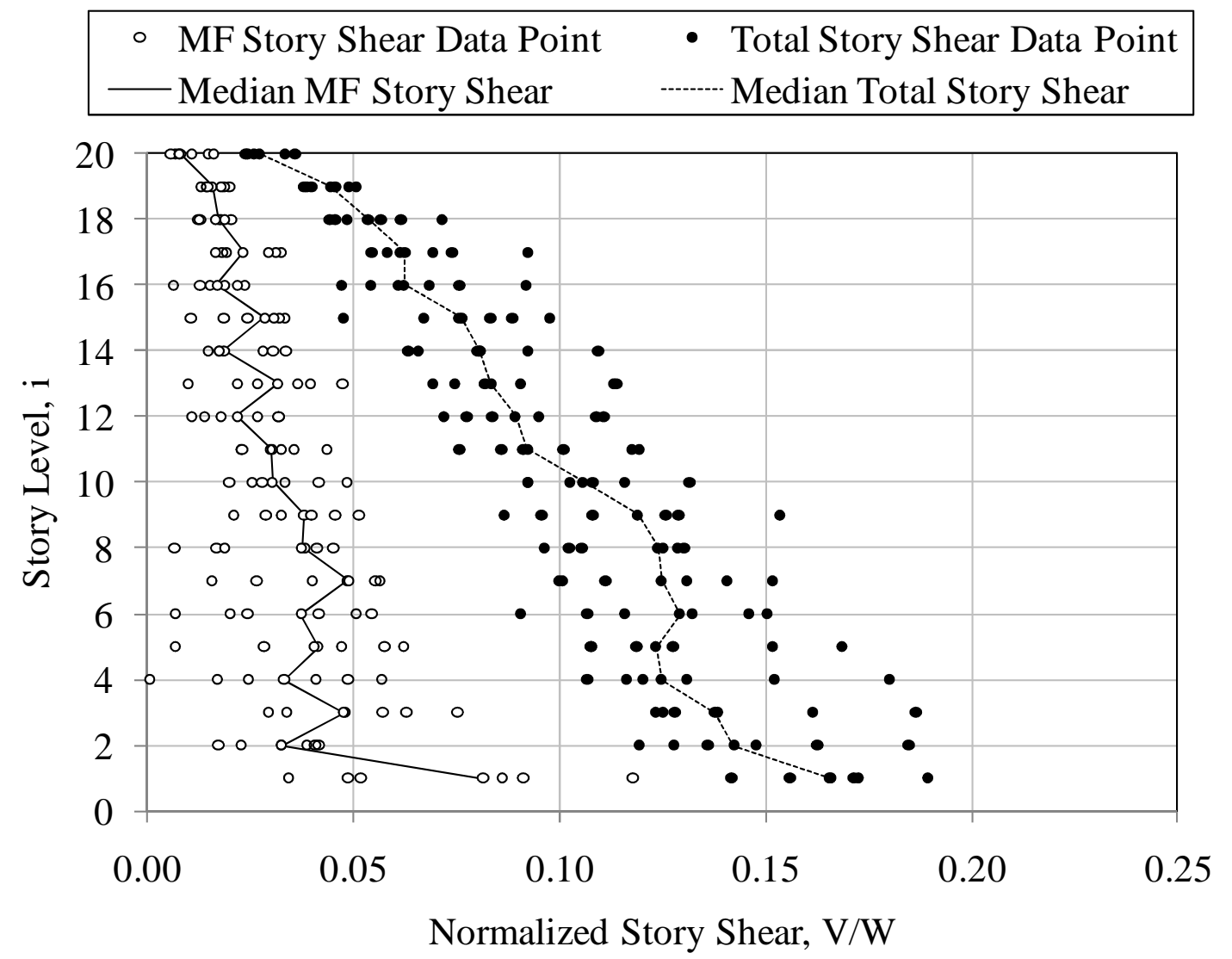

Figure KK: Model 40 nonlinear dynamic results for maximum total story shear demands

Source: Author, Using Excel

The median results of Figure II through Figure KK are plotted simultaneously on

Figure LL. This graph shows levels 4 through 10 show the biggest difference in how forces are distributed based on the available MF strength. Following Figure LL, Table 15 reports the ground motion record that contributed the median result of the nonlinear dynamic analysis for total story shear. This table shows the median earthquake record varies for each model and that the difference in MF strength distribution does in fact behave differently in response to different ground motions. 


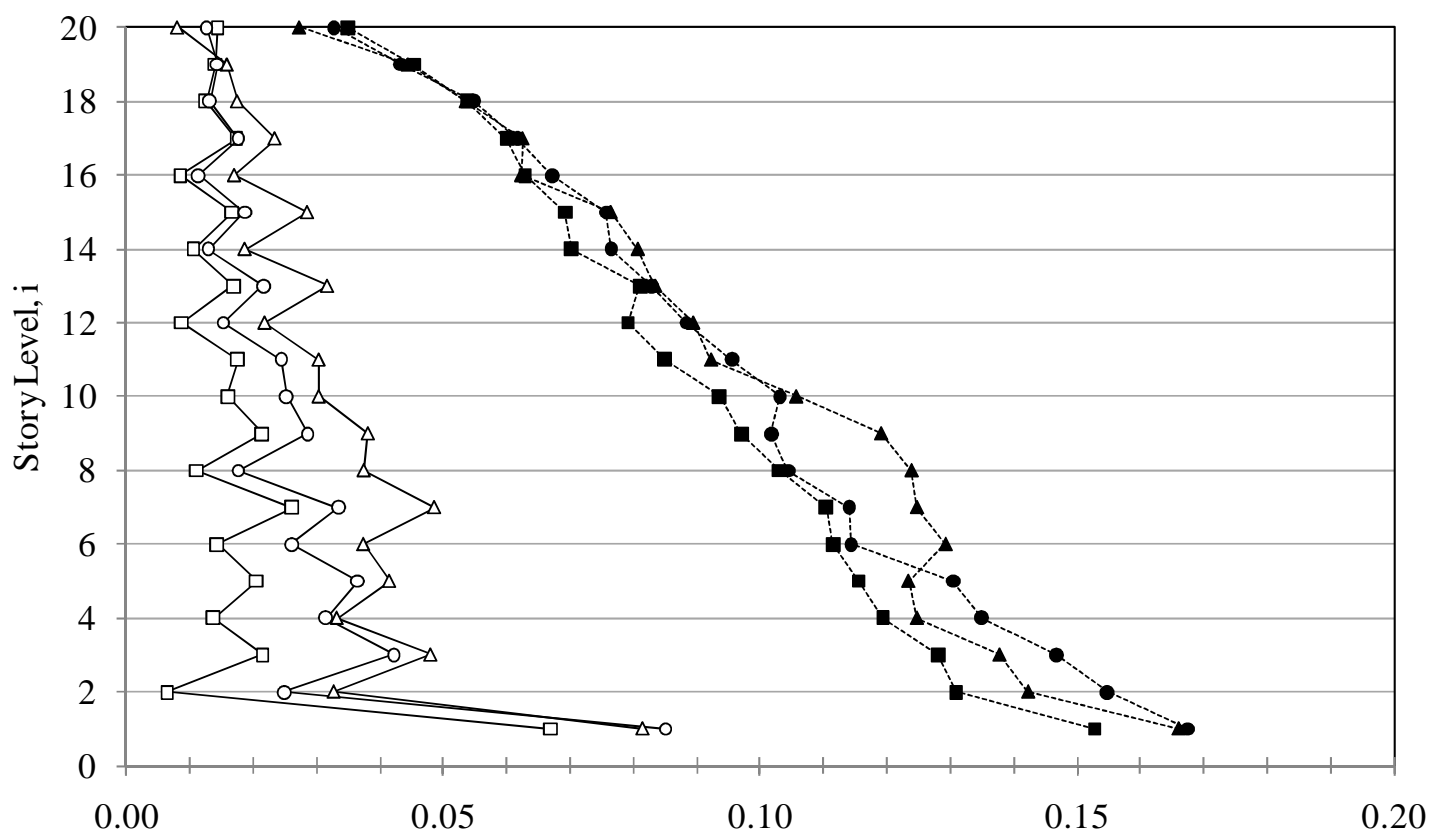

Normalized Story Shear, V/W

Figure LL: Comparison of nonlinear dynamic median results for maximum net story shear demands 
4.0 Nonlinear Analysis

\begin{tabular}{|c|c|c|c|}
\hline Story & Model 15 & Model 25 & \begin{tabular}{|c|} 
Model 40 \\
\end{tabular} \\
\hline 1 & Kalamata - Kalamata & Coalinga - Pleasant Valley & Imperial Valley - Bonds Corner \\
\hline 2 & Loma Prieta - Capitola & Kalamata - Kalamata & Loma Prieta - Capitola \\
\hline 3 & Loma Prieta - Capitola & Imperial Valley - Bonds Corner & Coalinga - Pleasant Valley \\
\hline 4 & Loma Prieta - Capitola & Imperial Valley - Bonds Corner & Northridge - Saticoy Station \\
\hline 5 & Loma Prieta - Capitola & Kalamata - Kalamata & Coalinga - Pleasant Valley \\
\hline 6 & Loma Prieta - Capitola & Imperial Valley - Bonds Corner & Loma Prieta - Capitola \\
\hline 7 & Imperial Valley - Bonds Corner & Loma Prieta - Capitola & Loma Prieta - Capitola \\
\hline 8 & Imperial Valley - Bonds Corner & Loma Prieta - Capitola & Loma Prieta - Capitola \\
\hline 9 & Loma Prieta - Capitola & Loma Prieta - Capitola & Imperial Valley - El Centro \\
\hline 10 & Imperial Valley - Bonds Corner & Loma Prieta - Capitola & Coalinga - Pleasant Valley \\
\hline 11 & Imperial Valley - Bonds Corner & Loma Prieta - Capitola & Coalinga - Pleasant Valley \\
\hline 12 & Northridge - Saticoy Station & Imperial Valley - Bonds Corner & Coalinga - Pleasant Valley \\
\hline 13 & Coalinga - Pleasant Valley & Kalamata - Kalamata & Coalinga - Pleasant Valley \\
\hline 14 & Kalamata - Kalamata & Kalamata - Kalamata & Northridge - Saticoy Station \\
\hline 15 & Coalinga - Pleasant Valley & Loma Prieta - Capitola & Imperial Valley - Bonds Corner \\
\hline 16 & Kalamata - Kalamata & Northridge - Saticoy Station & Coalinga - Pleasant Valley \\
\hline 17 & Coalinga - Pleasant Valley & Kalamata - Kalamata & Imperial Valley - Bonds Corner \\
\hline 18 & Kalamata - Kalamata & Northridge - Saticoy Station & Coalinga - Pleasant Valley \\
\hline 19 & Imperial Valley - Bonds Corner & Loma Prieta - Capitola & Coalinga - Pleasant Valley \\
\hline 20 & Northridge - Saticoy Station & Coalinga - Pleasant Valley & Imperial Valley - Bonds Corner \\
\hline
\end{tabular}

Table 15: Ground motion records contributing the nonlinear dynamic median results for total story shear from Figure $L L$.

Source: Author, Using Excel

Story shear results were also recorded for the instant at which the maximum

moment frame story shear was observed. This data is unexpectedly different from the median results of maximum total story shear, as the maximum MF story shear often occurs when the total story shear is very low, or even negative. These results are provided below in Figure MM through Figure PP. 


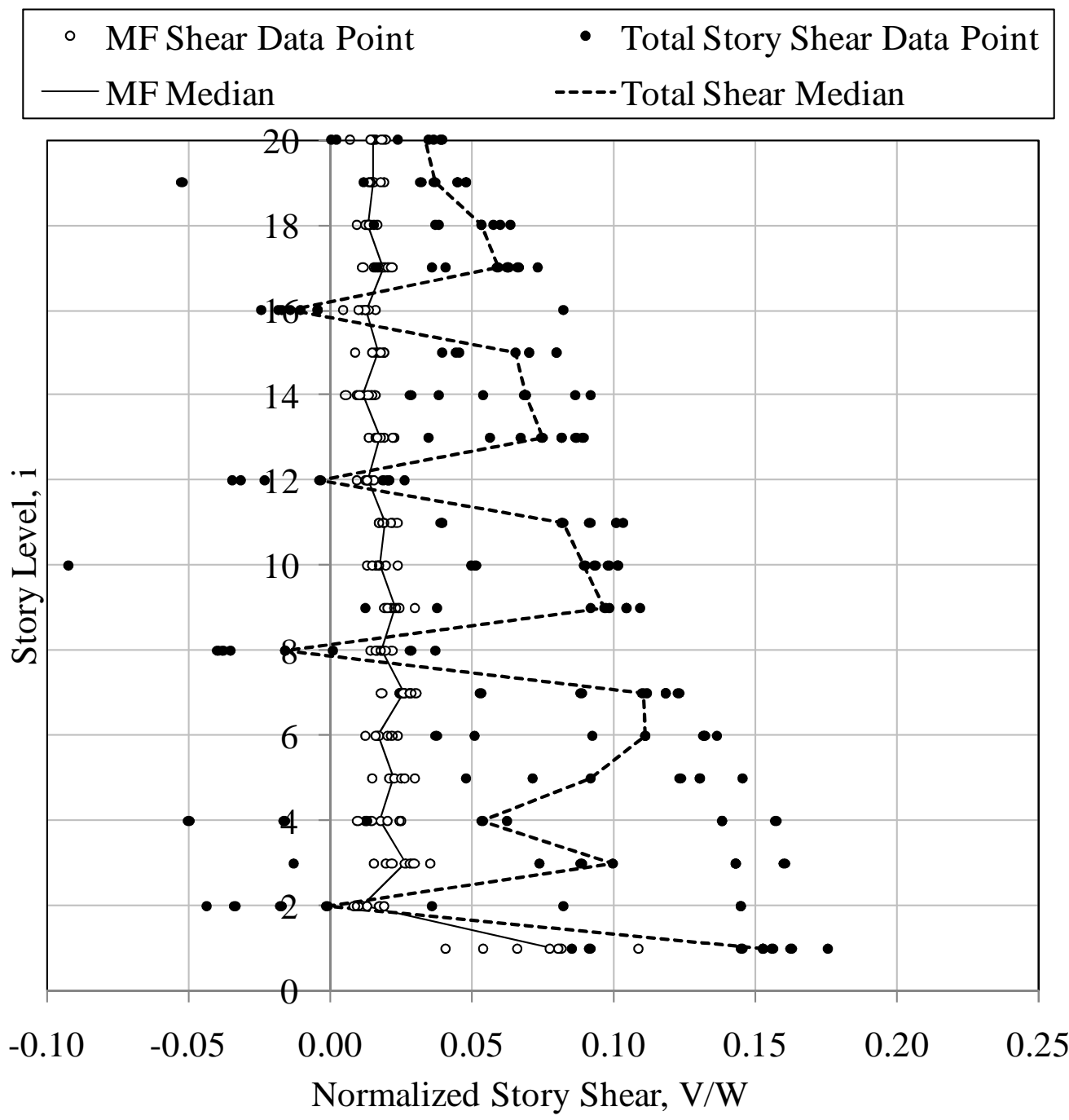

Figure MM: Model 15 nonlinear dynamic results for maximum moment frame story shear demands

Source: Author, Using Excel

Figure MM shows the results for Model 15. The median results for maximum MF story shear are more linear than was observed for maximum total shear; however, in this case, the total story shear is negative at levels $2,8,12$, and 16 . This behavior is seen at every fourth floor of Model 15. At these levels, the braces are in adjacent interior bays just as observed in the elastic analysis of this thesis. Low or negative net story shear force 
is a result of the difference in stiffness of the two systems. Where the BRBFs are in adjacent bays, the BF stiffness is maximized at that level (levels 4, 8, 12, 16, and 20 as shown in elevation in Figure B).

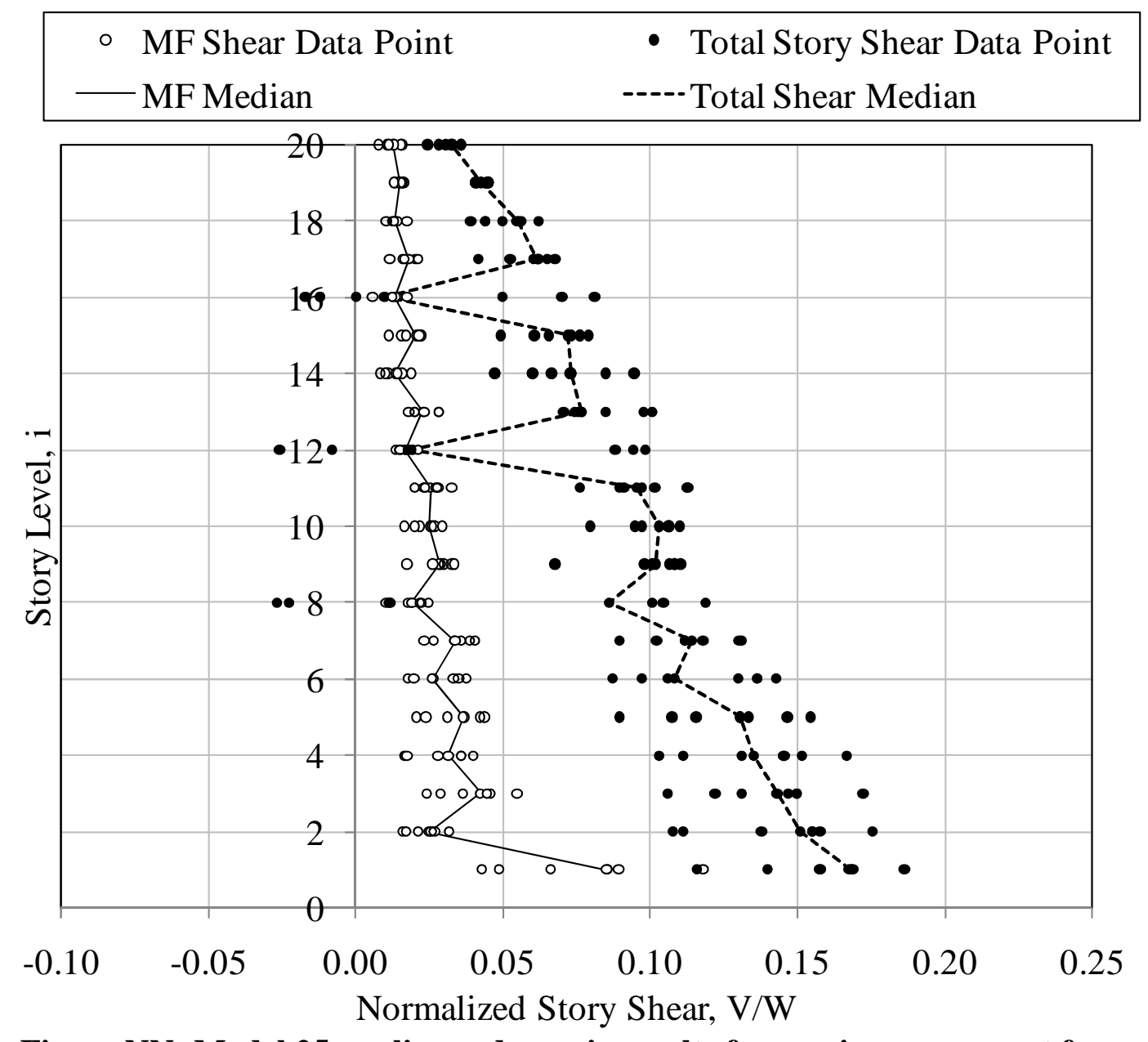

Figure NN: Model 25 nonlinear dynamic results for maximum moment frame story shear demands

Source: Author, Using Excel

As the moment frame design strength is increased from $15 \%$ to $25 \%$ of the base shear, the relative distribution of forces is directly affected. In Model 25 shown in 
Figure NN, the braced frame attracts almost no force at levels 12 and 16, where the total story shear is approximately equal to the moment frame shear. For all other levels, the vertical trend of MF story shear is more linear.

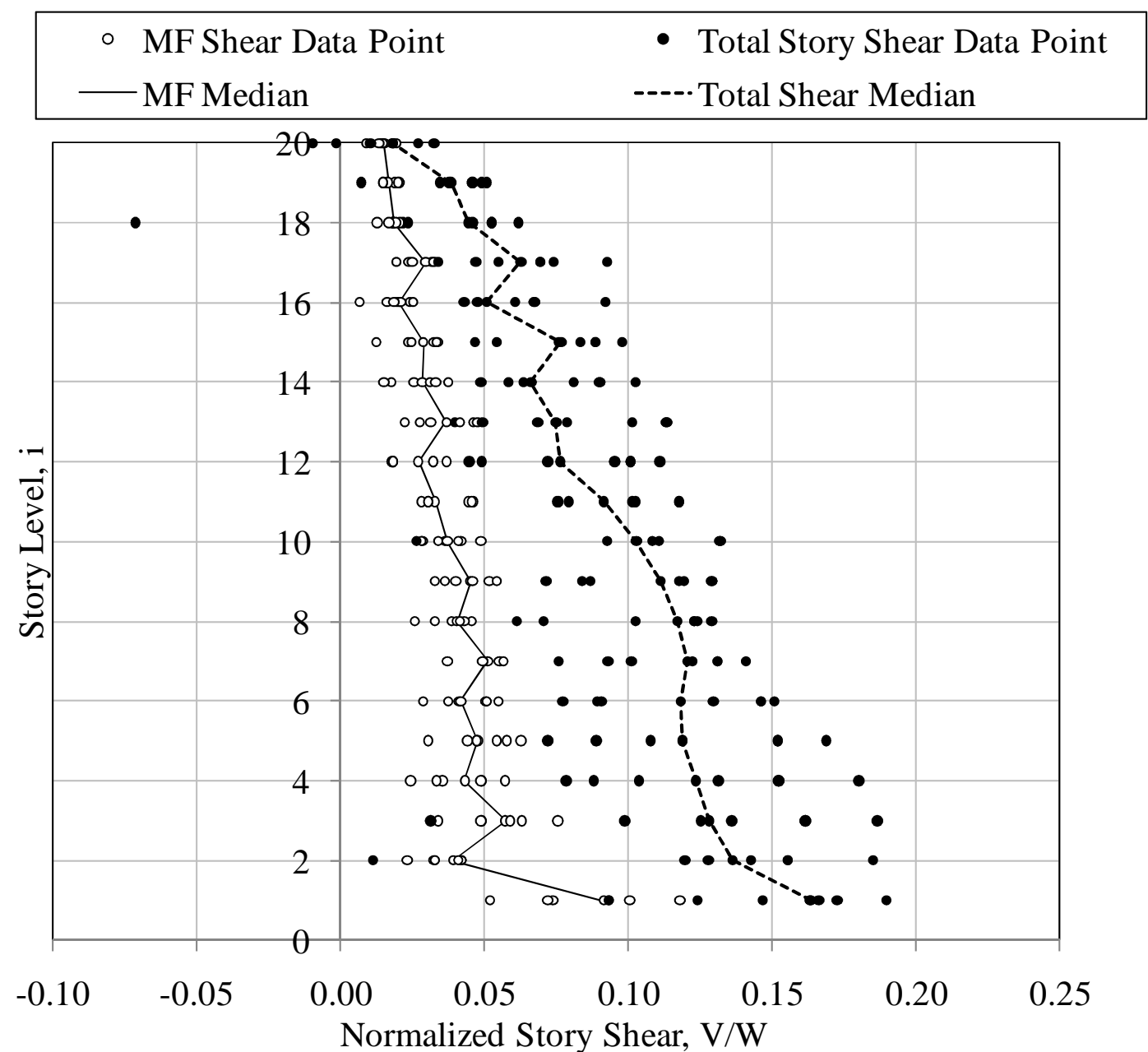

Figure OO: Model 40 nonlinear dynamic maximum moment frame story shear demands

Source: Author, Using Excel

Finally, increasing the design strength $25 \%$ to $40 \%$ seismic demands the relative distribution becomes more regular as the median results above in Figure OO show the BF 
and MF consistently work together resisting unidirectional forces. A comparison of the median results for Models 15, 25, and 40 in the maximum moment frame story shear state is shown below in Figure PP.

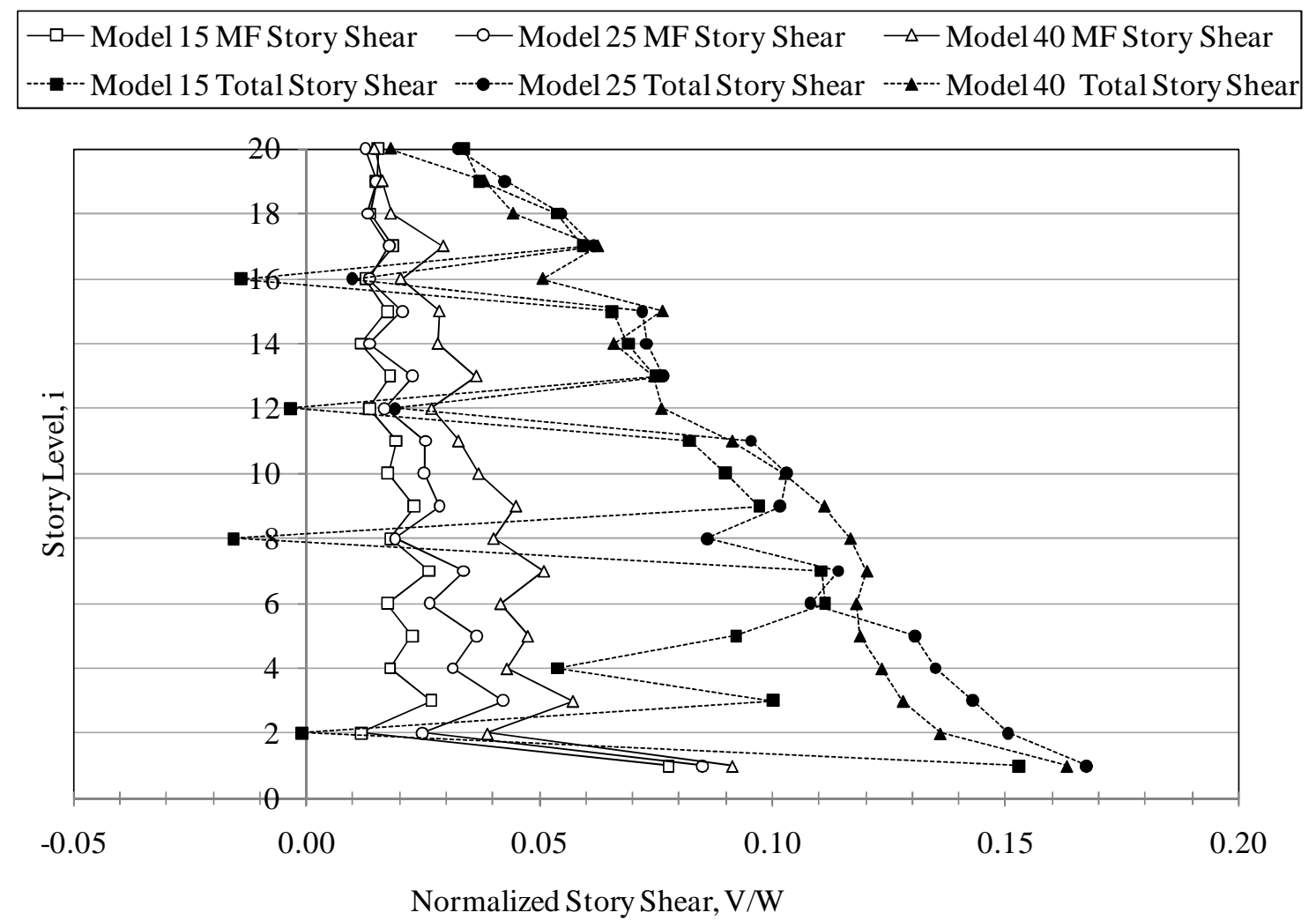

Figure PP: Comparison of median nonlinear dynamic results for maximum MF story shear demands

Source: Author, Using Excel

The results presented in Figure PP show a trend related to the brace pattern of the BRBF. As previously mentioned, the low or negative outlier values for the median total story shear are levels where braces are in adjacent bays (with exception of level 2).

Figure PP also shows a linear trend in total story shear for the other levels, disregarding levels of adjacent braces. 
Since the BRBF design was based on the relative stiffness of the BRBF to the MF, the most flexible MF required a stronger and therefore stiffer braced frame in order to adequately resist the linear dynamic forces it was designed for. This design method caused the highest stiffness difference between the BRBF and MF to exist in Model 15, and the smallest difference to occur in Model 40. It is clear from Figure PP that the reverse shear behavior is most distinct in Model 15 and hardly seen in Model 40.

\begin{tabular}{|c|c|c|c|}
\hline Story & Model 15 & Model 25 & Model 40 \\
\hline 1 & Coalinga - Pleasant Valley & Coalinga - Pleasant Valley & Imperial Valley - Bonds Corner \\
\hline 2 & Loma Prieta - Capitola & Imperial Valley - Bonds Corner & Imperial Valley - Bonds Corner \\
\hline 3 & Imperial Valley - Bonds Corner & Imperial Valley - Bonds Corner & Imperial Valley - Bonds Corner \\
\hline 4 & Imperial Valley - Bonds Corner & Imperial Valley - Bonds Corner & Imperial Valley - Bonds Corner \\
\hline 5 & Imperial Valley - Bonds Corner & Kalamata - Kalamata & Northridge - Canoga Park \\
\hline 6 & Loma Prieta - Capitola & Loma Prieta - Capitola & Loma Prieta - Capitola \\
\hline 7 & Loma Prieta - Capitola & Kalamata - Kalamata & Northridge - Canoga Park \\
\hline 8 & Imperial Valley - El Centro & Northridge - Saticoy Station & Coalinga - Pleasant Valley \\
\hline 9 & Imperial Valley - El Centro & Loma Prieta - Capitola & Loma Prieta - Capitola \\
\hline 10 & Loma Prieta - Capitola & Loma Prieta - Capitola & Loma Prieta - Capitola \\
\hline 11 & Imperial Valley - Bonds Corner & Loma Prieta - Capitola & Imperial Valley - Bonds Corner \\
\hline 12 & Kalamata - Kalamata & Imperial Valley - Bonds Corner & Imperial Valley - Bonds Corner \\
\hline 13 & Kalamata - Kalamata & Imperial Valley - Bonds Corner & Imperial Valley - Bonds Corner \\
\hline 14 & Northridge - Canoga Park & Kalamata - Kalamata & Imperial Valley - Bonds Corner \\
\hline 15 & Kalamata - Kalamata & Imperial Valley - Bonds Corner & Coalinga - Pleasant Valley \\
\hline 16 & Northridge - Canoga Park & Coalinga - Pleasant Valley & Imperial Valley - Bonds Corner \\
\hline 17 & Loma Prieta - Capitola & Loma Prieta - Capitola & Kalamata - Kalamata \\
\hline 18 & Northridge - Saticoy Station & Northridge - Saticoy Station & Kalamata - Kalamata \\
\hline 19 & Imperial Valley - Bonds Corner & Kalamata - Kalamata & Coalinga - Pleasant Valley \\
\hline 20 & Imperial Valley - Bonds Corner & Imperial Valley - Bonds Corner & Coalinga - Pleasant Valley \\
\hline
\end{tabular}

Table 16: Ground motion records contributing the nonlinear dynamic median results for maximum MF story shear from Figure PP.

Source: Author, Using Excel

The ground motions that caused the median result for maximum MF story shear are listed for each model in Table 16. The Imperial Valley, Bonds Corner ground motion caused the median MF story shear results around levels 1-5 for the three models and for 
levels 11-14 of Models 25 and 40 as well. For the remaining data, all seven records are seen as a median result for at least one model.

\subsubsection{Ductility Ratios}

For each structure, the ductility ratios have been calculated as the ratio of element demand to yield capacity. As shown below in Figure QQ (a), the $84^{\text {th }}$ percentile RBS ductility ratio for all three models ranges from 1.25 to 1.75 which is classified by ASCE 41-06 as the Immediate Occupancy performance category; only mild plastic behavior was seen from the RHA. The 84th percentile results also show that Model 40 is likely to see the least ductility demand as expected.

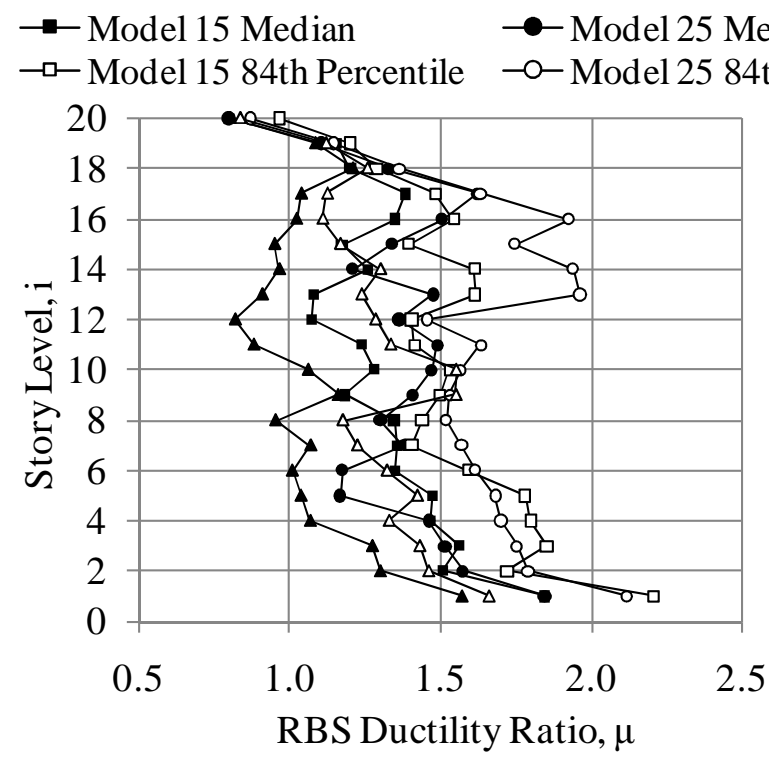

(a)

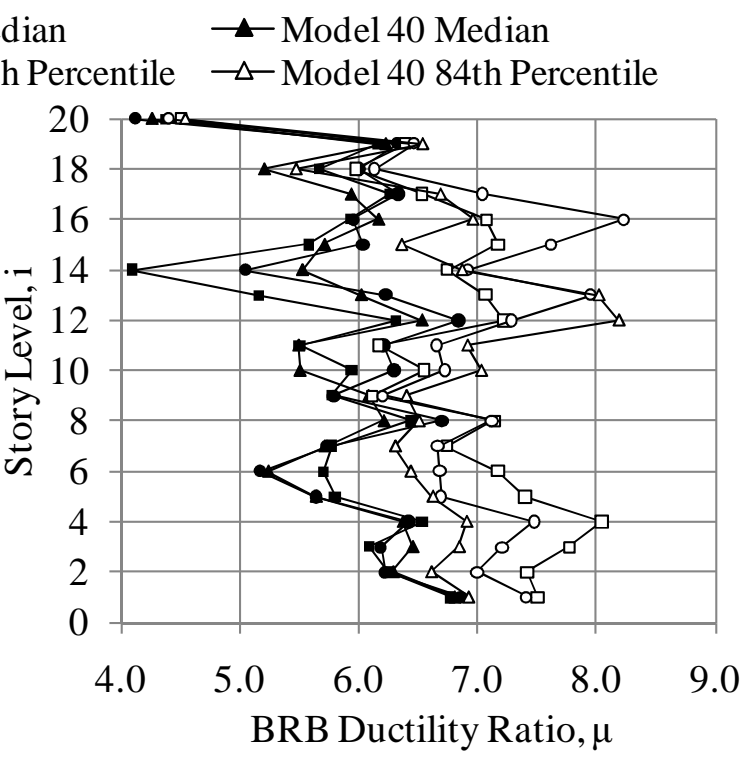

(b)

Figure QQ: Nonlinear Dynamic Ductility Ratios

Source: Author, Using Excel

The results for maximum BRB ductility demands reported in Figure QQ (b) for levels 1 through 9 show a clear trend in the $84^{\text {th }}$ percentile data as Model 40 experiences 
the least ductility and Model 15 experiences the most. $84^{\text {th }}$ percentile ductility values at levels 12 through 16 for Model 25 correspond to relatively higher story drifts in Figure SS. Also for model 25, in which BRB ductility is highest, the RBS ductility is also higher because demands shed from the BRBF into the MF as intended.

The $84^{\text {th }}$ percentile results of all three models for BRB ductility in Figure QQ (b) range from 6.5 to 8.0. BRB element testing shows core yielding beyond 15 times the yield displacement is unsafe. For all BRB elements in the three models, the $84^{\text {th }}$ percentile data presented above is also within the Immediate Occupancy to Life Safety range. Both RBS and BRB ductility responses show the 3 prototype structures behave similarly.

\subsubsection{Displacement and Drift}

The drift profile corresponding to the maximum roof displacement normalized by the roof height is displayed in Figure RR (a) through (c) for Models 15, 25 and 40 as labeled. The results of EQ 4 (El Centro) have been included up to the time at which the BRBs reached their yield limit which was defined in Table 6. Similar behavior is observed between the three models. The magnitude of the median roof drift is approximately 0.005 radians for all models (approximately 15 inches) which is less than the target displacement roof drift of 0.0068 radians. 


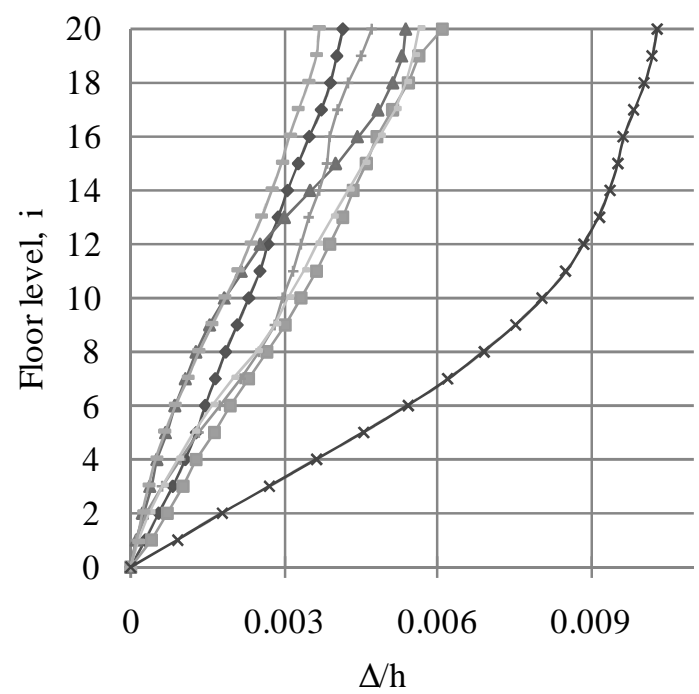

(a) Model 15

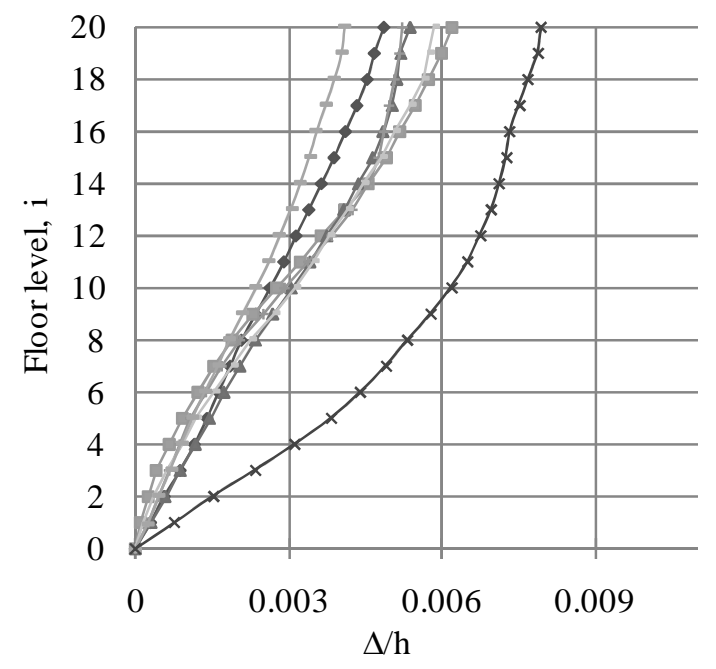

(c) Model 40

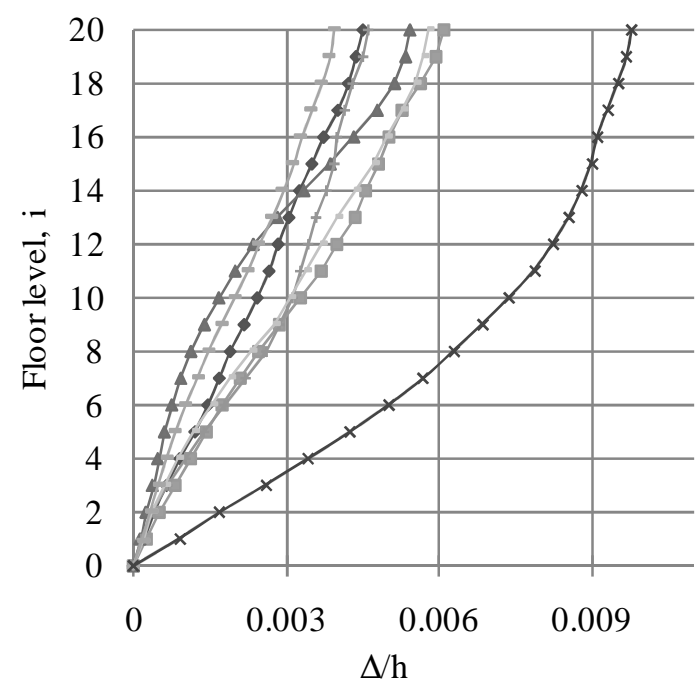

(b) Model 25

$\multimap$ Northridge- Canoga Park

- Loma Prieta - Capitola

—- Imperial Valley- Bonds Corner

—_ Ka lamata- Ka lamata

Coalinga-Pleasant Valley

—_ Northridge- Saticoy Station

* Imperial Valley- El Centro

Figure RR: Nonlinear Dynamic Maximum Roof Displacement Source: Author, Using Excel

The displacement data for Model 40 shows the least variability between earthquake records while Model 15 demonstrates more scattered results at the lower levels. For all three structures, the El Centro record induced the highest roof displacements before reaching the brace ductility limit which caused analysis 
termination. For the El Centro ground motion specifically, the stronger moment frame structures underwent less roof displacement at the time the lowest level braces reached their maximum allowable ductility.

For each structure, the maximum story drift angle has been calculated from the results of the nonlinear dynamic analysis with the following equation:

$$
\theta=\frac{\left(\Delta_{i}-\Delta_{i-1}\right)}{h_{i}},
$$

where $\theta$ is the story drift angle (radians),

$\Delta$ is the absolute floor displacement (in), $\mathrm{h}$ is the story height (in), and $i$ is the story level of interest (dimensionless).

and the floor displacements, $\Delta_{\mathrm{i}}$ and $\Delta_{\mathrm{i}-1}$ used for the calculations are recorded at the same time step.

The median and 84th percentile value for the story drift angle for each level are shown below in Figure SS and Table 17 displays a median of the story results reported in Figure SS. 


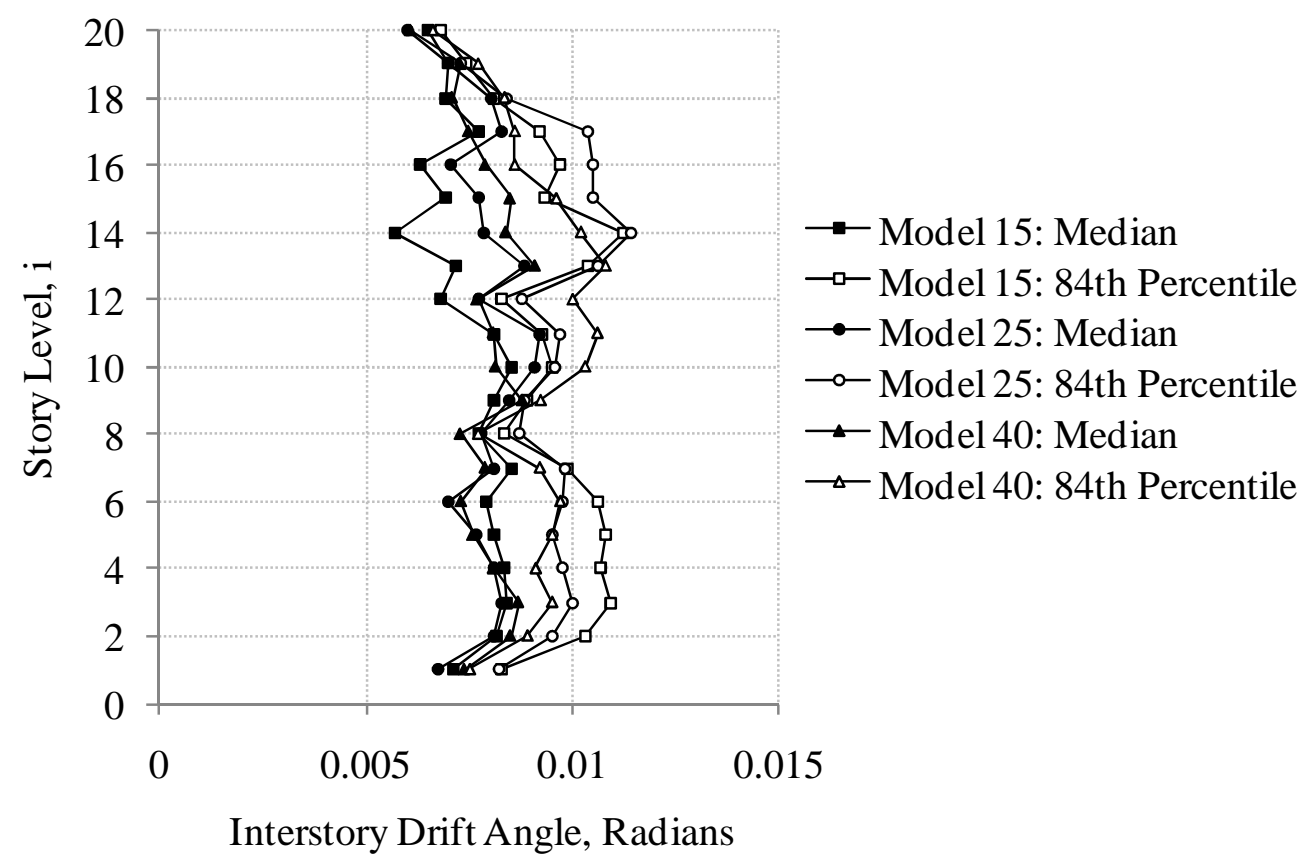

Figure SS: Nonlinear dynamic story drift results for Models 15, 25, and 40 Source: Author, Using Excel

\begin{tabular}{l|c|c|}
\multicolumn{1}{c}{} & \multicolumn{1}{c}{ Average Median } & Average 84th Percentile \\
\cline { 2 - 3 } Model 15 & 0.00750 & 0.00940 \\
\cline { 2 - 3 } Model 25 & 0.00826 & 0.00958 \\
\cline { 2 - 3 } Model 40 & 0.00787 & 0.00908 \\
\cline { 2 - 3 } & &
\end{tabular}

Table 17: Median story drift angles, radians

The varying design criteria between models results in unique story drift demands.

Model 15 experiences the largest range of drift values as the difference between the median and $84^{\text {th }}$ percentile results is the highest. Model 25 experiences the overall highest $84^{\text {th }}$ percentile story drift ratio equal to 0.012 radians at level 14 . Model 40 shows the smallest range between the median and $84^{\text {th }}$ percentile results decrease. Different trends can be observed for the upper and lower portions of the structure; a change in curvature of the displaced shape is observed near level 9. This behavior corresponds to the way the 
$\mathrm{BF}$ and MF engage each other as shown in Figure A. These results show that no conclusive statement can be made about which design is optimal for minimizing story drift. ASCE 7-05 provides a limit of $0.020 \mathrm{~h}_{\mathrm{sx}}$ for drift in Table 12.12-1. Figure SS shows that all three models performed well within the code limits for story drift. If a stricter drift limit of $0.010 \mathrm{~h}_{\mathrm{sx}}$ is used, only Model 40 would pass. Such a drift limit could apply to high performance structures and hospitals.

The varying design criteria between models results in unique story drift demands. While no single model experiences either the highest or the lowest story drift in Figure SS, the overall median and $84^{\text {th }}$ percentile result for all three models is reported in Table 17. 


\subsection{CONCLUSIONS}

Comments are given below on the design method and analysis results previously shown in this thesis.

\subsection{Final assessment of results}

After results of the elastic and nonlinear pushover analyses were reported, the results of the nonlinear dynamic analyses focused on the story shear distribution, maximum ductility ratios, drift and displacements, which were presented in Section 4.0 of this document. A final assessment of results is provided in each section below.

\subsubsection{Story Shear}

The stronger moment frames in general carried more shear force in the linear static analysis, the nonlinear pushover analysis, as well as the response history analysis.

When the story shear was examined at the instant of maximum total story shear, the MF demands increased consistently with the MF strength and the total story shears showed little variation (see Figure LL).

Figure PP also showed that shear reversal, or negative shear, was more apparent in Model 15 where the stiffness difference was the highest between the BF and the MF. Further discussion of shear reversal at particular levels is discussed in section 5.2.2.

\subsubsection{Ductility Demand}

As expected from the simple, two-frame, single degree-of-freedom hand calculation that was presented in section 4.1, the BRB elements underwent more postyield deformation than the MF reduced beam sections. Since this is one of the overall 
objectives of a dual system, the design was successful for all three models in this respect. After the braces reached first yield, the BF stiffness tangent became very small and the MF was engaged to control displacement. The RBS ductility demands attained by the MF are approximately 2 -only mildly inelastic.

In level 12-16, particularly high ductility demands are observed correspond to locations where the story drift is also high. High ductility is expected at high displacements since there is more rotation/elongation. The $84^{\text {th }}$ percentile ductility demands for the BRBs remained below 8.3, within the Immediate Occupancy to Life Safety range.

\subsubsection{Drift and Displacement}

Drift and displacement demands did not show one model as performing significantly better than another. The MF designed to $40 \%$ of the design base shear resulted in the least scatter of results from the 7 ground motions; however, all models performed adequately based on ASCE 7-05 table 12.12-1 where story drift must be limited to less than $0.02 \mathrm{~h}_{\mathrm{sx}}$. Figure SS shows that the $84^{\text {th }}$ percentile interstory drift for all three models is approximately $0.01 \mathrm{~h}_{\mathrm{sx}}$. The general displacement profile for each structure was close to linear as expected for a BRBF and MF Dual System.

RHA results shown in Figure SS for Model 40 show the most linear displacement profile. When the MF strength (and stiffness) is reduced, the overall trend of results becomes less linear and more scattered. 
The overall median drift results for the buildings do not show a trend as the lowest drift median, 0.0075 radians, is observed from Model 15 while the highest drift median value, 0.00826 radians, is recorded from Model 25. However, similar to the visual observation of the displacement results previously discussed. Higher MF strength produced less variability of results. The range of data between the median values and the $84^{\text {th }}$ percentile results is the largest in Model 15 and the smallest in Model 40. In terms of $84^{\text {th }}$ percentile demands from the RHA, the story drift demands remained below 0.012 .

\subsection{Implications of Prototype Design}

ASCE 7-05 requires a secondary system to be designed for a minimum of $25 \%$ seismic forces; however, the results show that Model 15 performs similarly to Model 25 and Model 40 and there appears to be no apparent reason not to allow its consideration as a dual system per ASCE 7-05. All three models showed the overall structural response to inelastic drift from the RHA was well within the code limitations.

\subsubsection{Buckling-Restrained Braced Frame Design}

As discussed in Section 2.3.1, the alternating braces were placed as shown in the elevation of Figure B (page 12) to reduce column sizes. The alternating pattern yielded interesting results since each braced frame level has a varying lateral stiffness, causing an irregular pattern of forces attracted by the MF in design and an irregular trend of brace sizes up the elevation. If the brace sizes (rather than DCR) were consistently increased down the elevation, a more linear trend may have been seen in the reported ductility results. 
The beam-column connections in the braced frame were modeled as non-moment resisting where gusset plates would not occur. This assumption should be investigated further.

\subsubsection{Moment Frame Design}

By varying the design forces of the MF between $15 \%, 25 \%$ and $40 \%$ of seismic demands, this analysis showed only a slight variation of strength reduction of the primary system between models.

The moment frames were designed to a specific strength (i.e. $15 \%, 25 \%$, and $40 \%$ ) of the total base shear. To achieve the said strength, only five column lines (four bays) of lateral resistance were necessary. Since the braces were scattered across the entire building length engaging 7 columns (6 bays), the stiffness ratio of the $\mathrm{BF}$ to $\mathrm{MF}$ was amplified by the relative aspect ratios (height/length) of the BF to MF. A different configuration could potentially produce significantly different results

\subsubsection{Dual System Interaction}

The dual system interaction was greatly affected by the brace pattern. The implications due to shear reversal observed in this thesis have not been closely examined. Further analysis of steel dual systems, specific to those which contain alternating brace patterns, is suggested to understand shear reversal between a combined stiff and flexible system.

As suggested, the results presented in this thesis may vary dramatically between different dual system layouts. It is suggested by the author that this research be continued 
with additional variations to more fully understand the design implications of mixing a strong and flexible system in a dual seismic force resisting system.

\subsubsection{Final Remarks}

In general, the allowed BRBF relative stiffness strength reduction per ASCE 7-05 did not seem to cause any deficiencies with the dual system performance. Each model was found to easily satisfy the drift and ductility limitations described in the ASCE 7-05 and AISC 341. Since the strength of the MF was varied in each model, the precise role of the MFs is not apparent. An additional study should be completed for a BRBF with no secondary system to quantify the overall MF contribution to the dual system behavior.

ASCE 7-05 requires a secondary system to be designed for a minimum of $25 \%$ of the seismic base shear; however, the results show that the Model 15 performs similarly to the Model 25. Thus there appears to be no clear argument to not categorize the seismic force resisting system as a dual system. Clearly, the design technique presented here 8 for a dual seismic force resisting system provides a high performance structure. This paper shows that advanced analysis is required in order to fully quantify the system performance and required MF strength with respect to the performance criteria, and to quantify the added cost of the backup MF system. 


\subsection{APPENDIX}

\begin{tabular}{|c|c|c|c|c|}
\hline Dead Load & $\begin{array}{l}\text { Typical Floor } \\
\quad\left(\mathrm{DL}_{\mathrm{flr}}\right)\end{array}$ & $\begin{array}{c}\text { Typical Floor } \\
\text { Seismic Mass } \\
(\mathrm{SW})\end{array}$ & $\begin{array}{l}\text { Roof } \\
\left(\mathrm{DL}_{\mathrm{rf}}\right)\end{array}$ & $\begin{array}{c}\text { Roof } \\
\text { Penthouse } \\
\left(\mathrm{DL}_{\mathrm{ph}}\right) \\
\end{array}$ \\
\hline $\begin{array}{l}2 \text { 1/2" Normal Weight Concrete Fill Over } \\
\text { 3"x18 ga Metal Deck }\end{array}$ & 53 & 53 & 53 & 53 \\
\hline Steel Framing (Assumption) & 13 & 13 & 13 & 13 \\
\hline Ceiling/Flooring & 3 & 3 & 3 & 3 \\
\hline MechanicaV/Electrical & 7 & 7 & 7 & \\
\hline Roofing & & & 7 & 7 \\
\hline Penthouse & & & & 40 \\
\hline Total Floor Dead Load (psf) & 76 & 76 & 83 & 116 \\
\hline Partitions (psf) & 0 & 10 & - & \\
\hline Total Design Load (psf) & 76 & 86 & 83 & 116 \\
\hline Live Loads & Load (psf) & \multicolumn{3}{|c|}{ Load (psf) } \\
\hline Typical Floor & 80 & \multicolumn{3}{|c|}{$\begin{array}{l}\text { (Governs over } 50 \mathrm{psf}+ \\
15 \mathrm{psf}(\text { partitian load }))\end{array}$} \\
\hline Typical Roof & & & 20 & \\
\hline Design Live Load Proposed & 80 & & 20 & \\
\hline
\end{tabular}

\section{Cladding Load}

Floor $1=15^{\prime}-6^{\prime \prime *}\left[2 *\left(102^{\prime}+146^{\prime}\right)\right]^{*} 0.025=$ 192 kips

Floor 2 to $13^{\prime} *\left[2 *\left(102^{\prime}+146^{\prime}\right)\right]^{*} 0.025=$ 161 kips

Roof $=\left(13^{\prime} / 2+42 / 12^{\prime}\right) *\left[2 *\left(102^{\prime}+146^{\prime}\right)\right]^{*} 0.025=$

Penthouse $12^{\prime *}\left[2^{*}\left(22^{\prime}+42^{\prime}\right)\right]^{*} 0.025=$ 124 kips 38 kips

Building Area

\begin{tabular}{|c|c|c|c|c|c|}
\hline$A_{\text {bldg }}=$ & Building Envelope= & $104^{\prime} * 148^{\prime}=$ & & \multicolumn{2}{|c|}{$15392 \mathrm{sf}$} \\
\hline$A_{D L}=$ & Floor Slab Envelope $(\mathrm{DL})=$ & $102^{\prime} * 146^{\prime}=$ & & \multicolumn{2}{|c|}{$14892 \mathrm{sf}$} \\
\hline$A_{L L}=$ & Floor Slab Envelope $(\mathrm{LL})=$ & $100 * 144=$ & & \multicolumn{2}{|c|}{$14400 \mathrm{sf}$} \\
\hline $\mathrm{A}_{\mathrm{PH}}=$ & Penthouse Envelope = & $22^{\prime} \times 42^{\prime}=$ & & \multicolumn{2}{|c|}{$924 \mathrm{sf}$} \\
\hline \multicolumn{3}{|c|}{ Floor Seismic Dead Weights } & & Whole & Half \\
\hline Level & Calculation & & Weight $[\mathrm{k}]$ & \multicolumn{2}{|c|}{ Mass $\left[\mathrm{k}-\mathrm{s}^{2} / \mathrm{ft}\right]$} \\
\hline Roof & \multicolumn{2}{|c|}{ 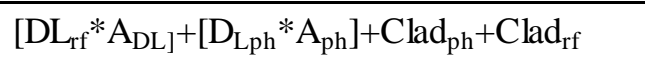 } & 1506 & 46.76 & 23.38 \\
\hline $2-19$ & \multicolumn{2}{|c|}{$\left[\mathrm{SW}_{\mathrm{flr}} * \mathrm{~A}_{\mathrm{DL}}\right]+\mathrm{Clad}_{\mathrm{flr} 2-19}$} & 1442 & 44.78 & 22.39 \\
\hline \multirow[t]{2}{*}{1} & \multirow{2}{*}{\multicolumn{2}{|c|}{$\left[\mathrm{SW}_{\mathrm{flr}} * \mathrm{~A}_{\mathrm{DL}}\right]+\mathrm{Clad}_{\mathrm{flr} 1}$}} & 1473 & 45.74 & 22.87 \\
\hline & & & 28933 & 899 & 449 \\
\hline
\end{tabular}


Point Loads on EW Braced Frame Members (DL)

\begin{tabular}{clcr}
\hline Level & Calculation & Force [k] & (half) \\
\hline \hline Roof & DL $_{\mathrm{rf}}{ }^{*}\left[211^{\prime} \times 12 '\right]$ & 20.9 & 10.5 \\
$2-19$ & $\mathrm{DL}_{\mathrm{flr} 2-19}{ }^{2}\left[21^{\prime} \mathrm{x} 12 '\right]$ & 19.2 & 9.6 \\
1 & $\mathrm{DL}_{\mathrm{flr} 1}{ }^{*}[21$ 'x12'] & 19.2 & 9.6
\end{tabular}

Point Loads on EW Braced Frame Members (LL)

\begin{tabular}{|c|c|c|c|}
\hline Level & Calculation & Force $[\mathrm{k}]$ & (half) \\
\hline Roof & $\mathrm{LL}_{\mathrm{rf}} *\left[20 ' \mathrm{x} 12^{\prime}\right]$ & 4.8 & 2.4 \\
\hline $2-19$ & $\mathrm{LL}_{\text {flr } 2-19} *\left[20^{\prime} \mathrm{x} 12^{\prime}\right]$ & 19.2 & 9.6 \\
\hline 1 & $\mathrm{LL}_{\mathrm{flr}}$ 1 $^{*}[20$ 'x12'] & 19.2 & 9.6 \\
\hline
\end{tabular}

Distributed Loads on EW Frame Members (Cladding)

\begin{tabular}{clc}
\hline Level & Calculation & Force $[\mathrm{klf}]$ \\
\hline \hline Roof & $0.025 \mathrm{ksf} *\left(13^{\prime} / 2+42 / 12^{\prime}\right)$ & 0.250 \\
$2-19$ & $0.025 \mathrm{ksf} * 13^{\prime}$ & 0.325 \\
1 & $0.025 \mathrm{ksf} * 15^{\prime}-6^{\prime \prime}$ & 0.388
\end{tabular}

Point Loads on EW Moment Frame Members (DL)

\begin{tabular}{|c|c|c|c|}
\hline Level & Calculation & Force $[\mathrm{k}]$ & (half) \\
\hline Roof & $\mathrm{DL}_{\mathrm{rf}} *\left[30 ' \mathrm{x} 12^{\prime}\right]$ & 29.9 & 14.94 \\
\hline $2-19$ & $\mathrm{DL}_{\mathrm{flr} 2-19} *\left[30^{\prime} \mathrm{x} 12^{\prime}\right]$ & 27.4 & 13.68 \\
\hline 1 & $\mathrm{DL}_{\mathrm{flr} 1} *\left[30^{\prime} \mathrm{x} 12^{\prime}\right]$ & 27.4 & 13.68 \\
\hline
\end{tabular}

Point Loads on EW Moment Frame Members (LL)

\begin{tabular}{clcr}
\hline Level & Calculation & Force [k] & (half) \\
\hline \hline Roof & $\mathrm{LL}_{\mathrm{rf}}{ }^{*}\left[300^{\prime} \times 12 '\right]$ & 7.2 & 3.6 \\
$2-19$ & $\mathrm{LL}_{\mathrm{flr} 2-19}{ }^{*}\left[300^{\prime} \mathrm{x} 12^{\prime}\right]$ & 28.8 & 14.4 \\
1 & $\mathrm{LL}_{\mathrm{flr} 1} *\left[30^{\prime} \times 12 '\right]$ & 28.8 & 14.4
\end{tabular}

Table 18: Load takeoff and calculations for analytical modeling

Source: Takeoff Items per SAC, Calculations by Author 


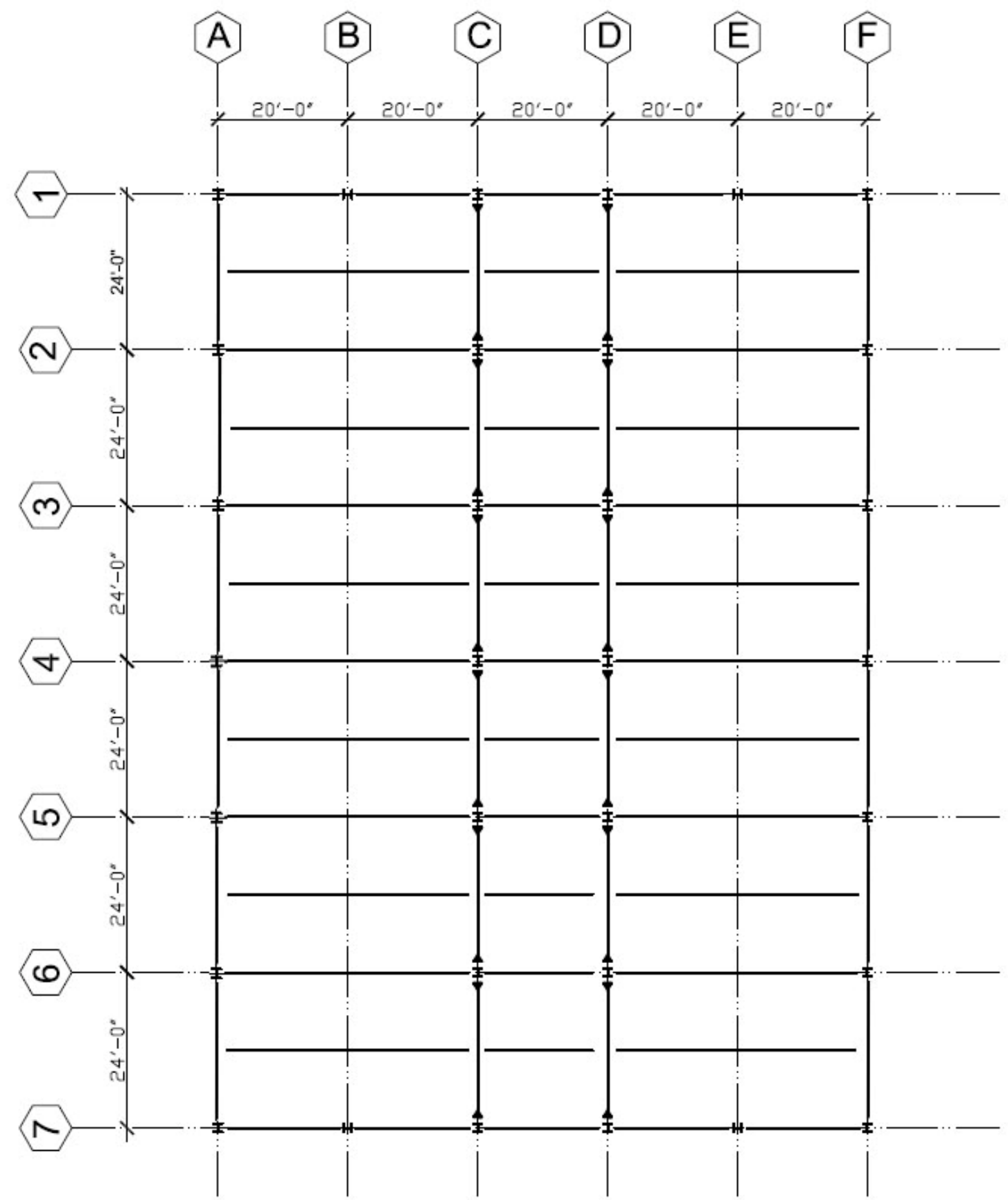

Figure TT: Building plan referenced for load takeoff and design

Source: Author Using AutoCAD 


\begin{tabular}{|c|c|c|c|c|c|c|c|c|c|}
\hline \multicolumn{5}{|c|}{ COLUMNS } & \multicolumn{4}{|c|}{ BEAMS } & \multirow{3}{*}{\begin{tabular}{|c} 
BRACES \\
Core \\
Area \\
in $^{2}$
\end{tabular}} \\
\hline & \multicolumn{2}{|c|}{ Braced Frame } & \multicolumn{2}{|c|}{ Moment Frame } & \multicolumn{3}{|c|}{ Braced Frame } & \multirow{2}{*}{\begin{tabular}{|l} 
Moment Frame \\
C2-C3, C3-C4, \\
C4-C5, C5-C6
\end{tabular}} & \\
\hline & $\mathrm{A} 1, \mathrm{~A} 7$ & $\begin{array}{c}\mathrm{A} 2, \mathrm{~A} 3 \\
\mathrm{~A} 4, \mathrm{~A} 5 \\
\mathrm{~A} 6\end{array}$ & $\mathrm{C} 2, \mathrm{C} 6$ & $\mathrm{C} 3-\mathrm{C} 5$ & $\begin{array}{l}\mathrm{A} 1-\mathrm{A} 2 \\
\mathrm{~A} 6-\mathrm{A} 7\end{array}$ & $\begin{array}{l}\mathrm{A} 2-\mathrm{A} 3 \\
\mathrm{~A} 5-\mathrm{A} 6\end{array}$ & $\begin{array}{l}\text { A3-A4 } \\
\text { A4-A5 }\end{array}$ & & \\
\hline & W14X48 & "W14X53 & W14X68 & W14X132 & $\overline{\mathrm{W} 21 \mathrm{X} 50}$ & W21X50 & $\begin{array}{l}\mathrm{W} 21 \mathrm{X} 68 \\
\end{array}$ & W21X44 & 2.00 \\
\hline & W14X48 & W14X53 & W14X68 & W14X132 & W21X50 & W21X68 & W21X57 & W21X44 & 2.50 \\
\hline & W14X53 & W14X132 & W14X82 & W14X132 & W21X93 & W21X68 & W21X57 & W21X44 & 3.50 \\
\hline & W14X53 & W14X132 & W14X82 & W14X132 & W21X68 & W21X93 & W21X57 & W21X44 & 3.25 \\
\hline & W14X68 & W14X176 & W14X145 & W14X145 & W21X57 & W21X68 & W21X111 & W21X44 & 5.00 \\
\hline & W14X68 & W14X176 & W14X145 & W14X145 & W21X57 & W21X111 & W21X83 & W21X44 & 3.75 \\
\hline & W14X132 & $\mathrm{W} 14 \mathrm{X} 193$ & W14X132 & W14X159 & W21X111 & W21X83 & W21X57 & W21X44 & 6.00 \\
\hline & W14X132 & W14X193 & W14X132 & W14X159 & W21X83 & W21X111 & W21X57 & W21X44 & 4.75 \\
\hline & W14X132 & $\mathrm{W} 14 \mathrm{X} 211$ & W14X132 & $\mathrm{W} 14 \mathrm{X} 211$ & W21X57 & W21X83 & W21X111 & W21X44 & 7.00 \\
\hline & W14X132 & $\mathrm{W} 14 \mathrm{X} 211$ & W14X132 & W14X211 & W21X57 & W21X122 & W21X93 & W21X44 & 5.25 \\
\hline & W14X132 & $\mathrm{W} 14 \mathrm{X} 233$ & W14X132 & W14X257 & W21X122 & W21X93 & W21X57 & W21X50 & 6.75 \\
\hline & W14X132 & W14X233 & W14X132 & W14X257 & W21X93 & W21X122 & W21X57 & W21X50 & 5.75 \\
\hline & W14X145 & $\mathrm{W} 14 \mathrm{X} 257$ & W14X145 & W14X311 & W21X57 & W21X93 & $\mathrm{W} 21 \mathrm{X} 122$ & W21X50 & 8.00 \\
\hline & W14X145 & W14X257 & W14X145 & W14X311 & W21X57 & W21X122 & W21X93 & W21X50 & 6.00 \\
\hline & W14X193 & $\mathrm{W} 14 \mathrm{X} 342$ & W14X159 & $\mathrm{W} 14 \mathrm{X} 342$ & W21X132 & W21X111 & W21X57 & W21X50 & 8.00 \\
\hline & W14X193 & W14X342 & W14X159 & W14X342 & W21X111 & W21X132 & W21X57 & W21X50 & 7.25 \\
\hline & W14X193 & $\mathrm{W} 14 \mathrm{X} 342$ & W14X176 & W14X398 & W21X57 & W21X111 & W21X132 & W21X50 & 9.00 \\
\hline & W14X193 & $\mathrm{W} 14 \mathrm{X} 342$ & W14X176 & W14X398 & W21X57 & W21X132 & W21X111 & W21X50 & 8.75 \\
\hline & W14X257 & W14X455 & W14X283 & W14X550 & W21X132 & W21X111 & W21X57 & W21X50 & 9.00 \\
\hline & W14X257 & $\mathrm{W} 14 \mathrm{X} 455$ & W14X283 & W14X550 & W21X111 & W21X132 & W21X57 & W21X50 & 10.75 \\
\hline
\end{tabular}

Table 19: Member sizes for Model 15

Source: Author Using Excel 
6.0 Appendix 98

\begin{tabular}{|c|c|c|c|c|c|c|c|c|c|}
\hline & \multicolumn{4}{|c|}{ COLUMNS } & \multicolumn{4}{|c|}{ BEAMS } & \multirow{3}{*}{\begin{tabular}{|c} 
BRACES \\
Core Area \\
in $^{2}$
\end{tabular}} \\
\hline & \multicolumn{2}{|c|}{ Braced Frame } & \multicolumn{2}{|c|}{ Moment Frame } & \multicolumn{3}{|c|}{ Braced Frame } & \multirow{2}{*}{\begin{tabular}{|l} 
Moment Frame \\
C2-C3, C3-C4, \\
C4-C5, C5-C6
\end{tabular}} & \\
\hline & A1, A7 & $\begin{array}{c}\text { A2, A3, } \\
\text { A4, A5, } \\
\text { A6 } \\
\end{array}$ & $\mathrm{C} 2, \mathrm{C} 6$ & $\mathrm{C} 3-\mathrm{C} 5$ & $\begin{array}{l}\mathrm{A} 1-\mathrm{A} 2 \\
\mathrm{~A} 6-\mathrm{A} 7\end{array}$ & $\begin{array}{l}\mathrm{A} 2-\mathrm{A} 3 \\
\mathrm{~A} 5-\mathrm{A} 6\end{array}$ & $\begin{array}{l}\text { A3-A4 } \\
\text { A4-A5 }\end{array}$ & & \\
\hline 20 & W14X48 & W14X53 & W14X68 & W14X132 & $\overline{\mathrm{W} 21 X 50}$ & W21X50 & W21X68 & W21X44 & 2.00 \\
\hline 19 & W14X48 & 'W14X53 & W14X68 & W14X132 & W21X50 & W21X68 & W21X57 & W21X44 & 2.25 \\
\hline 18 & W14X53 & W14X132 & W14X82 & $\mathrm{W} 14 \mathrm{X} 132$ & W21X93 & W21X68 & W21X57 & W21X44 & 3.25 \\
\hline 17 & W14X53 & "W14X132 & W14X82 & W14X132 & W21X68 & W21X93 & W21X57 & W21X44 & 3.00 \\
\hline 16 & W14X68 & W14X176 & W14X132 & $\mathrm{W} 14 \times 176$ & W21X57 & W21X68 & W21X111 & W21X44 & 4.75 \\
\hline 15 & W14X68 & 'W14X176 & W14X132 & W14X176 & W21X57 & W21X111 & W21X83 & W21X50 & 3.50 \\
\hline 14 & W14X132 & W14X193 & W14X132 & W14X193 & W21X11 & W21X83 & W21X57 & W21X50 & 5.75 \\
\hline 13 & W14X132 & 'W14X193 & W14X132 & $\mathrm{W} 14 \times 193$ & W21X83 & W21X111 & W21X57 & W21X50 & 4.50 \\
\hline 12 & W14X132 & W14X211 & W14X132 & W14X233 & W21X57 & W21X83 & W21X111 & W21X62 & 6.75 \\
\hline 11 & W14X132 & 'W14X211 & W14X132 & $\mathrm{W} 14 \mathrm{X} 233$ & W21X57 & $\mathrm{W} 21 \mathrm{X} 122$ & W21X93 & W21X62 & 5.00 \\
\hline 10 & W14X132 & $\mathrm{W} 14 \mathrm{X} 233$ & W14X132 & $\mathrm{W} 14 \mathrm{X} 283$ & W21X122 & W21X93 & W21X57 & W21X68 & 6.50 \\
\hline 9 & W14X132 & 'W14X233 & W14X132 & $\mathrm{W} 14 \mathrm{X} 283$ & W21X93 & W21X122 & W21X57 & W21X68 & 5.50 \\
\hline 8 & W14X145 & $\mathrm{W} 14 \mathrm{X} 257$ & W14X145 & $\mathrm{W} 14 \mathrm{X} 311$ & W21X57 & W21X93 & W21X122 & W21X68 & 7.75 \\
\hline 7 & W14X145 & 'W14X257 & W14X145 & $\mathrm{W} 14 \mathrm{X} 311$ & W21X57 & W21X122 & W21X93 & W21X68 & 5.75 \\
\hline 6 & W14X193 & W14X342 & W14X159 & W14X342 & W21X132 & W21X111 & W21X57 & W24X76 & 7.75 \\
\hline 5 & W14X193 & 'W14X342 & W14X159 & $\mathrm{W} 14 \mathrm{X} 342$ & W21X11 & W21X132 & W21X57 & W24X76 & 7.00 \\
\hline 4 & W14X193 & $\mathrm{W} 14 \mathrm{X} 342$ & W14X176 & W14X398 & W21X57 & W21X111 & W21X132 & W24X76 & 8.75 \\
\hline 3 & W14X193 & 'W14X342 & W14X176 & W14X398 & W21X57 & W21X132 & W21X111 & W24X76 & 7.50 \\
\hline 2 & $\mathrm{~W} 14 \mathrm{X} 257$ & $\mathrm{~W} 14 \mathrm{X} 455$ & W14X283 & $\mathrm{W} 14 \times 550$ & W21X132 & W21X111 & W21X57 & W24X76 & 8.75 \\
\hline 1 & W14X257 & $\mathrm{W} 14 \mathrm{X} 455$ & W14X283 & $\mathrm{W} 14 \times 550$ & W21X111 & W21X132 & W21X57 & W24X76 & 10.50 \\
\hline
\end{tabular}

Table 20: Member sizes for Model 25

Source: Author Using Excel 
6.0 Appendix 99

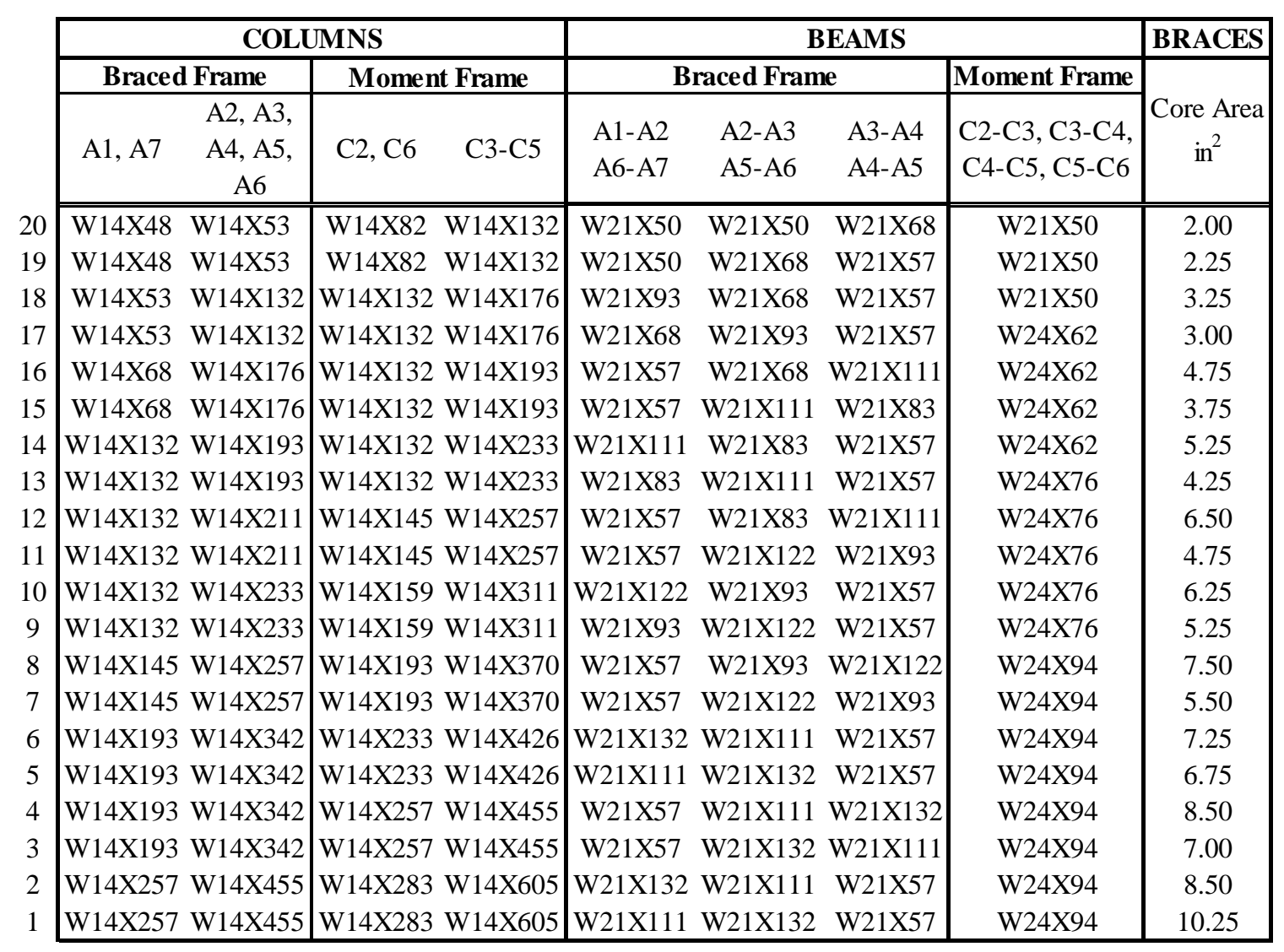

Table 21: Member sizes for Model 40

Source: Author Using Excel 


\subsection{REFERENCES}

(AISC 2005) American Institute of Steel Construction (AISC). Steel Construction Manual. 13th ed. Chicago: American Institute of Steel Construction, 2005.

(AISC and SSEC, 2006) American Institute of Steel Construction (AISC), and Structural Steel Educational Council (SSEC). Seismic Design Manual. Chicago: American Institute of Steel Construction, 2006.

(Ambrose, 2001) Ambrose, Clinton. "Fox Tower Rises Over Portland." Modern Steel Construction 43.2 (2001) 38-41.

(Argiris 1995) Argiris, Leo. "Dual System." Modern Steel Construction 37.7 (1995): 2628.

(ASCE 7-05 2005) American Society of Civil Engineers (ASCE), and Structural Engineering Institute (SEI). Minimum Design Loads for Buildings and Other Structures. Reston, VA: American Society of Civil Engineers/Structural Engineering Institute, 2006.

(ASCE 41-06, 2007) American Society of Civil Engineers (ASCE). ASCE/SEI 41-06: Seismic Rehabilitation of Existing Buildings. Reston, VA: American Society of Civil Engineers, 2007.

(ATC 1978). Applied Technology Council (ATC). ATC-3-06: Tentative Provisions for the Development of Seismic Provisions for Buildings. Redwood City, CA: Applied Technology Council, 1978.

(Black et al., 2004) Black, Cameron J., Nicos Makris, and Ian D. Aiken. "Component Testing, Seismic Evaluation and Characterization of Buckling-Restrained Braces." Journal of Structural Engineering 130.6 (2004): 880.

(Clark et al. 1999) Clark, Peter, Kazuhiko Kasai, Ian Aiken, and Isao Kimura."Evaluation of Simplified Design Approaches for Structures with Yielding Steel Braces for Energy Dissipation." Los Angeles: Proceedings of 1999 Annual Meeting of the Los Angeles Tall Buildings Structural Design Council. Los Angeles: 1999.

(CSI 2006a) Computers and Structures, Inc. (CSI). Perform-3D Nonlinear Analysis and Performance Assessment for 3D Structures, User Guide. Version 4, Berkeley, CA: Computers and Structures, Inc. 2006. 
(CSI 2006b) Computers and Structures, Inc. (CSI). Perform Components and Elements For Perform-3D and Perform-Collapse,. Version 4. Berkeley, CA: Computers and Structures, Inc. 2006.

(Degenkolb 1994) Degenkolb, Henry J. "Connections: The EERI Oral History Series, Henry J. Degenkolb." Interview by Stanley Scott. Connections: EERI Oral History Series Apr. 1994: 226.

(FEMA 369, 2001) National Earthquake Hazards Reduction Program (NEHRP). FEMA 369: 2000 NEHRP Recommended Provisions for Seismic Regulations for New Buildings and Other Structures and Accompanying Commentary and Maps. Washington, D.C.: Federal Emergency Management Agency, 2001.

(FEMA 355, 2000) United States Department of Homeland Security's Federal Emergency Management Agency (FEMA). FEMA 355: State of the Art Report of Systems Performance of Steel Moment Frames Subject to Earthquake Ground Shaking. Washington, D.C.: Federal Emergency Management Agency, 2000.

(Goel and Chopra 2004) Goel, Rakesh K., and Anil K. Chopra. "Evaluation of Modal and FEMA Pushover Analyses: SAC Buildings." Earthquake Spectra 20.1 (2004): 225-254.

(IBC 2006) International Code Council (ICC). 2006 International Building Code. Falls Church, VA: ICC, 2006.

(Jin et. al. 2000) Jin, Limin, Atila Zekioglu, and King-Le Change. "Performance Based Analysis and Modeling of a Dual Seismic Force-Resisting System." 12th World Conference on Earthquake Engineering. New Zealand Society for Earthquake Engineering, Auckland, New Zealand. 2000.

(Kiggins and Uang 2006 ) Kiggins, Shawn, and Chia-Ming Uang. "Reducing Residual Drift of Buckling-restrained Braced Frames as a Dual System." Engineering Structures 28.11 (2006): 1525-532.

(Lopez et al. 2001) Lopez, Walterio, David Gwie, Mark Saunders, and Thomas Lauck. "Lessons Learned From Large-Scale Tests of Unbonded Braced Frame Subassemblages." Earthquake Engineering Research Center (EERC): University of California, Berkeley. 2001. Web. 14 Mar. 2011. <http://nisee.berkeley.edu/elibrary/Text/LIB050244>. 
(Magnusson 1997) Jon, Magnusson D. "Earthquake-Resisting Dual Systems and the 25\% Rule." Building to Last: Proceedings of Structural Congress 1 (1997): 124-129.

(Maley et al. 2010) Maley, Timothy J., Timothy J. Sullivan, Gaetano Della Corte. "Development of a Displacement-Based Design Method for Steel Dual Systems with Buckling-Restrained Braces and Moment-Resisting Frames", Journal of Earthquake Engineering, 14:1 (2010): 106-140.

(Moore and Feng, 2011) Moore, Kevin S., and Joyce Y. Feng. Steel Tips from the Structural Steel Educational Council. Web. 14 Mar. 2011. <http://www.steeltips.org/steeltips/tip_details.php?id=100>.

(Null and Sabelli, 2001) Null, Walterio A., and Rafael Sabelli. "Steel Tips: Seismic Design of Buckling-Restrained Braced Frames." Steel Tips from the Structural Steel Educational Council. Web. 14 Mar. 2011. <http://www.steeltips.org/steeltips/tip_details.php?id=76>.

(Poon et al. 2002) Poon, Dennis C., Shaw-song Shieh, Leonard M. Joseph, and ChingChang Chang. "The Sky's the Limit" Modern Steel Construction, 44.12 (2002) . 24-28.

(Rahimian and Martinez-Romero, 2003) Rahimian, Ahmad and Martinez Romero, Enrique. "Standing Tall” Modern Steel Construction, 45.4 (2003) 28-33.

(SEAOC Seismology Committee 2007) SEAOC Seismology Committee.

The SEAOC Blue Book: Seismic Design Recommendations, Jan. 2007, 17 Aug. 2009. <http://www.seaoc.org/bluebook/index.html>.

(Sigmund et al. 2008) Sigmund, Vladimir, Ivica Guljas, and Marijana Hadzima-Nyarko, "Base Shear Redistribution Between the R/C Dual System Structural Components." The World Conference on Earthquake Engineering. vol. 14. Beijing, China: 2008.

(Somerville 1997) Somerville, Paul, Nancy Smith, Sujan Punyamurthula, and Joseph Sun, "Development of Ground Motion Time Histories for Phase 2 of the FEMA/SAC Steel Project | SAC Background Reports | SAC Reports: Steel Moment-Frame Bldg Seismic Hazard Mitigation | Applied Technology Council." Applied Technology Council. 14 Mar. 2011. <http://www.atcouncil.org/SACBackground-Reports/Development-of-Ground-Motion-Time-Histories-for-Phase2-of-the-FEMA/SAC-Steel-Project/flypage.tpl.html>. 
(Soulages and Rubbo, 1998) Soulages, Jeffrey and Rubbo, Anthony. "Future Hospital Design: Focusing on Performance" Modern Steel Construction, 40.5 (1998) 2430.

(UBC 1961). International Conference of Building Officials (ICBO), Uniform Building Code. Los Angeles, CA: UBC, 1961.

(UBC 1985) International Conference of Building Officials (ICBO), Uniform Building Code. Whittier, CA: UBC, 1985.

(UBC 1988) International Conference of Building Officials, Uniform Building Code. Whittier, CA: UBC, 1988.

(Whittaker et al. 1990) Whittaker, Andrew, Chia-Ming Uang, and Vitelmo Bertero. "An Experimental Study of the Behavior of Dual Steel Systems." Earthquake Engineering Research Center (EERC): University of California, Berkeley. 1990. Web. 14 Mar. 2011. <http://nisee.berkeley.edu/elibrary/eerc/1988>. 